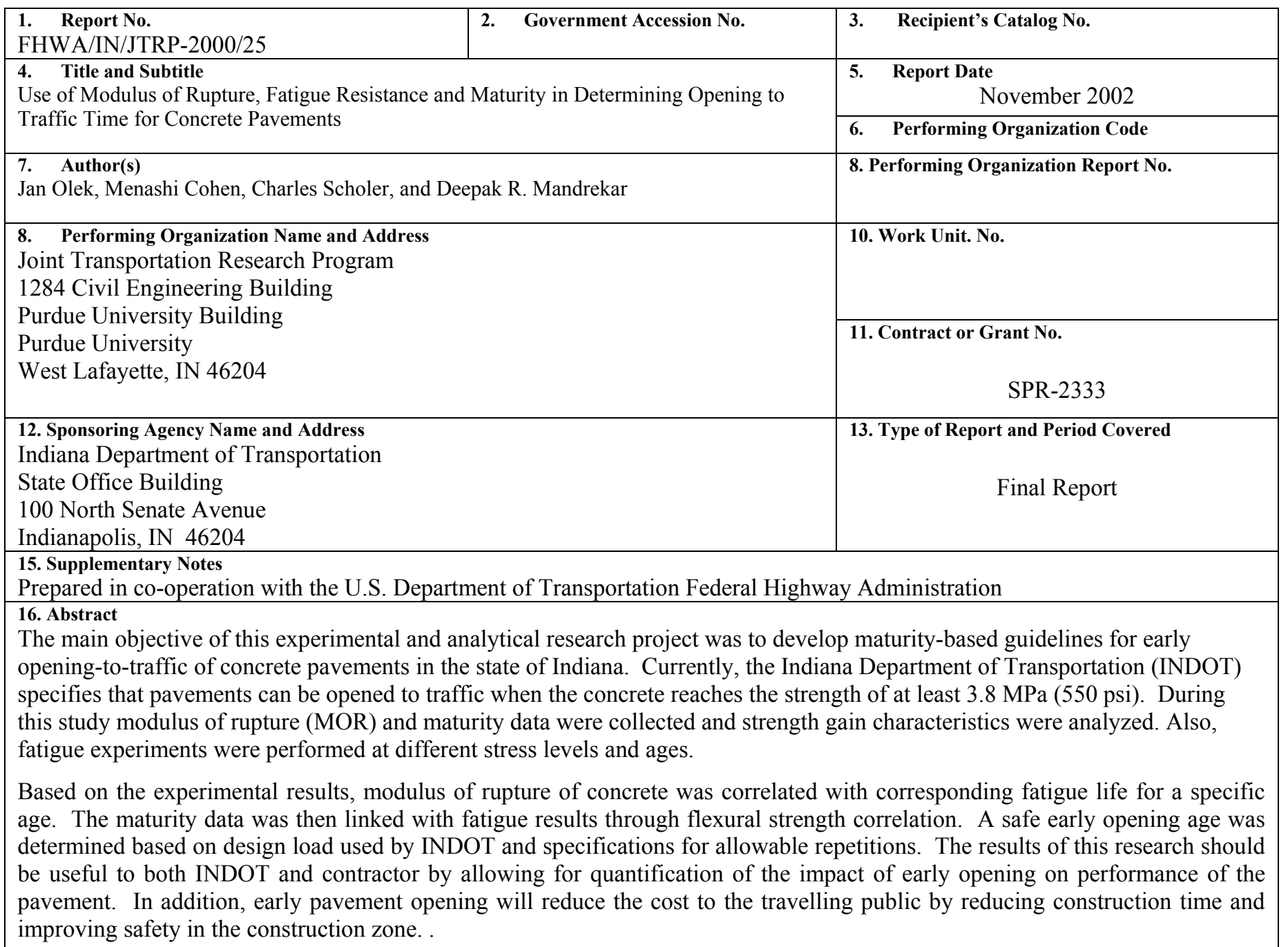

improving safety in the construction zone. .

\section{Key Words}

concrete pavements, modulus of rupture, fatigue resistance, maturity, opening to traffic.
18. Distribution Statement

No restrictions. This document is available to the public through the National Technical Information Service, Springfield, VA 22161
19. Security Cassif. (of this report) Unclassified
20. Security Classif .( of this page) Unclassified

\begin{tabular}{|c|c|}
\hline $\begin{array}{c}\text { 21. No of Pages. } \\
86\end{array}$ & 22. Price \\
&
\end{tabular}




\section{TECHNICAL Summary}

INDOT Research

Technology Transfer and Project Implementation Information

TRB Subject Code: 32-3 Concrete Curing

Publication No.: FHWA/IN/JTRP-2000/25, SPR-2333

November 2002

Final Report

\section{Use of Modulus of Rupture, Fatigue Resistance and Maturity in Determining Opening to Traffic Time for Concrete Pavements}

\section{Introduction}

The main objective of this study was to develop maturity-based guidelines for early opening-to-traffic of concrete pavements in the state of Indiana.

The scope of the research included characterization of flexural strength development with time, establishment of relationship between flexural strength and maturity, and determination of earliest opening-to-traffic by correlating opening flexural strength with fatigue of concrete. Flexural strength is widely accepted as the opening to traffic criterion for concrete pavements. Indiana Department of Transportation (INDOT) uses flexural strength of $550 \mathrm{psi}(3.79 \mathrm{MPa})$ for opening concrete pavements to traffic

A typical concrete mixture used in pavement construction in Indiana was adopted for this study. The study was conducted using both laboratory and field concrete. The temperature inside the beam specimens was

\section{Findings}

The following conclusions can be drawn based on the results from this study:

- There is a strong $\left(\mathrm{R}^{2}=0.945\right)$ correlation between the flexural strength and maturity. Based on the maturity data obtained from the field, pavements can be opened at the maturity of $1995 \mathrm{C}$-hrs. That value of maturity corresponds to the current INDOT opening to traffic criteria of $550 \mathrm{psi}$.

- Fatigue tests on 3-days old samples reveal that the pavement can withstand more than 100,000 cycles of load as long as the stress monitored with thermocouples for a prescribed period of time and the data was used to compute maturity. Modulus of Rupture (MOR) was determined for the same samples and a relationship between maturity and corresponding flexural strength was developed using regression analysis. Maturity value corresponding to MOR of 550 psi was used as target maturity for opening to traffic purposes

Fatigue tests were performed at 3, 5, and 7 days. At each age, about 9 beams were tested at three different stress levels $(60,80$ and $90 \%$ of ultimate MOR at that age). The fatigue curves were developed for this data using regression analysis. The fatigue curves were used to obtain allowable number of repetitions of a given load (stress level) for each age. Combining the allowable number of repetitions with the maturityMOR relationship allows for determination of the opening to traffic time. in pavement does not exceed $35 \%$ of ultimate MOR in equivalent $6 \times 9 \times 21$-in. beam. .

- To further refine opening-to-traffic criteria, the fatigue curves should be developed at various ages (ranging from 12 hours to 7 days) so that safe opening-to-traffic time can be established for variety of mixes and curing conditions.

- Wet burlap curing, like that used in this study, should be adopted in the field in order ensure proper hydration of cement. 
- Vebe test was confirmed to be a good tool for assessing the consistency of field-type (stiff) mixes.

\section{Implementation}

The results of this investigation indicate that maturity method can be reliably used to determine the pavement opening to traffic time. However, in order to implement this method a correlation must be developed between the maturity value and the modulus of rupture value for each of the individual mixture designs.

Once this correlation is developed, it can be combined with the MOR-fatigue strength relationship to determine the opening to traffic time. In order to implement this approach the user should calculate the stress induced in the pavement by the type of vehicles expected on the pavement after opening and compare it with the stress level (using fatigue curves) that will provide a required number of fatigue cycles (specified by particular agency). As long as the cumulative stress level generated by various vehicles expected on the pavement during the initial period after opening to traffic is lower than the stress level determined from the fatigue curves the pavement can be safely opened to traffic.

\section{Contact}

For more information:

Prof. Jan Olek

Principal Investigator

School of Civil Engineering

Purdue University

West Lafayette, IN 47907

Phone: (765) 494-5015

Fax: (765) 496-1364
Indiana Department of Transportation

Division of Research

1205 Montgomery Street

P.O. Box 2279

West Lafayette, IN 47906

Phone: (765) 463-1521

Fax: (765) 497-1665

Purdue University

Joint Transportation Research Program

School of Civil Engineering

West Lafayette, IN 47907-1284

Phone: (765) 494-9310

Fax: (765) 496-1105 
Final Report

FHWA/IN/JTRP-2000/25

\title{
USE OF MODULUS OF RUPTURE, FATIGUE RESISTANCE AND MATURITY IN DETERMINING OPENING TO TRAFFIC TIME FOR CONCRETE PAVEMENTS
}

\author{
Jan Olek \\ Principal Investigator \\ Menashi D. Cohen \\ and \\ Charles F. Scholer \\ Co-Principal Investigators \\ and \\ Deepak R. Mandrekar \\ Research Assistant
}

School of Civil Engineering

Purdue University

Joint Transportation Research Program

Project No. C-36-37II

File No. 5-8-35

Prepared in Cooperation with the

Indiana Department of Transportation and the

U.S. Department of Transportation

Federal Highway Administration

The contents of this report reflect the views of the authors who are responsible for the facts and the accuracy of the data presented herein. The contents do not necessarily reflect the official views of or policies of the funding agencies. This report does not constitute a standard, specification, or regulation.

Purdue University

West Lafayette, Indiana 47907

November 2002 
TABLE OF CONTENTS

Page

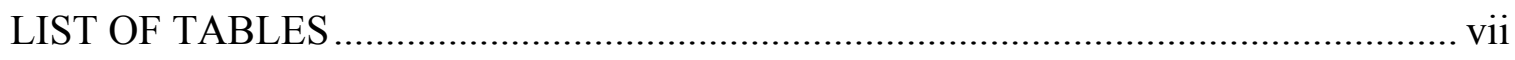

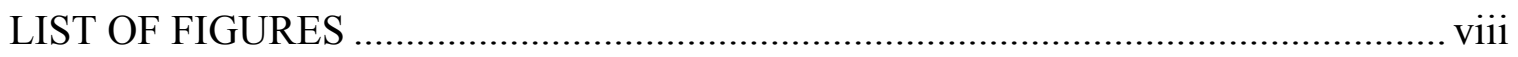

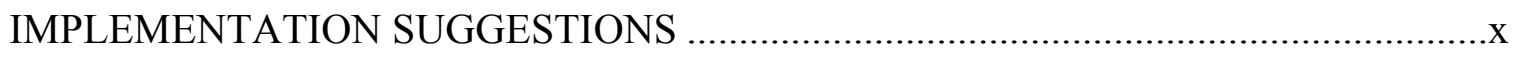

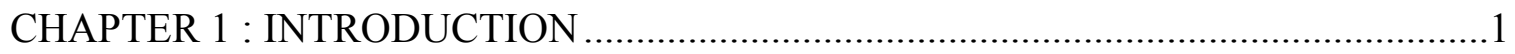

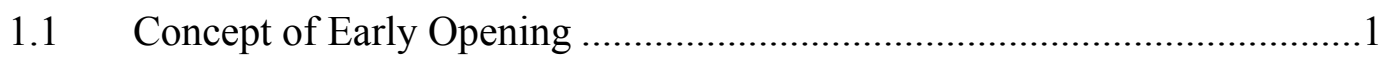

1.2 Some Tips for Early Opening of Pavement to Traffic ....................................3

CHAPTER 2 : RESEARCH PLAN AND OBJECTIVES.................................................

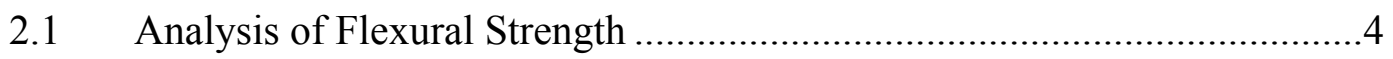

2.2 Development of Flexural Strength - Maturity Relationship........................5

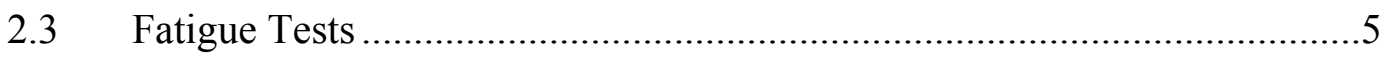

2.4 Earliest Opening Time for Concrete Pavements..........................................6

CHAPTER 3 : REVIEW OF PAVEMENT OPENING-TO-TRAFFIC CRITERIA ...........8

3.1 Time as Opening-to-Traffic Criterion........................................................

3.2 Strength as Opening-to-Traffic Criterion..................................................

3.2.1 Determination of In-Place Concrete Strength..................................9

3.2.1.1 Pulse Velocity Method (ASTM C 597) ..............................10

3.2.1.2 Pull Out Strength Method (ASTM C900)..........................12

3.2.1.3 Break-off Test (ASTM C 1150) .........................................12

3.3 Maturity as Opening-to-Traffic Criterion .................................................13

3.3.1 Maturity Concept ……………………………………………..... 14

3.3.2 Implementation of Maturity by Iowa DOT .....................................15 
4.1 Construction of Thin Bonded Overlay at U.S. Route 13, Northampton

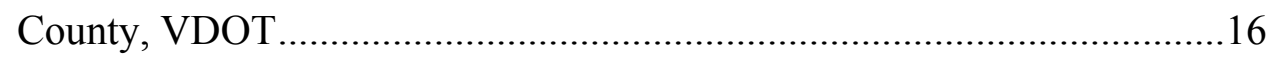

4.1.1 Highlighting Project Features .......................................................17

4.1.2 Mix Components.......................................................................17

4.1.3 Strength Results ........................................................................19

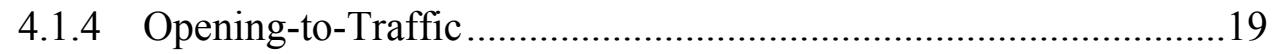

4.2 Pavement Construction in Manhattan, Kansas (KDOT Project 81-U) ......19

4.2.1 Materials and Mix Design.............................................................19

4.2.2 Project Construction.................................................................20

4.2.3 Opening to Traffic...................................................................21

4.2.4 Significant Observations ...........................................................21

4.2.5 Use of Maturity Method.................................................................22

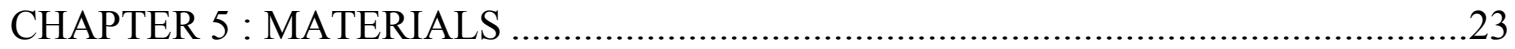

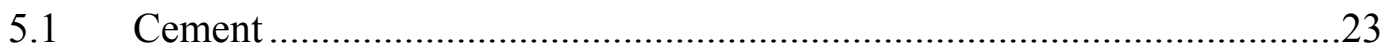

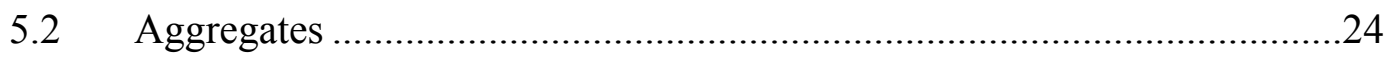

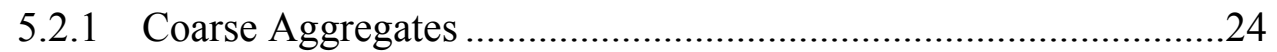

5.2.2 Fine Aggregates …………………………….........................25

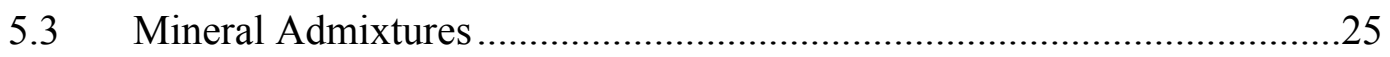

5.4 Chemical Admixtures …………………….......................................26

5.4.1 Air Entraining Admixtures ..........................................................26

5.4.2 Water Reducing Admixtures......................................................26

CHAPTER 6 : MIX PREPARATION AND CURING ...............................................27

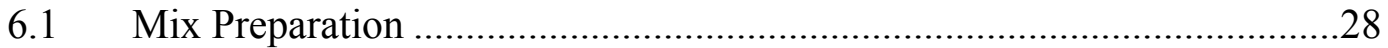

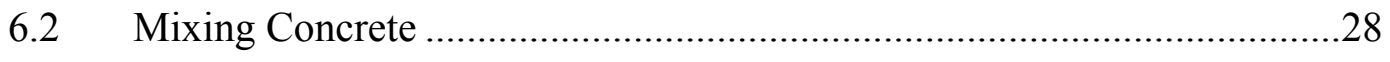

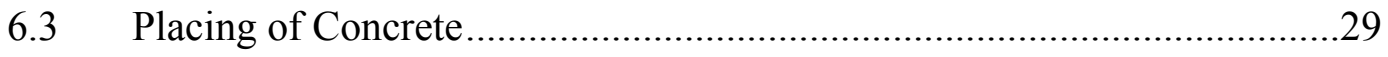

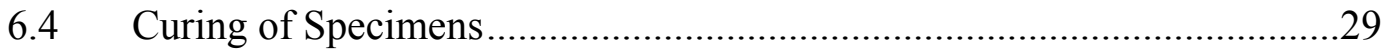


CHAPTER 7 : EXPERIMENTS .31

7.1 Measurement of Properties of Fresh Concrete ............................................31

7.1.1 Consistency of Fresh Concrete ...........................................................31

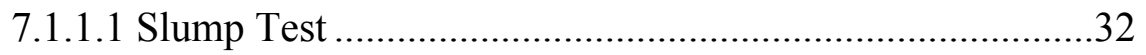

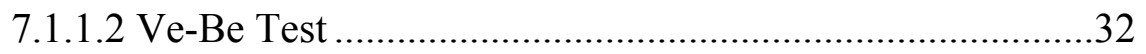

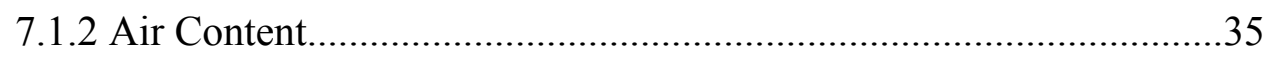

7.2 Measurement of Properties of Hardened Concrete ......................................35

7.2.1 Compressive Strength ....................................................................

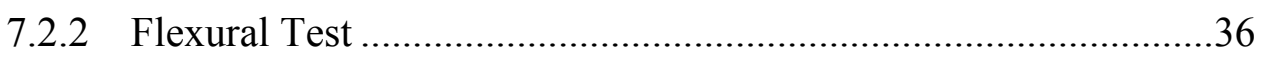

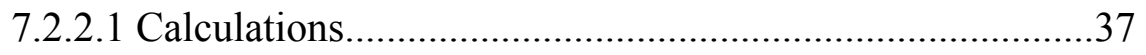

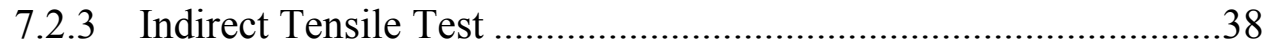

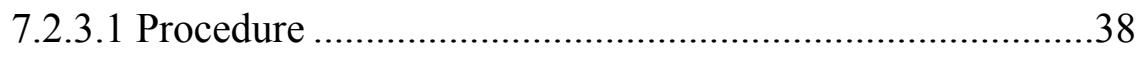

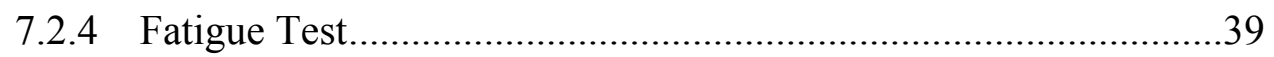

7.2.4.1 Cyclic Loading Pattern .........................................................39

7.2.4.2 Fatigue Testing Procedure ..................................................40

7.2.4.3 Fatigue Loading .............................................................. 43

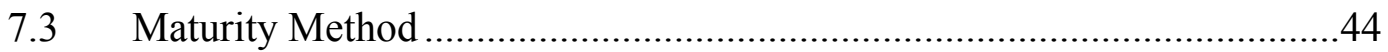

7.3.1 Laboratory Setup for Maturity Determination ..................................45

7.3.2 Establishment of Flexure Strength-Maturity Relationship .............46

7.3.3 Computation of Maturity ..................................................................48

CHAPTER 8 : EXPERIMENTAL RESULTS AND DISCUSSION ………………........49

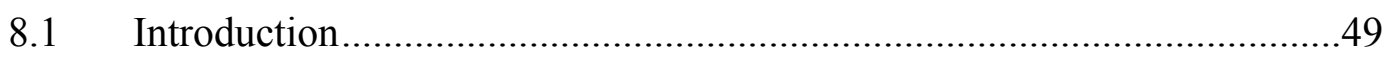

8.2 Time-Temperature History in Test Specimens ........................................50

8.3 Early Age Strength Analysis..................................................................

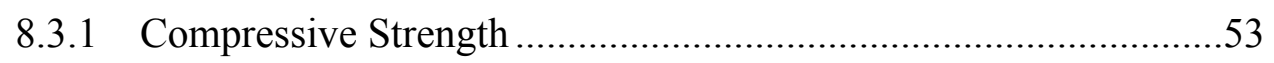

8.3.2 Split Tensile Strength Development with Time..............................55

8.3.3 Flexural Strength and Opening-to-Traffic Period............................56 
8.4 Development of MOR - Maturity Relationship

8.5 Analysis of Fatigue Test Data ..........................................................61

8.5.1 Development of Fatigue Curves .............................................61

8.5.2 Observation on Broken Beams Tested for Fatigue Curve .............65

8.5.3 Use of S-N Curves to Determine Opening-to-Traffic Time ..........67

8.5.4 Overall Fatigue Curve............................................................. 70

8.5.5 Combining Maturity with MOR and Fatigue Data ......................71

CHAPTER 9 : CONCLUSIONS \& RECOMMENDATIONS ….................................73

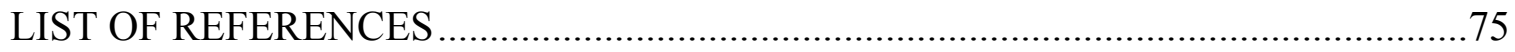

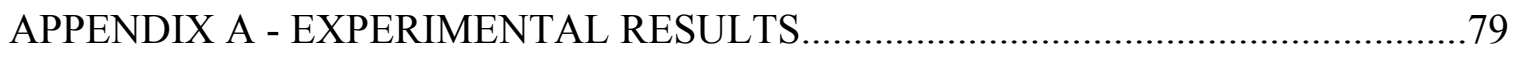

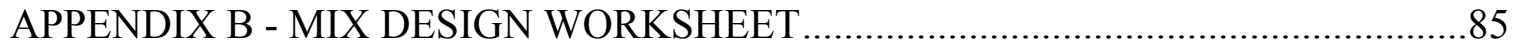




\section{LIST OF TABLES}

Table

Page

4.1 Examples of applications that used accelerated paving technique .........................16

4.2 Some mixture components on US 13, VDOT Project ....................................... 17

4.3 Mix characteristics on Kansas U 81 Project …..................................................20

5.1 Composition of Type I Portland cement ..............................................................24

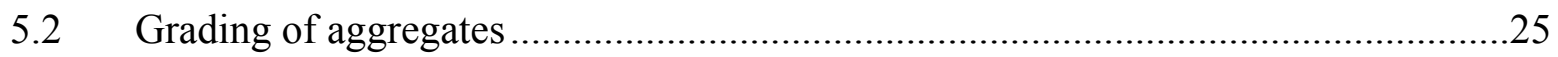

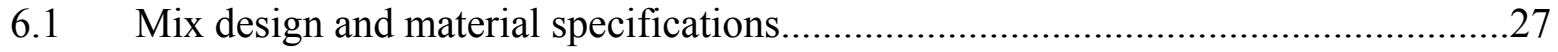

8.1 Compressive strengths at different curing periods..........................................54

8.2 Indirect tensile strength at different curing periods ..........................................55

8.3 Flexure strengths at different curing periods ..................................................56

8.4 Maturity, MOR and compressive strength at 3, 5 and 7 days...............................58

8.5 Maturity and MOR for field specimens .........................................................60 


\section{LIST OF FIGURES}

Figure

Page

1.1 Typical strength development in an early opened pavement v/s conventional

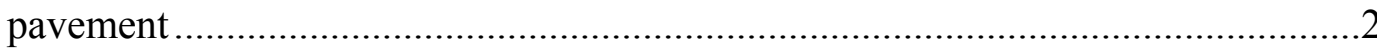

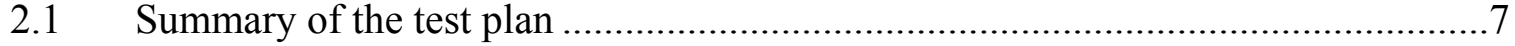

3.1 Schematic diagram of pulse velocity testing circuit .......................................11

3.2 Schematic cross-section of pull-out test ..................................................... 12

3.3 Typical time-temperature curve for maturity method........................................14

4.1 Strength curve for U.S. Route 13 (VDOT) project .........................................18

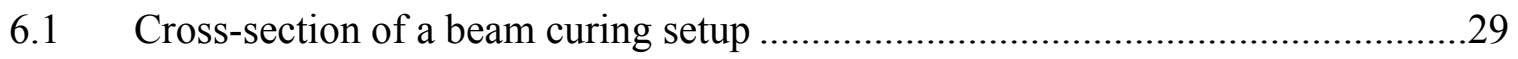

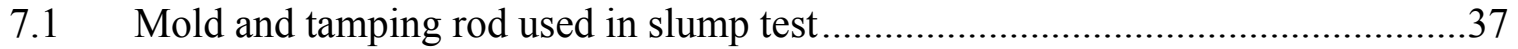

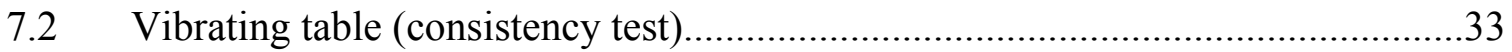

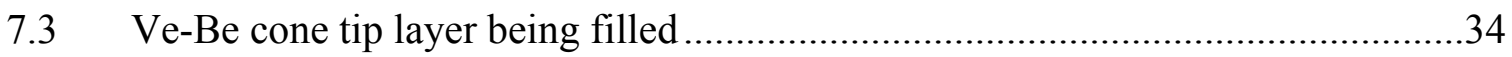

7.4 Concrete specimen placed in the test mold on vibrating table..............................34

7.5 Diagrammatic view of apparatus used for test in flexure .................................36

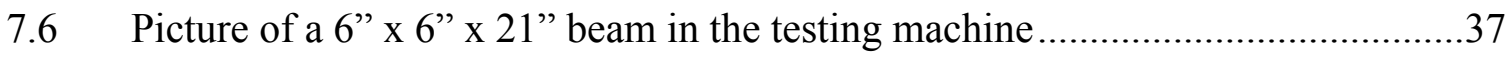

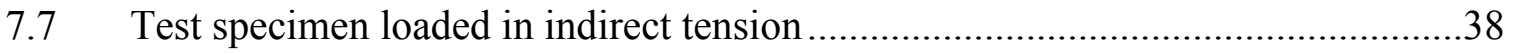

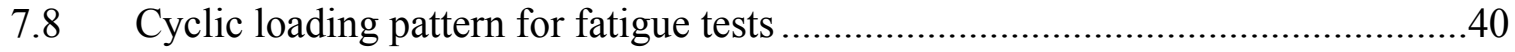

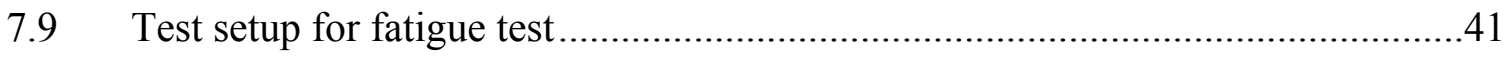

7.10 Actuator head touching the loading assembly at the start of test........................42

7.11 Load computation for fatigue test using a 50-kip load cell ..............................44

7.12 Schematic diagram of time-temperature measurement setup in the laboratory.....45

8.1 Temperature in specimens being monitored by datalogger ...............................51

8.2 Time-temperature history of concrete specimens tested at 3 days ......................51 
Figure

8.3 Time-temperature history of concrete specimens tested at 5 days ......................52

8.4 Time-temperature history of concrete specimens tested at 7 days ......................53

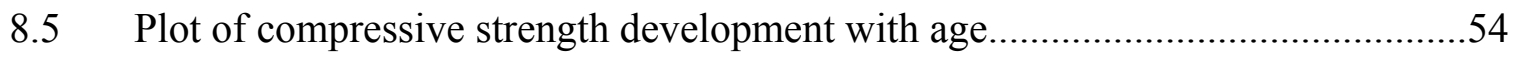

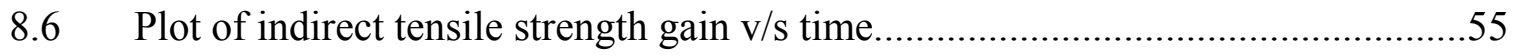

8.7 Development of flexural strength with time for a typical mix used in this research56

8.8(a) Flexural strength-maturity relationship in laboratory specimens ........................58

8.8(b) Compressive strength-maturity relationship in laboratory specimens ..................59

8.9 Flexural strength-maturity relationship developed for field specimens ..............60

8.10 Flexural strength-maturity relation from lab and field concretes .......................61

8.11 Fatigue curve for beams tested at 3 days ......................................................62

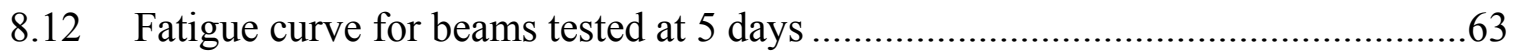

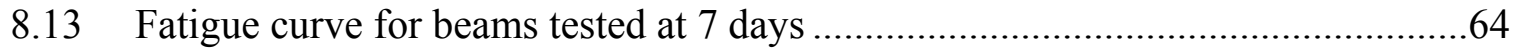

8.14 Cross-section of a beam that failed at 3360 cycles at $90 \%$ stress level after 7 days of curing

8.15 Cross-section of a beam that failed at 1073 cycles at $90 \%$ stress level after 3 days of curing

8.16 A beam that failed after 14764 cycles when tested at $80 \%$ stress level at 3 days .67

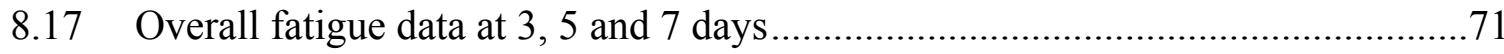




\section{Implementation Suggestions}

Pursuant to findings presented in this report the following suggestions are being provided as a means of implementing the maturity method and fatigue resistance for determining the opening to traffic time for concrete pavements in Indiana.

1. The maturity method can be used for monitoring the development of flexural strength during concrete pavement construction providing that a calibration curve is established for these two parameters using the same materials as selected for the actual project.

2. While developing the maturity-flexural strength relationship it is important to keep all samples under the same moisture and temperature conditions. These conditions should be as close as possible to the conditions expected in the actual pavement.

3. Although the maturity-strength relationship will give an indication as to what maturity value is needed to reach the required (currently $550 \mathrm{psi}$ ) level of strength for opening to traffic, it will not provide an answer to the question as to what level of stress can cause the fatigue damage. The answer to the last question can only be obtained by conducting a fatigue test on set of specimens similar to those used for flexural testing and correlating the results with the strength test values. Combining the maturity data (that give an indication of the shortest time when the strength needed to ensure adequate fatigue life can be obtained) with strength and fatigue data will allow the user to make a rational decision as to the opening to traffic time.

4. In order to implement this approach the user should calculate the stress induced in the pavement by the type of vehicles expected on the pavement after opening and compare it with the stress level (using fatigue curves) that will provide a required number of fatigue cycles (specified by particular agency). As long as the cumulative stress level generated by various vehicles expected on the pavement during the initial period after opening to traffic is lower than the stress level determined from the fatigue curves the pavement can be safely opened to traffic. 
5. Based on the result of this study, the pavement constructed from mixture of similar composition as the one tested and cured under similar conditions can be opened to traffic as early as 3 days after construction. This time for opening to traffic is based on the current INDOT's criteria of MOR value of 3.8 MPa (550 psi) and minimum of 7,000 cycles under the load of $40 \mathrm{kN}(9,000 \mathrm{lb})$. It is probably a conservative estimate due to lack of knowledge of exact state of stresses in the pavement and some uncertainty involved with maturity-based strength assessment. Should some of these uncertainties be eliminated or reduced (say, by using advanced numerical modeling of the state of stresses) the time to opening can be shortened even further. 


\section{CHAPTER 1 - INTRODUCTION}

Due to a dramatic increase in the number of vehicles on the roadways in the last few decades, transportation departments and travelers are facing a major traffic congestion problem during pavement repairs and rehabilitation. Repairs and rehabilitation of a given pavement section may take up to a month depending on the techniques and materials used for construction. There is a growing trend to open pavements to traffic as soon as possible (after repair has been completed) in order to minimize the inconvenience to the road users.

The early opening-to-traffic technology should not be confused with fast track construction. While the former approach allows for opening of the pavement to traffic as soon as (typically) the concrete reaches the minimum specified strength, the latter uses specially formulated materials to attain high-early strength within few hours after placement.

\subsection{Concept of Early Opening}

Early opening of concrete pavements to traffic is essentially a new technology which employs advanced materials like mineral and chemical admixtures, to produce concrete that can attain the required strength earlier (1 - 3 days) than the conventional concrete (about 5 - 7 days), as illustrated in Figure 1.1. 
There are several factors that should be considered in order to open the pavements to traffic early and economically. These factors include:

1. Minimum flexural strength required.

2. Climatic conditions at the site, which would significantly affect rate of hydration and strength development in the concrete.

3. Amount of fatigue damage due to early opening and its effects on long term performance.

4. Allowable number of load repetitions.

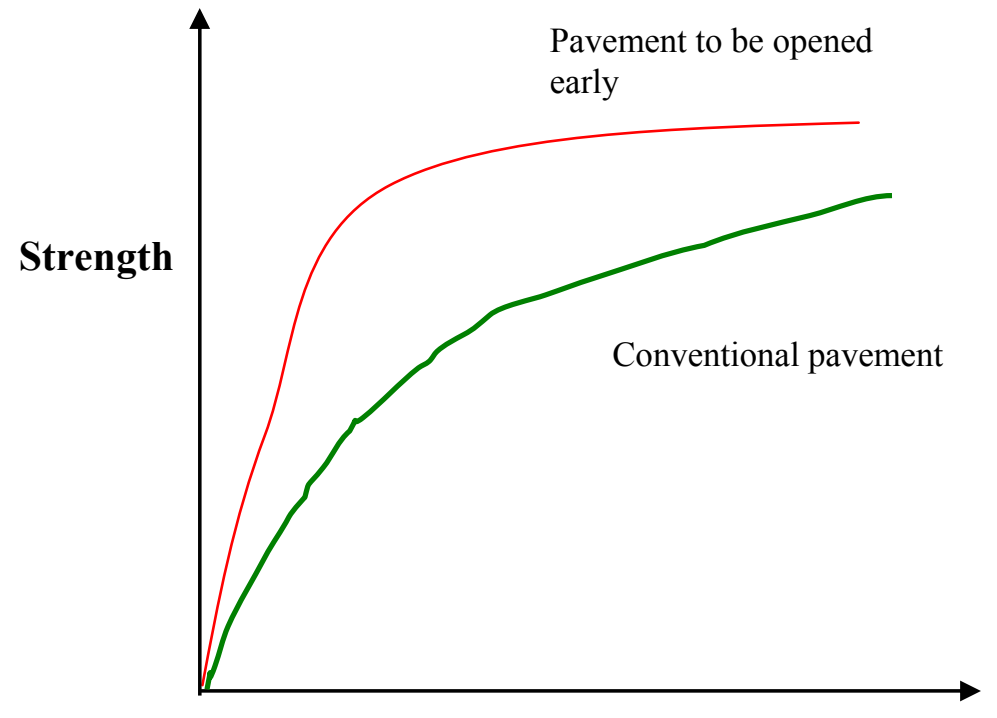

Age

Fig. 1.1 Typical strength development in an early opened pavement versus conventional pavement 


\subsection{Some Tips for Early Opening of Pavement to Traffic}

Pavements can be opened-to-traffic early by using a systematic plan for executing construction operations and also by selecting raw materials with desired properties. Some tips for early opening of pavements to traffic are provided below based on past experience.

- Aggregates should be graded uniformly so that appropriate sizes are available to produce well-graded dense matrix.

- Water-cement ratio should be below 0.43 .

- Sawing should be done with ultra-light saws.

- Sealant that is unaffected by moisture must be used.

- Strength gain within the mix should be studied by monitoring the internal temperature of concrete.

- Concrete temperatures may be increased before placement in order to expedite hydration process in cold weather. 


\section{CHAPTER 2 - RESEARCH PLAN AND OBJECTIVES}

The goal of this research was to explore the possibility of using the maturity method to aid in determining the time to early opening-to-traffic for concrete pavements in the state of Indiana.

The scope of the research included the evaluation of flexural strength development with time as a function of maturity and the determination of opening-totraffic time by correlating flexural strength at a given maturity with fatigue of concrete. The flow chart summarizing the overall research plan is presented in Figure 2.1.

The main tasks of this research included the following:

- Analysis of flexural strength development with age for a typical Indiana concrete pavement mixture.

- Development of flexural strength maturity.

- Development of fatigue curves at different ages and stress levels.

- Determination of earliest opening time based on maturity/flexural strength results and fatigue test data.

\subsection{Analysis of Flexural Strength}

Flexural strength is widely used as the basis for opening-to-traffic for concrete pavements. The value used on pavement projects in Indiana is $3.79 \mathrm{MPa}$ (550 psi). 
During the preliminary phase of this project, several beams $(6 " \times 6$ " 621 " or 15 $\mathrm{cm} \times 15 \mathrm{~cm} \times 52.5 \mathrm{~cm}$ ) were tested in third point loading mode. Flexural strength and corresponding age for each beam were recorded, and a plot of flexural strength versus time was developed.

\subsection{Development of Flexural Strength -- Maturity Relationship}

In order to determine flexural strength-maturity relationship, a beam and two cylinders were prepared using a mixture with composition adopted from an actual paving project and tested at different ages. The specimens were instrumented with thermocouples to monitor the temperature development as a function of time. The temperature data was used to compute maturity for corresponding ages and a relationship between flexural strength versus maturity (logarithmic scale) was obtained. Regression analysis was performed in order to determine the confidence level of the established relationships.

Maturity corresponding to modulus of rupture (MOR) of $3.79 \mathrm{MPa}(550 \mathrm{psi}$ ) was used as a target value maturity for opening concrete pavements to traffic.

\subsection{Fatigue Tests}

Fatigue tests are of high relevance in determining the time to opening-to-traffic as these tests resemble the type of loading a concrete pavement would have to resist. In order to determine the relationship between fatigue life and MOR at various stages, the fatigue life (number of repetitive load cycles to failure) values were determined at 3,5 and 7 days. At each age, 9 beams were tested at three different stress levels $(60,80$ and $90 \%$ of ultimate MOR at that age). 
2.4 Earliest Opening-to-Traffic Time for Concrete Pavements

Based on standards set by individual department of transportation, a pavement can be opened to traffic if a beam of standard size can withstand a specified number of load cycles. In this research, a $15 \mathrm{~cm}$ x $15 \mathrm{~cm}$ x $52.5 \mathrm{~cm}(6 " \times 6$ " x 21 ") beam was used as a standard beam for determining the fatigue life at the given age and maturity level. If this beam failed at a higher number of repetitions, then the pavement was considered safe for opening at that age. 


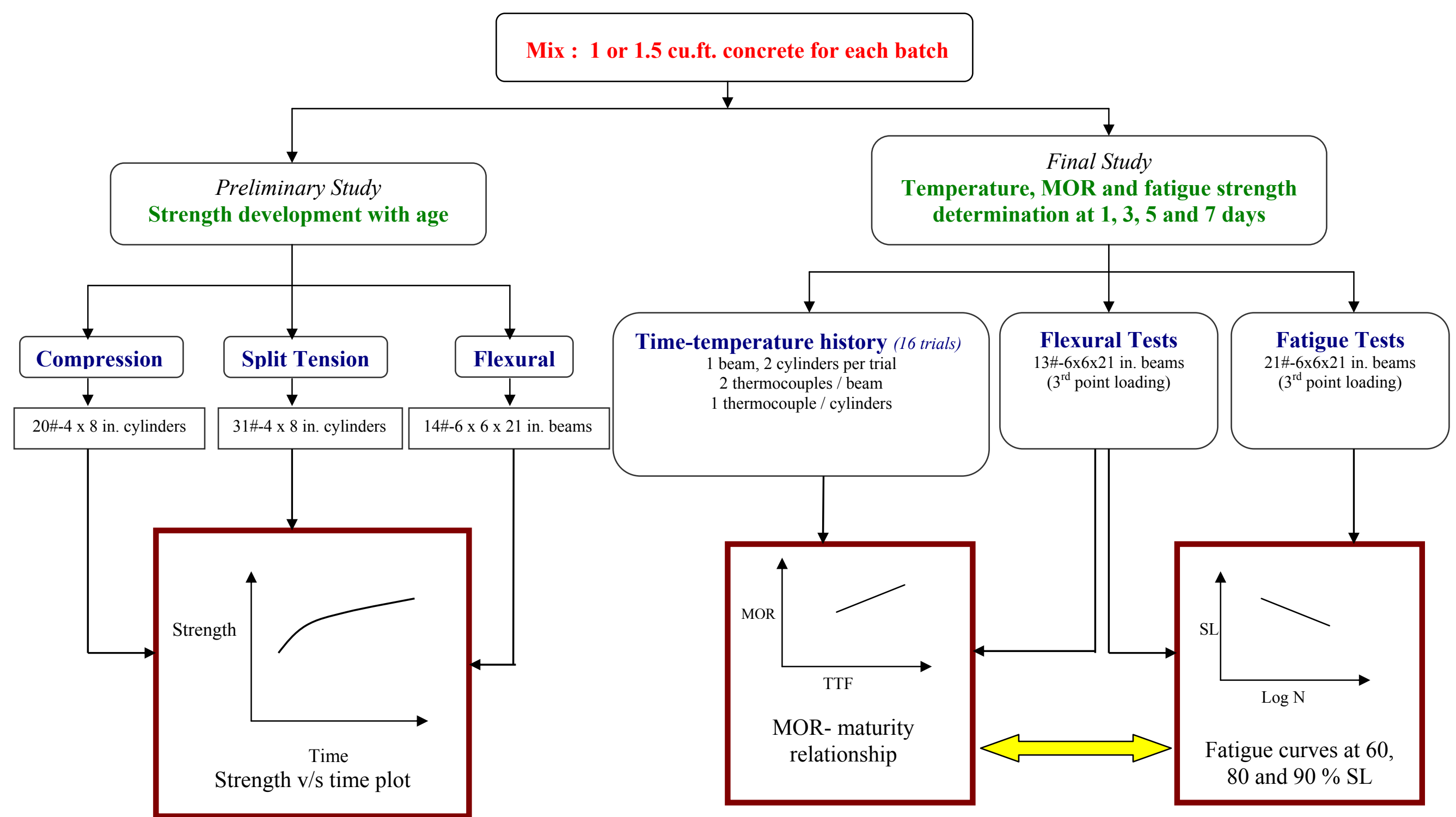

Fig. 2.1 Summary of the test plan 


\section{CHAPTER 3 - REVIEW OF PAVEMENT OPENING-TO-TRAFFIC CRITERIA}

This chapter discusses different criteria used for determining the time to openingto-traffic. The most commonly used criteria include:

1. Time

2. Strength, and

3. Maturity

All these criteria are discussed in further detail below.

\subsection{Time as Opening-to-Traffic Criterion}

It is mentioned in ref. (2) that time was previously used as a criterion for opening of concrete pavements to traffic. However, this method has some serious limitations as it could only be used with those concrete mixes whose strength gain and performance was well understood from the past experience ${ }^{(2)}$. In these cases the regression analysis on the tests conducted is required to be comparatively high.

In general, it is not advisable to base the opening standards on time alone as the concrete properties are different for different projects and vary with environmental conditions. This could result in a weak pavement that might not be able to withstand loads safely. 


\subsection{Strength as Opening-to-Traffic Criterion}

Strength is usually considered as a reliable criterion for opening concrete pavements to traffic as it is an indication of the pavement's ability to withstand traffic loads. Sometimes, a combination of strength and time may be used in projects of vital importance. Typically ${ }^{(2,4,29)}$, flexural strength (MOR) is used (rather than compressive strength) as the traffic loads impose bending in the pavement. However, one should realize that at a given time strength of concrete pavement will not be the same even if identical mix design is used. Curing temperature, humidity, moisture in coarse and fine aggregates, etc., are some of the factors that are responsible for strength development in particular concrete. If possible, in-place strength should be used as it gives a better indication of pavement ability to withstand loads.

Some of the methods that can be used for in-place strength determination are presented below.

\subsubsection{Determination of In-Place Concrete Strength}

FHWA (Federal Highway Administration) initiated a demonstration project on accelerated rigid paving techniques ${ }^{(2)}$ in 1988 to promote the development of fast track concept. Since then, several projects have been completed based on this approach. As a result of this, many states have initiated a concept of early opening that is used to open a pavement within $12-48$ hours. This is achieved typically by using high cement content and a low water cement ratio.

Minimum strength levels must be achieved for opening concrete pavements so that safety and durability of construction is ensured. In-situ tests save a lot of time and 
money and also reduce the efforts that are required in core extraction for testing representative samples from the concrete slabs. A variety of in-situ test methods are available. The most common ones include:

- Pulse Velocity Method (ASTM C 597)

- $\quad$ Pull Out Method (ASTM C 900)

- Break Off Method (ASTM C 1150)

\subsubsection{Pulse Velocity Method (ASTM C 597)}

This method is widely used in concrete industry, mainly for determination of uniformity of cross-section within a concrete structure. In this test method, the time taken by mechanical pulse to pass from one point of the object to the other is measured and used to compute pulse velocity. A piezo-electric transducer generating pulses is held in contact with one surface of concrete as shown in Fig. 3.1. These pulses traverse through the concrete and are later received by a second transducer that converts these pulses into electrical signals. The time $(\mathrm{T})$ taken by a pulse to traverse from one transducer to the other located at a distance $(\mathrm{L})$ is recorded and used to calculate velocity of the wave propagating through the material as shown below.

$$
V=\frac{L}{T}
$$

where, $V=$ Pulse velocity, $\mathrm{m} / \mathrm{s}(\mathrm{ft} / \mathrm{s})$

$\mathrm{L}=$ Distance between tansducers, $\mathrm{m}(\mathrm{ft})$, and

$\mathrm{T}=$ Effective transit time, $\mathrm{s}$ 
Limitations of Pulse Velocity Method: There are some restrictions that the user needs to be aware of before using this technique. Pulse velocity is very sensitive to moisture content in the structure. A proper source for pulse generation shall be used when testing larger structures, as the penetration of pulses in the thicker elements is limited.

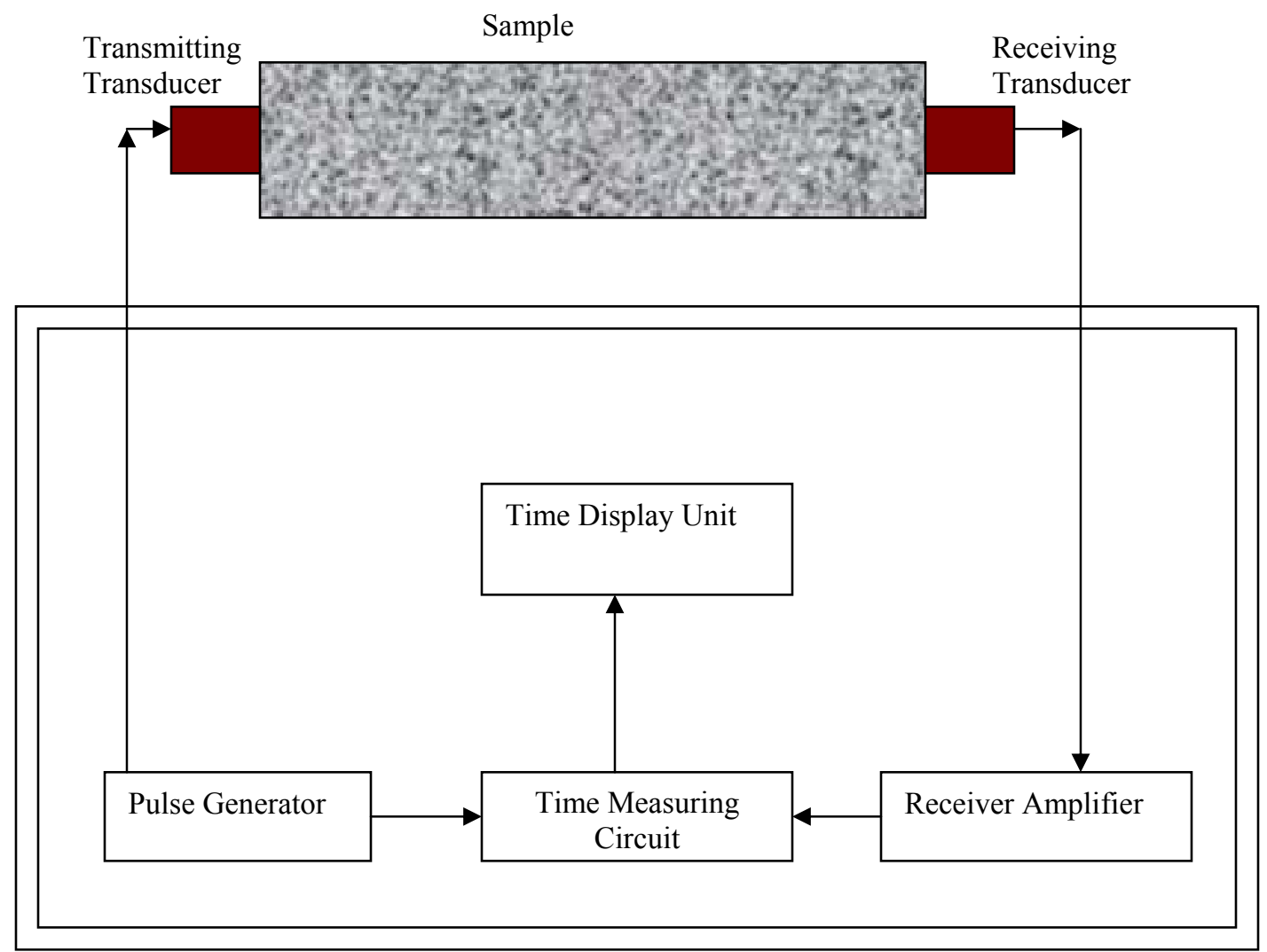

Fig. 3.1 Schematic Diagram of Pulse Velocity Test Set-up 


\subsubsection{Pull Out Strength Method (ASTM C 900)}

In Pull-out strength method ${ }^{(36)}$, the hardened strength of concrete is determined by measuring the force required to pull an embedded metal insert (and the attached concrete fragment) from a test specimen. Schematic layout of a pull out test can be seen in Fig. 3.2. The pull out strength obtained from this test can be correlated with other strength results provided same concrete mix design is used. There are several other factors that affect the strength values obtained by this technique, such as,

1. Type of metal insert

2. Bearing ring dimensions

3. Depth of embedment, and

4. Level of strength development in a particular concrete mix.

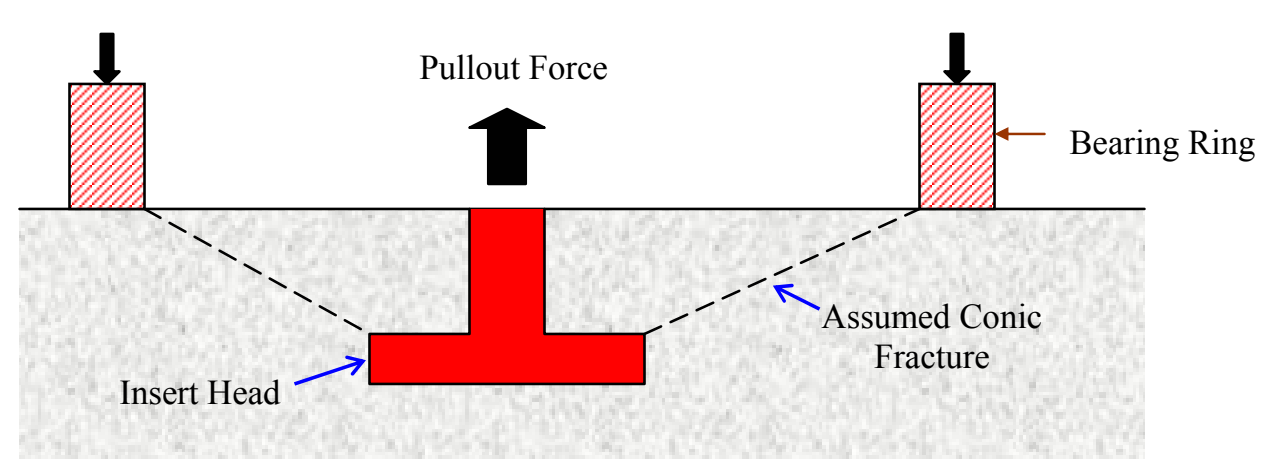

Fig. 3.2 Schematic Cross-section of Pull-out Test

\subsubsection{Break-Off Test (ASTM C 1150)}

In this test method the force required to cause break-off a drilled core specimen loaded as a cantilever is determined. In a typical application a plastic sleeve with an annular seating ring is inserted in fresh concrete to form a cylindrical test specimen and a 
counter bore. After the concrete has hardened, the sleeve is removed and a force is applied at the uppermost section of the cylinder so as to break the cylindrical test specimen from the concrete mass. The maximum hydraulic pressure recorded by the gage applied by loading the specimen is noted as the break-off strength value.

\subsection{Maturity as Opening-to-Traffic Criterion}

Maturity method has become a popular tool in concrete industry and its range of application is increasing. This method deals with measurement of internal temperature of concrete, which is related to the amount of hydration and strength gain. The temperature within the concrete increases as the hydration progresses. It is well known that strength has a direct relation with the amount of hydration taking place in the specimens. Temperature development is measured at regular intervals and the data is recorded by means of a datalogger ${ }^{(35)}$. The temperature and time data are used to develop maturity curves as discussed in Section 3.3.1.

Maturity method is widely used to correlate flexural strength of concrete with time-temperature factor. Due to high precision of this method, it is now used as openingto-traffic criteria. Now-a-days, many construction projects use maturity to open concrete pavements based on time-temperature factor that concrete has attained at opening time. Maturity is now used on several projects for early opening and can be used as another opening-to-traffic criterion.

Maturity method is a very useful technique compared to other available techniques discussed in this chapter. Most of these test methods are destructive and also may not give a correct measure of in-place strength development. Whereas, maturity test 
computes hydration amount from time-temperature factor that is directly related to strength development in concrete.

\subsubsection{Maturity Concept}

Hydration of cement and strength gain of concrete is dependent on both time and temperature. Concrete strength is directly proportional to amount of hydration that has taken place. Thus, the strength of concrete can be expressed as some function of time and temperature. This function is called the maturity. Maturity is defined as the integral of time and temperature of concrete above a datum temperature.

Maturity is computed using Nurse-Saul equation, given by

$$
\mathrm{M}=\left(\mathrm{T}-\mathrm{T}_{\mathrm{o}}\right) \Delta \mathrm{t}
$$

$\mathrm{M}=$ Maturity of concrete at time $\mathrm{t},{ }^{\circ} \mathrm{C}$-hrs

$\mathrm{T}=$ Temperature of concrete at time, $\mathrm{t} \mathrm{hrs},{ }^{\circ} \mathrm{C}$

$\mathrm{T}_{\mathrm{o}}=$ Datum temperature, $-10^{\circ} \mathrm{C}$

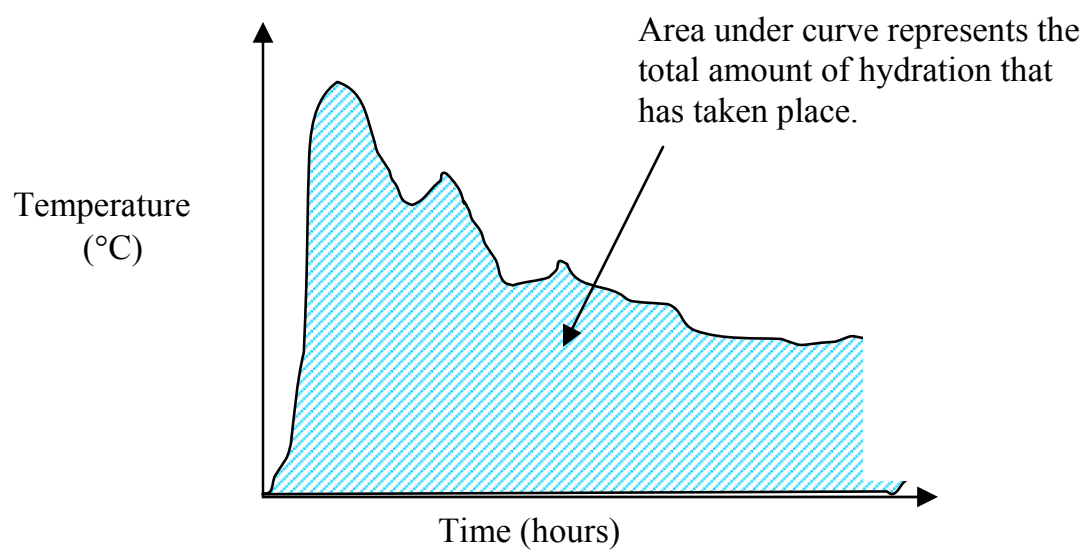

Fig. 3.3 Typical time-temperature curve (TTF) used in maturity method 
A relation between strength and maturity is developed in the laboratory and later used on the site for strength determination for corresponding value of maturity.

\subsubsection{Implementation of Maturity Method by Iowa DOT}

Iowa DOT first used the maturity method for strength determination as a part of field trial in 1988. Until 1996, around 12 to 16 beams were required on a given project to determine the confidence level. Starting in 1996, 9 beams were cast but that requirement was later increased to 12 beams to reduce the range of $95 \%$ confidence level. The established values of TTF were periodically validated by casting 3 beams and checking whether the strength falls between $\pm 345 \mathrm{kPa}(50 \mathrm{psi})$ at opening TTF. Casting 12 beams and testing 3 beams per time interval increased the uniformity of the results. 


\section{CHAPTER 4 - RECENT TRENDS IN EARLY OPENING-TO-TRAFFIC}

The introduction of accelerated rigid paving technology in United States in mid1980s resulted in development of high performance concrete mixtures suitable for use in cases where early opening to traffic was desired. Examples of application of accelerated paving technology are given in Table 4.1 .

Table 4.1 Examples of applications that used accelerated paving technique ${ }^{(2)}$

\begin{tabular}{|c|c|}
\hline $\begin{array}{c}\text { Number of Projects } \\
\text { Completed }\end{array}$ & Application \\
\hline 10 & Airfield Projects \\
\hline 36 & Highway Projects \\
\hline 17 & Intersection Projects \\
\hline 26 & Street or Low Volume Projects \\
\hline 7 & Industrial Projects \\
\hline
\end{tabular}

There are several major projects where early opening to traffic have been accomplished very successfully. In this chapter, examples of some of these projects are discussed.

4.1 Construction of Thin Bonded Overlay at U.S. Route 13, Northampton County, Virginia Department of Transportation $\left(\right.$ VDOT) ${ }^{(2)}$

This project was the first experience of VDOT with the early opening-to-traffic concept was introduced. The key objective of this project was to open the pavement to 
traffic within 48 hours and also to test whether the overlay concrete bonds well with the underlying old concrete during a 5-year period.

\subsubsection{Main Project Features of the Project}

- Use of finely ground cement and concrete with a low water cement ratio (below 0.42) to obtain high early strength.

- Retention of heat in the concrete by means of blankets or other means to assist in faster strength development.

- Use of non-destructive techniques to achieve a better in-place strength evaluation to aid in determining time for early opening.

\subsubsection{Mixture Components}

Some of the mixture components and characteristics of concrete produced on U.S. Route 13 project are shown in table 4.2 .

Table 4.2 Some mixture components \& characteristics of US 13, VDOT project ${ }^{(2)}$

\begin{tabular}{|c|c|}
\hline Material & Quantity \\
\hline Nominal size of aggregate & $1 \mathrm{in}$. \\
\hline Minimum cement content & $750 \mathrm{lb} / \mathrm{yd}^{3}$ \\
\hline Maximum water content & 0.42 \\
\hline Slump & $0-3 \mathrm{in}$. \\
\hline Air content & $6 \pm 2 \%$ \\
\hline
\end{tabular}

Two types of cements were used in preliminary trial batches. One was finely ground Type II and the other was locally available Type III. The contractor selected the 
use of $W R+R$ (water reducer as well as retarder) at a lower dosage rate of $25 \mathrm{oz} / \mathrm{yd}^{3}$ for economic reasons and to reduce possible retardation. Commercially available neutralized vinsol oil was used as air entraining agent.

\subsubsection{Strength Results}

The air content in the field mixture was fairly close to that achieved in the laboratory trials. Concrete mixtures developed in the lab and on site had a reasonable slump of about $76 \mathrm{~mm}$ (3”), which provided a good workability for placing and finishing and developed relatively high flexural strength of $5.8 \mathrm{MPa}(835 \mathrm{psi})$ at 28 days. This project used compressive strength of $27.6 \mathrm{MPa}$ (4000 psi) as the opening-to-traffic criterion.

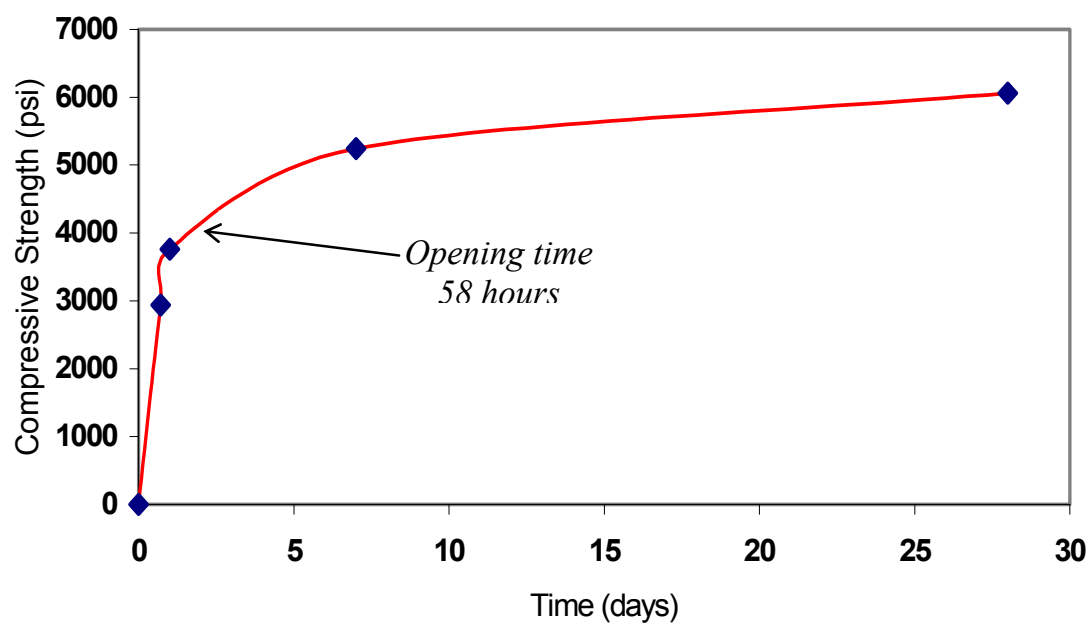

Fig.4.1 Compressive strength development for U.S. Route 13 (VDOT) project 


\subsubsection{Opening to Traffic}

The pavement was opened to traffic after 58 hours i.e., 10 hours later than the estimated opening time of 48 hours. The delay was caused by some problems in concrete transportation and also in sawing of joints. The tests for roughness conducted one week after opening-to-traffic indicated that the surface roughness had not changed compared to the surface roughness determined at the time of opening. Some spalling was noted due to harsh texture of concrete. All joint seals and early performance of the pavement were good.

\subsection{Pavement Construction in Manhattan, Kansas (KDOT Project 81-U) ${ }^{(6)}$}

Kansas Department of Transportation (KDOT) and the City of Manhattan jointly executed this project in 1989-90. As this route is one of the busiest in the locality, KDOT aimed to take the advantage of high early strength gain so that negative effect on city traffic is minimized.

\subsubsection{Materials and Mix Design}

Type III Portland cement having a Blaine fineness of $560 \mathrm{~m}^{2} / \mathrm{kg}{ }^{(6)}$ was used. This cement met KDOT cement specifications for Type III cement. This cement had a high calcium tri-silicate content of $59.3 \%$, which mainly contributes to early strength gain. Different types of locally available aggregates were used. Especially, the coarse aggregate was KDOT class I freeze thaw resistant aggregate. The composition of the concrete mixture used on this project is shown in Table 4.3. 
The resulting concrete mix had about 5\% air content. Both water reducing as well as air-entraining admixtures were used. Cylinders and beams were prepared with this mix and cured under thermal blanket. The compressive strength was found to be 25.2 $\mathrm{MPa}(3650 \mathrm{psi})$ and $27.5 \mathrm{MPa}(3990 \mathrm{psi})$ at 18 and 24 hours, respectively. The corresponding flexural strength values were 2.9 MPa (420 psi) and 3.8 MPa (545 psi), respectively.

Table 4.3 Mixture characteristics on Kansas 81-U project

\begin{tabular}{|c|c|}
\hline Mix Component & Details \\
\hline Cement (Type III) & $421 \mathrm{~kg} / \mathrm{m}^{3}\left(710 \mathrm{lb} / \mathrm{yd}^{3}\right)$ \\
\hline Water Cement ratio & $0.40-0.44$ \\
\hline Aggregates & Crushed limestone/ river sand \\
\hline Air entraining admixture & Daravair $(5 \%$ air entrainment $)$ \\
\hline Water reducer & Hycol \\
\hline
\end{tabular}

\subsubsection{Construction Process}

Two types of mixtures with design water-cement ratios of 0.40 and 0.44 were used. The mixture with w/c ratio of 0.44 had a higher air content and slump compared to the mix with w/c ratio of 0.40 and was used on most part of the project. Like the VDOT $^{(2)}$ project discussed earlier, this project also used a slipform paver. In some places where the use of paver was restricted, concrete was placed manually. Nuclear gauge was used to keep a constant check that the consolidated density of concrete was greater than $98 \%$ of rodded unit weight. Burlap was dragged to give a final finish to the surface of the pavement. A white curing compound along with insulated blankets was used on this project. The blanket cover was essentially a layer of closed cell polystyrene foam 
protected by at least one layer of plastic film. The thermal blankets were kept on the structure until a minimum flexural strength of $1.7 \mathrm{MPa}$ (250 psi) by third point loading was obtained. Thermocouples were used on this project to measure the time-temperature history of the concrete.

\subsubsection{Opening to Traffic}

The pavement was opened to traffic after the concrete had attained a modulus of rupture of 3.1 MPa (450 psi). All joints were sealed at all places and the pavement was opened to traffic within 48 hours.

\subsubsection{Significant Observations}

There were several studies conducted on this project involving influence of different parameters in early strength gain of concrete. It was observed that the 24-hour strength was higher when the daily high temperature exceeded $24^{\circ} \mathrm{C}$. However, the same concrete failed to achieve the desired flexural strength when the daily temperature fell below $0^{\circ} \mathrm{C}$. It was also observed that the concrete strength was highest when the average daily temperature was between $27^{\circ} \mathrm{C}\left(80.6^{\circ} \mathrm{F}\right)$ and $29^{\circ} \mathrm{C}\left(84.2^{\circ} \mathrm{F}\right)$.

Flexural strength decreased as the air content increased. This was true for both concrete mixtures adopted for this project. Air entrainment was also affected by average daily temperature. Increase in air entrainment raised the slump of the mix. It was observed that time of placing of concrete during the day had a little impact on the early strength gain. 


\subsubsection{Use of Maturity Method}

From the time-temperature history of concrete collected by means of maturity meter, maturity value was computed for the constructed pavement. Air temperatures as well as temperatures within the beams and slabs were monitored. It was found that relation between flexural strength and time at 24-hour period was linear. Also, significant differences in maturity values were noted at slab top and bottom. 


\section{CHAPTER 5 - MATERIALS}

Materials and experimental methods used in this research are described in the present section. Section 5.1 describes the chemical composition of Type I Portland cement used for preparation of samples. Section 5.2 deals with characteristics of aggregates that were used in the experimental study. Sections 5.3 and 5.4 provide details on mineral and chemical admixtures used for experimental work, respectively.

\subsection{Cement}

Type I cement conforming to ASTM C 150 was used during the entire experimental study. Lonestar Cement manufactured this cement in Greencastle, Indiana. On most of the early opening-to-traffic projects, type III cement is used due to its high early strength development. Type I cement manufactured by Lonestar has mineral composition similar to a typical type III cement. Contractors in Indiana are using this cement widely for pavement construction during the summer season because it is cheaper than type III cement.

The $\mathrm{CaO}$ composition varied from $63.83 \%$ to $65.17 \%$ and $\mathrm{SiO}_{2}$ content was in the range of $20.60 \%$ to $21.28 \%$. The detailed composition of this cement is shown in table 5.1. 
Table 5.1 Composition of Type I Portland Cement

\begin{tabular}{|l|c|}
\hline Oxide & Composition (\%) \\
\hline $\mathrm{CaO}$ & 64.72 \\
\hline $\mathrm{SiO}_{2}$ & 20.93 \\
\hline $\mathrm{Al}_{2} \mathrm{O}_{3}$ & 5.24 \\
\hline $\mathrm{Fe}_{2} \mathrm{O}_{3}$ & 2.49 \\
\hline $\mathrm{MgO} \mathrm{SO}_{3}$ & 2.22 \\
\hline $\mathrm{Na}_{2} \mathrm{O}$ & 2.34 \\
\hline $\mathrm{K}_{2} \mathrm{O}$ & 0.08 \\
\hline $\mathrm{TiO}_{2}$ & 0.58 \\
\hline $\mathrm{P}_{2} \mathrm{O}_{5}$ & 0.36 \\
\hline $\mathrm{Mn}_{2} \mathrm{O}_{3}$ & 0.11 \\
\hline $\mathrm{SrO} \mathrm{O}$ & 0.04 \\
\hline $\mathrm{Loss}$ & 0.09 \\
\hline $\mathrm{Free} \mathrm{CaO}$ & 1.04 \\
\hline $\mathrm{C}_{3} \mathrm{~S}$ & 0.34 \\
\hline $\mathrm{C}_{2} \mathrm{~S}$ & 58.93 \\
\hline $\mathrm{C}_{3} \mathrm{~A}$ & 15.55 \\
\hline $\mathrm{C}_{4} \mathrm{AF}$ & 9.68 \\
\hline $\mathrm{CaSO}$ & 7.58 \\
\hline & 3.98 \\
\hline
\end{tabular}

\subsection{Aggregates}

Coarse aggregates from Martin Marietta plant ( $96^{\text {th }}$ street, Indianapolis) were used in the project. Fine aggregates were obtained from IMI Greenwood. Details of coarse and fine aggregates are provided in sections 5.2.1 and 5.2.2.

\subsubsection{Coarse Aggregate}

Coarse aggregates of No.8 grading were used. Bulk specific gravity of these aggregates was 2.685. Absorption and moisture content of the coarse aggregates were $1.33 \%$ and $2.30 \%$, respectively. Both these values were taken into account when 
determining the quantity of additional water required for the mix. Grading of coarse and fine aggregate are shown in table 5.2.

Table 5.2 Grading of Aggregates

\begin{tabular}{|c|c|c|c|}
\hline \multicolumn{2}{|c|}{ Coarse Aggregate } & \multicolumn{2}{c|}{ Fine Aggregate } \\
\hline Sieve Size & $\%$ Passing & Sieve Size & \% Passing \\
\hline $1 "$ & 100 & $3 / 8 "$ & 100 \\
\hline $3 / 4 "$ & $85-100$ & No.4 & 100 \\
\hline $1 / 2 "$ & $25-55$ & No.8 & 98 \\
\hline $3 / 8 "$ & $8-25$ & No.10 & 75.6 \\
\hline No.4 & $0-5$ & No.30 & 47.4 \\
\hline \multirow{2}{*}{} & & No.50 & 11.2 \\
\cline { 3 - 4 } & & No.100 & 2.1 \\
\cline { 2 - 4 } & & No.200 & 0.9 \\
\hline
\end{tabular}

\subsubsection{Fine Aggregate}

Natural sand of No.23 grading was obtained from White River (IMI, Greenwood). It had a bulk specific gravity of 2.608. Absorption and moisture contents were $1.41 \%$ and $4.10 \%$, respectively. These were taken into account along with coarse aggregate characteristics to adjust the amount of water required.

\subsection{Mineral Admixtures}

Class C fly ash conforming to ASTM C 618 was used in this study. This fly ash was obtained from American Electric Power Plant in Rockport, Indiana. Bulk specific gravity of this fly ash was 2.74 . 


\subsection{Chemical Admixtures}

Chemical admixtures were used for air entrainment and also for improving workability.

\subsubsection{Air Entraining Admixture}

Dravair 1400 produced by W. R. Grace \& Co. was used for air entrainment in the concrete. The properties of this admixture conform to ASTM C 260. This admixture was added at a dosage rate of $0.425 \mathrm{~g}$ per $\mathrm{kg}$ by cement weight.

\subsubsection{Water Reducing Admixtures}

Type A water reducer (WRDA 82) manufactured by W. R. Grace \& Co. was used to improve workability of concrete. WRDA 82 water reducer conforms to ASTM C 494 type A requirements. 


\section{CHAPTER 6 - MIX PREPARATION AND CURING}

This chapter covers the mix details and procedures for mixing and curing of concrete specimens in the laboratory. A typical mix design used in the field by Indiana contractor was adopted for this study. The detailed mixture proportions are shown in

Table 6.1.

Table 6.1 Mix design and material specifications

\begin{tabular}{|ll|ll|}
\hline \multicolumn{2}{|c|}{ Design Factors } & \multicolumn{2}{c|}{ Design Factors } \\
\hline Test Batch Size & 85 liters $\left(3 \mathrm{ft}^{3}\right)$. & Air content & $6.50 \%$ \\
Cement content & $262 \mathrm{~kg} / \mathrm{m}^{3}(442 \mathrm{pcy})$ & Fine agg/ Total agg. & $43.00 \%$ \\
Fly ash content & $41.5 \mathrm{~kg} / \mathrm{m}^{3}(70 \mathrm{pcy})$ & Air Entr. Content & $0.425 \mathrm{~g} / \mathrm{kg}$ of cement \\
Water-cement ratio & $0.42-0.45$ & Water reducer & $2.92 \mathrm{oz} / \mathrm{cwt}$ of cement \\
\hline
\end{tabular}

\begin{tabular}{|l|l|l|c|c|c|}
\hline Material & Size/Type & Source & Bulk S.G. & Absorb. & Moist. \\
\hline Cement & Type I & Lonestar, Greencastle & 3.15 & ----- & ------ \\
Fly Ash & Class C & American Flyash, & 2.74 & ----- & ---- \\
& & Rockport & & & \\
Fine Agg. & \# 23 Sand & IMI, Greenwood & 2.608 & $1.41 \%$ & $4.10 \%$ \\
Coarse Agg. & \# 8 Stone & Martin Marietta, Indpls. & 2.685 & $1.33 \%$ & $2.30 \%$ \\
Air Entr. & Daravair 1400 & W. R. Grace & ----- & ----- & ----- \\
Water Red. & WRDA 82 & W. R. Grace & ---- & ---- & ---- \\
\hline
\end{tabular}

\begin{tabular}{|l|l|l|l|}
\hline Batch Weight for: & $1 \mathrm{yd}^{3}$ & $1 \mathrm{ft}^{3}$ & $3 \mathrm{ft}^{3}$ \\
\hline Cement & $442 \mathrm{lb} .(200.7 \mathrm{~kg})$ & $16.37 \mathrm{lb} .(7.43 \mathrm{~kg})$ & $49.11 \mathrm{lb} .(22.29 \mathrm{~kg})$ \\
\hline Fly Ash & $70 \mathrm{lb} .(31.78 \mathrm{~kg})$ & $2.59 \mathrm{lb} .(1.17 \mathrm{~kg})$ & $7.78 \mathrm{lb} .(3.53 \mathrm{~kg})$ \\
\hline Mix Water & $162 \mathrm{lb} .(73.54 \mathrm{~kg})$ & $6.00 \mathrm{lb} .(2.72 \mathrm{~kg})$ & $18.00 \mathrm{lb} .(8.17 \mathrm{~kg})$ \\
\hline Fine Aggregate & $1,375 \mathrm{lb} .(624.25 \mathrm{~kg})$ & $50.92 \mathrm{lb} .(23.11 \mathrm{~kg})$ & $152.77 \mathrm{lb} .(69.36 \mathrm{~kg})$ \\
\hline Coarse Aggregate & $1,845 \mathrm{lbs} .(837.63 \mathrm{~kg})$ & $68.35 \mathrm{lb} .(31.03 \mathrm{~kg})$ & $205.05 \mathrm{lb} .(93.09 \mathrm{~kg})$ \\
\hline Air Entrainment & 3 oz. $(85.05 \mathrm{~g})$ & $0.111 \mathrm{oz} .(3.14 \mathrm{~g})$ & $0.333 \mathrm{oz} .(9.44 \mathrm{~g})$ \\
\hline Water Reducer & $14.9504 \mathrm{oz} .(423.83 \mathrm{~g})$ & $0.554 \mathrm{oz} .(15.7 \mathrm{~g})$ & $1.661 \mathrm{oz} .(47.09 \mathrm{~g})$ \\
\hline Total & $3,894 \mathrm{lb} .(1767.9 \mathrm{~kg})$ & $144.24 \mathrm{lb} .(65.48 \mathrm{~kg})$ & $432.71 \mathrm{lb} .(196.45 \mathrm{~kg})$ \\
\hline
\end{tabular}




\subsection{Mixture Preparation}

Procedure described below was followed in preparing the concrete mixtures in the laboratory. All mixtures were prepared in a pan mixer with nominal capacity of 56.6 liters $\left(2 \mathrm{ft}^{3}\right)$.

(a) Required amount of cement and fly ash was weighed.

(b) Small samples of coarse and fine aggregate were collected, weighed, placed on a hot plate and ignited with alcohol to accelerate the water removal process. Both the aggregates were kept on a hot plate and were ignited with alcohol to accelerate the water removal process. The samples were then re-weighed and the total amount of water lost was calculated. This amount of water was adjusted for, when weighing aggregate and water for the mixture.

(c) Required amounts of coarse and fine aggregate were weighed.

(d) Required quantities of water-reducing and air-entraining admixtures were weighed.

\subsection{Mixing Concrete}

Coarse aggregate and fly ash were added to the mixer and switched on for 2 minutes. Water reducing and air entraining admixtures were added to the mix water, stirred well and added to the mixer while it was running. The mixer was stopped and cement was added along with fine aggregate. After the addition of all materials, the mixer was switched on for 3 minutes. It was then stopped for 3 minutes and later turned on for 2 minutes. The mixer lid was kept closed to avoid loss of moisture due to evaporation. 


\subsection{Placing of Concrete}

Slump and Ve-Be tests were performed to check for the consistency of mix. Also yield and air content tests were conducted before placing the concrete. Cylinder molds (4" diameter x 8" height) and beams molds (6" x 6" x 21") were filled in three layers by vibrating each layer for 8 - 10 seconds on a vibrating table. Excess concrete was added prior to tamping the final layer. Top surface was smoothened and finished with the help of tamping rod and trowel.

\subsection{Curing of Specimens}

A special technique was adopted during this research to cure the specimens so that $100 \%$ relative humidity and access to data-logger was ensured.

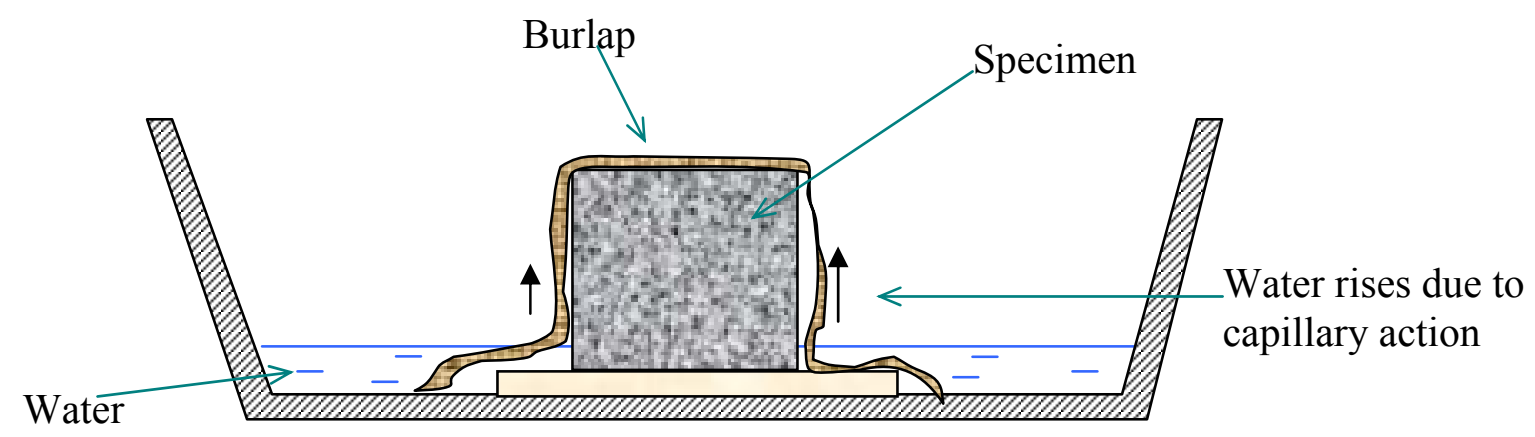

Fig. 6.1 Cross-section of a beam curing setup

Curing technique used in this research is shown in Fig. 6.1. A plastic water tub was used that was large enough to accommodate a few beams and cylinders. This tub was filled with water up to $15 \%$ of its total depth. Plastic or stainless steel bars were placed on the floor of the tub to support the bottom of the beams. Cylinders were placed 
directly on the tub. All specimens were then covered with its wet burlap with ends well dipped in water. The burlap was kept wet by capillary rise of water and by sprinkling every 24 hours. Since specimens were tested at early ages, the beams were continuously cured by above procedure. 


\section{CHAPTER 7 - EXPERIMENTS}

This chapter primarily discusses different experiments that were conducted in the laboratory as well as in the field. Some advanced techniques along with conventional methods were used in this research to study the properties of fresh and hardened concrete.

\subsection{Measurement of Properties of Fresh Concrete}

Properties of fresh concrete evaluated during this test program included consistency (Slump and Ve-Be test), air content and unit weight.

\subsubsection{Consistency of Fresh Concrete}

Consistency test shows the ability of concrete to flow. Slump test is a commonly adopted test to measure consistency of concrete that has a moderate or high flow. For concrete pavement construction, the water-cement ratios are in the range of $0.3-0.45$, often resulting in a stiff mix. Concrete produced during this research was very stiff and it was difficult to determine its consistency using a slump cone. Therefore, Ve-Be test was used in addition to slump test. 


\subsubsection{Slump Test}

The slump test was performed following the requirements of ASTM C $143^{(40)}$ (AASHTO T119) specifications. In this test, fresh concrete was placed into the frustum shaped cone in three equal layers. Each layer was tamped 25 times uniformly on all sides to ensure a good compaction. After filling the cone, the mold was lifted in vertical direction. Slump was measured with accuracy up to a quarter of an inch.

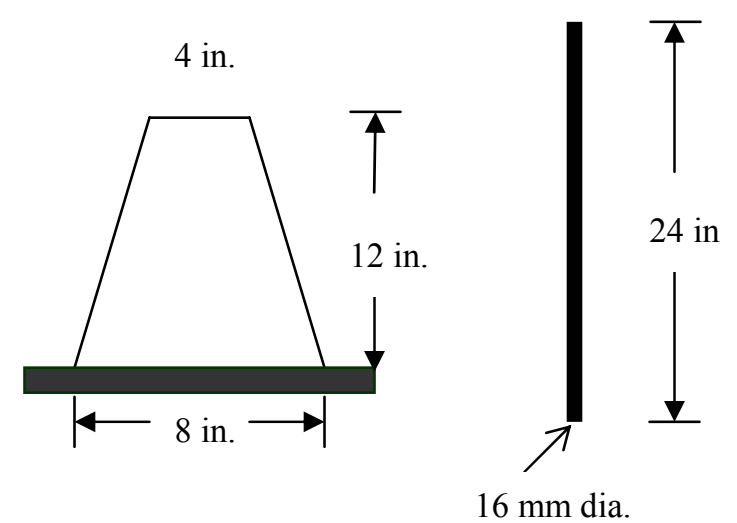

Fig. 7.1 Mold and tamping rod used in slump test

\subsubsection{Ve-Be Test}

Ve-Be test was performed in accordance to ASTM C $1170^{(39)}$ specifications. Consistency was measured, as the time required to consolidate a given mass of concrete by vibrating a cylindrically shaped mold filled with concrete.

Apparatus: A vibrating table with a $19 \mathrm{~mm}(3 / 4$ ") thick steel deck and with dimensions of $381 \mathrm{~mm} \times 260 \mathrm{~mm}$ x $305 \mathrm{~mm}(15 "$ x 10.25" x 12") as shown in Fig.7.2 was used. This table was placed on a floor and clamped to it to avoid displacement of table while in 
operation. A cylindrical mold $241 \mathrm{~mm}$ x $197 \mathrm{~mm}$ x $6.4 \mathrm{~mm}(9.5 "$ x 7.75" x 0.25") with permanently affixed slotted metal brackets was clamped to vibrating table. A swivel arm was attached to the frame of vibrating table. This arm has a groove that holds the metal shaft in a perpendicular position to the vibrating surface. A cylindrical steel mass with attached perpendicular plate is used as a surcharge weighing $50 \mathrm{lbs}$. The Ve-Be time is measured by means of a stopcock.

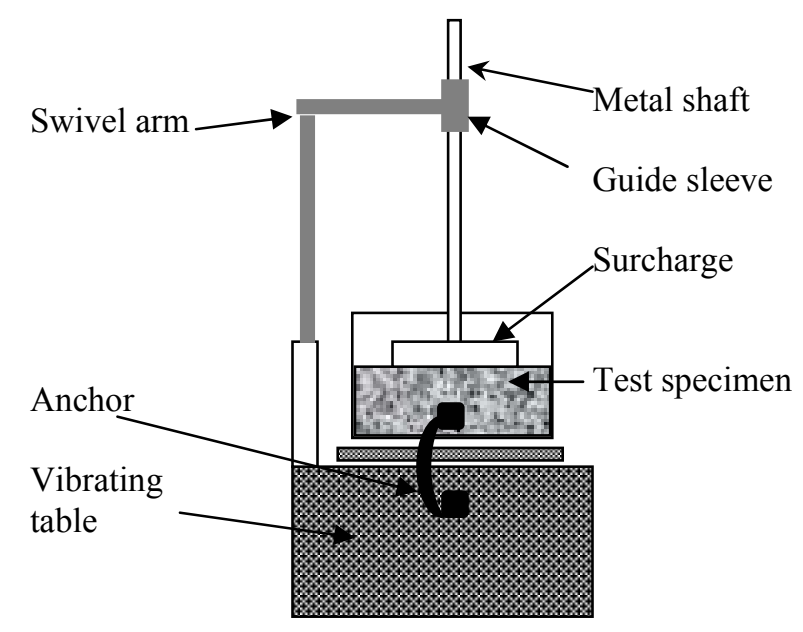

Fig. 7.2 Vibrating table ( Consistency test)

Procedure: The Ve-Be cone was clamped to the vibrating table and filled in three layers. After each layer was placed, the cone was vibrated for few seconds to ensure compaction. The mold was lifted vertically and vibrating table was switched on. Time taken by concrete to settle from horizontal layer was recorded as the Ve-Be time.

Fig. 7.3 shows the top layer of Vebe cone being filled. Concrete that is ready for Vebe test is shown in Fig. 7.4. 


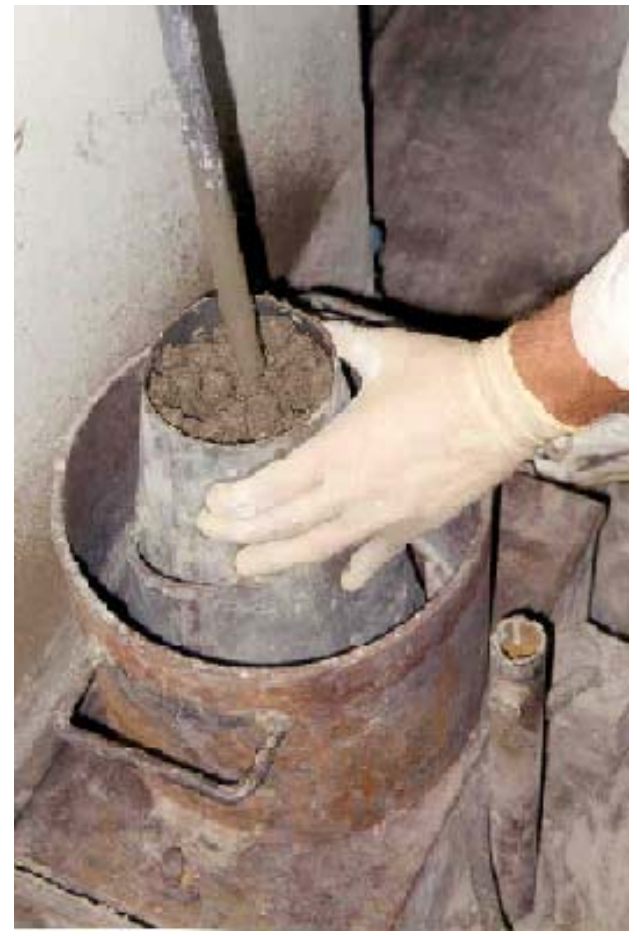

Fig. 7.3 Ve-Be cone top layer being filled

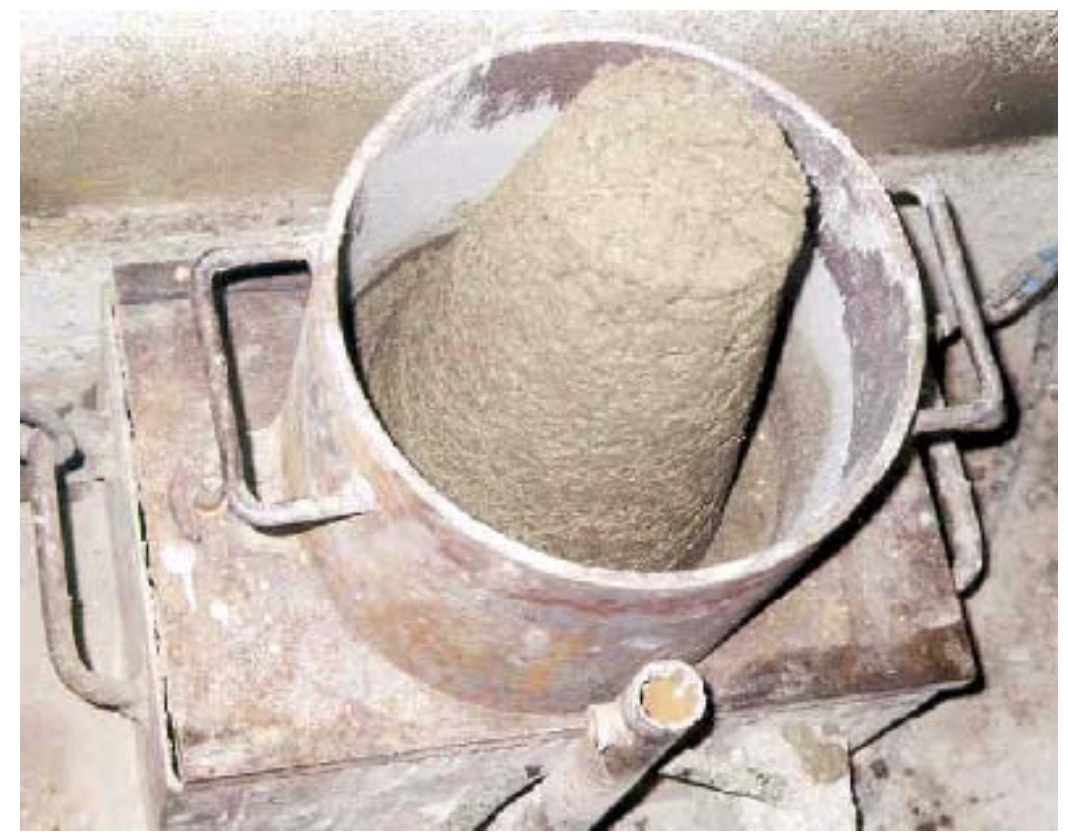

Fig. 7.4 Concrete specimen placed in the test mold on vibrating table right before starting the vibration 


\subsubsection{Air Content}

The air content of fresh concrete was determined following the procedure of ASTM C 231 ${ }^{(41)}$ (AASHTO T 196). The cylinder used for this test was filled in three layers with each layer being tamped 25 times with a tamping rod. The air content for concrete used was in range of $5.5-7.0 \%$.

\subsection{Measurement of Properties of Hardened Concrete}

In this section, the procedures used for determination of compressive, flexure and indirect tensile strengths are discussed. In addition, the procedure used for fatigue strength determination is also provided.

\subsubsection{Compressive Strength}

Compressive strength of concrete was determined conforming to ASTM C $39^{(42)}$ specification procedure using $102 \mathrm{~mm}$ dia. x $203 \mathrm{~mm}$ (4" x 8") cylinders. Two cylinders were tested from each mix that was typically of $0.028-0.042 \mathrm{~m}^{3}\left(1-1.5 \mathrm{ft}^{3}\right)$.

The following expression is used to compute compressive strength.

$$
\begin{aligned}
& \text { Compressive Strength }=\frac{\text { Maximum load at failure }}{\text { Area of cross }-\sec \text { tion }} \\
& \text { Area of cross }-\sec \text { tion of } 4 x 8 \text { in.cylinder }=\frac{\pi}{4} 5^{2}=12.566 \text { in. }^{2}
\end{aligned}
$$




\subsubsection{Flexural Test (Using Third-Point Loading)}

Flexural strength of concrete was determined on $153 \mathrm{~mm}$ x $152 \mathrm{~mm}$ x $533 \mathrm{~mm}$ (6" x 6" x 21") beams following the procedure given in ASTM C $78^{(43)}$ (AASHTO T97). Third point loading assembly as shown in Figs. 7.5 and 7.6 were used. Specimens were loaded at a loading rate of $8 \mathrm{kN}$ (1800 lbs.) per minute. In the first phase of research, both beams generated from $0.042 \mathrm{~m}^{3}\left(1.5 \mathrm{ft}^{3}\right)$ mix were tested for flexure to develop flexural strength versus time relationship. In the final phase, where fatigue tests were performed, one beam from $0.042 \mathrm{~m}^{3}\left(1.5 \mathrm{ft}^{3}\right)$ was tested for flexure and the other used for fatigue studies

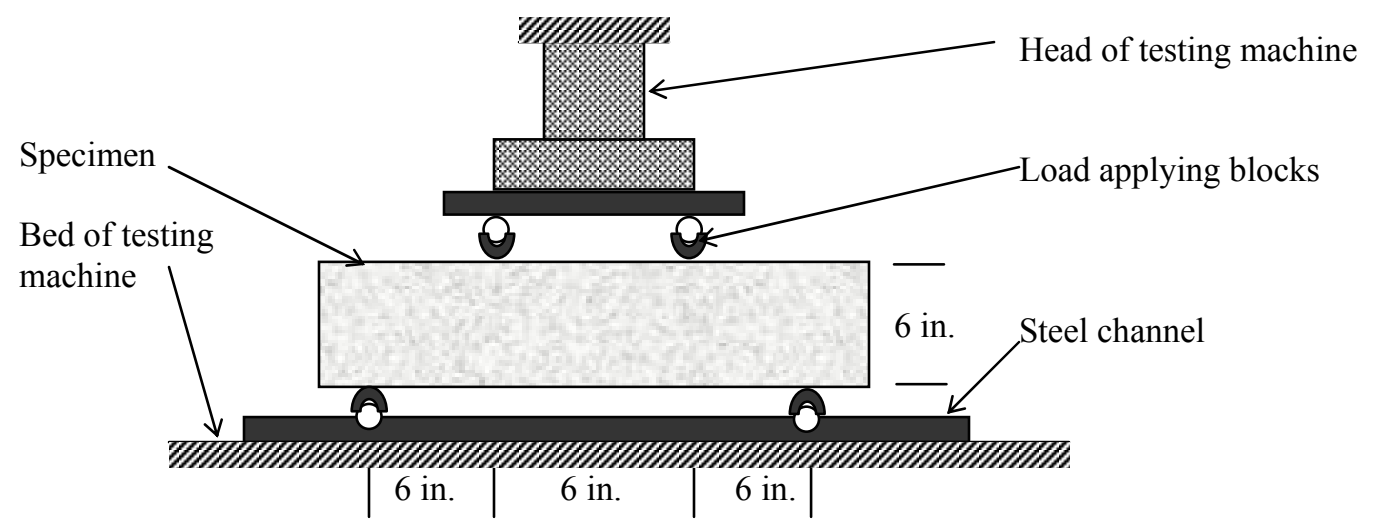

Fig. 7.5 Diagrammatic view of apparatus used for test in flexure 


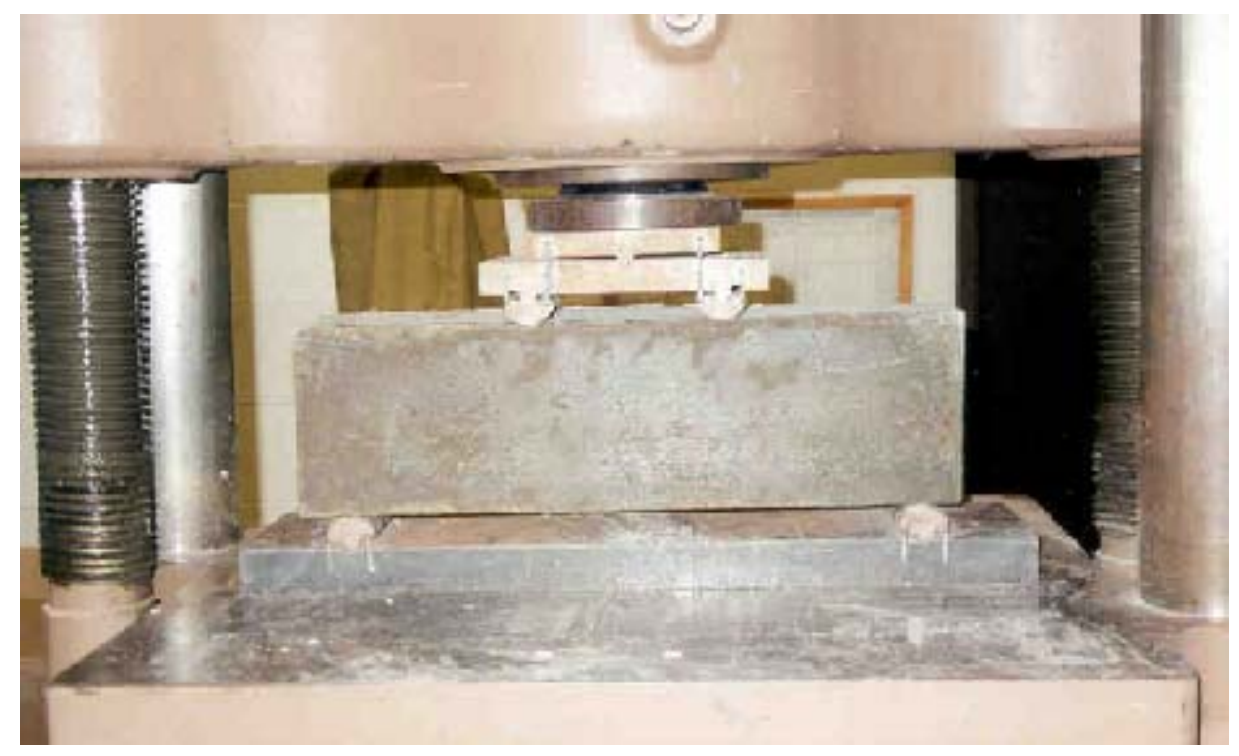

Fig. 7.6 Picture of a 6" 6 6" $\mathrm{x} 12$ " beam in the testing machine

\subsubsection{Calculations}

Fracture occurred in the middle third portion of the span of all beams that were tested. Therefore, following formula was used to compute flexural strength.

$$
\text { Flexural Strength }(p s i)=\frac{P L}{b d^{2}}
$$

where:

$$
\begin{aligned}
& \mathrm{P}=\text { maximum applied load }(\mathrm{lbs} \text { or } \mathrm{N}) \\
& \mathrm{L}=\text { span length of beam }(\mathrm{in} . \text { or } \mathrm{mm})=18 \mathrm{in} . \\
& \mathrm{b}=\text { average width of beam (in. or } \mathrm{mm}) \\
& \mathrm{d}=\text { average depth of specimen (in. or } \mathrm{mm})
\end{aligned}
$$

Ultimate load carrying capacity of beam at failure was computed by,

$$
\text { flexurestress }(\sigma)=\frac{\text { Moment of Inertia }(I)}{\text { Section Modulus }(Z)}
$$




\subsubsection{Indirect Tensile Test}

Indirect tensile strength of concrete was determined by following ASTM C $496^{(44)}$ specification procedure. For this test 4" $\mathrm{x} 8$ " cylinders were used. Test assembly for indirect tensile test (commonly known as split tensile test) is shown in Fig. 7.7.

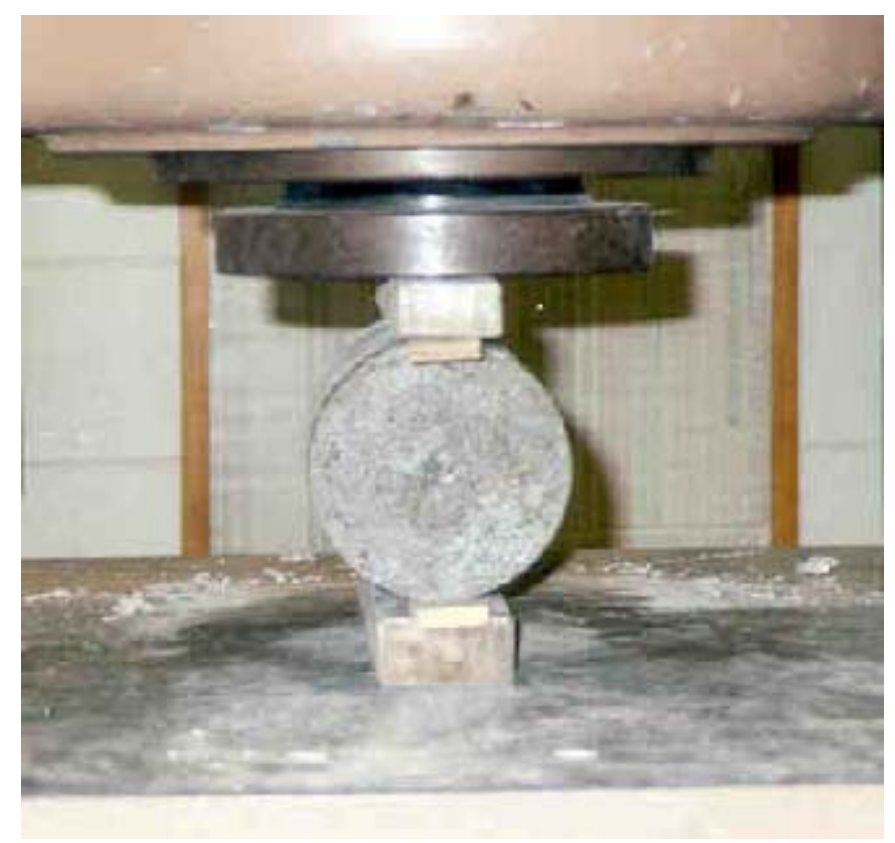

Fig. 7.7 Test specimen loaded in indirect tension

\subsubsection{1 $\underline{\text { Procedure }}$}

Cylinders were tested within a few minutes after they were brought out of curing container. In case of delays, the specimens were covered with a wet cloth to avoid loss of moisture. Wooden strips were used between steel bars to apply a uniform line load on cylinders. Specimens were loaded at a rate of $33.4 \mathrm{kN}$ (7500 lbs.) per minute. The load at failure of cylinder was recorded and used for computation of indirect tensile strength using the following expression. 


$$
\text { Split Tensile Strength }=\frac{2 P}{\pi l d}
$$

where:

$\mathrm{P}=$ Maximum load at failure (lb. or $\mathrm{N})$

$1=$ Length of cylinder $=20 \mathrm{~mm}\left(8^{\prime \prime}\right)$

$\mathrm{d}=$ Diameter of cylinder $=10 \mathrm{~mm}\left(4^{\prime \prime}\right)$

\subsubsection{Fatigue Test}

Although flexural or compressive strength of concrete is used to determine the opening-to-traffic time of rigid pavements, it is well understood that in reality the loads to which the pavements are subjected are cyclic (repetitive) in nature. In this research, beams of the same sizes as those used in the flexural test were used to establish the relationship between fatigue and flexural strength. In developing the test procedure, some of the test parameters established in the similar research by J. Gomez ${ }^{(38)}$ were adopted.

\subsubsection{Cyclic Loading Pattern}

Load controlled fatigue test were performed on 20 beams. Beams of 6" x 6" x 21 " size were tested under third point loading for fatigue. Based on previous research studies $^{(38)}$, a rate of 5 cycles/second was chosen for cyclic loading. A 222.4-kN (50-kips) capacity load cell and a 244.7-kN (55-kips) capacity hydraulic actuator were used. All loading parameters fed to the control program were a relative percentage to the load cell capacity. 
Loading pattern adopted in this study can be seen in Fig. 7.8. A minimum load of $2.2 \mathrm{kN}$ (500 lbs.) was used for all tests. Maximum load was set as a percentage of load cell capacity i.e., $222.4 \mathrm{kN}$ (50 kips). It varied in the range of 10 and $20 \%$ of load cell capacity.

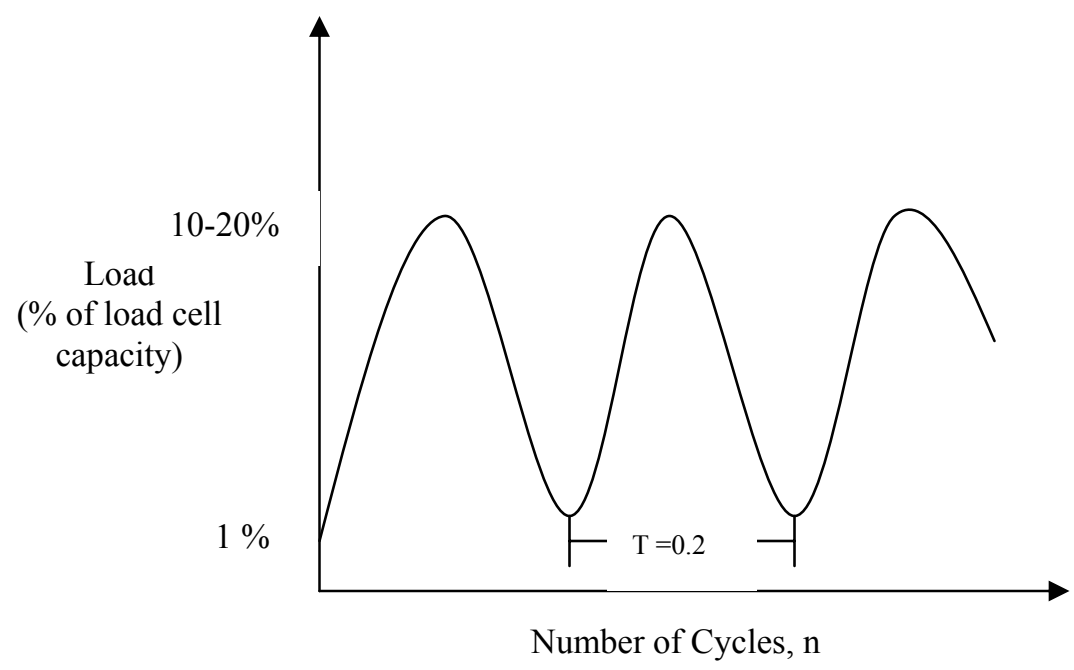

Fig. 7.8 Cyclic loading pattern for fatigue tests

In order to avoid the sudden release of load at end of each cycle, minimum load of $2.2 \mathrm{kN}(500 \mathrm{lb})$, i.e., $1 \%$ was maintained throughout the test.

\subsubsection{Fatigue Testing Procedure}

Following procedure was used to test the beams in fatigue.

Step 1:- A steel channel was used as a support bed on which a steel base plate ( $1 / 2$ " thick) was placed.

Step 2:- Beam support assembly was placed on top of the base plate and supports were aligned such that center-to-center distance between them was $457 \mathrm{~mm}$ (18"). The 
location of loading support points was marked on the beam and the beam was placed on the supports. The 3-point load assembly was then placed on the top of the beam.

Step 3:- The controller was switched on and DC error was set to zero. Using the load control knob of the controller, the head of hydraulic actuator was lowered to the point when it just touched the 3-point load assembly as shown in Fig.7.9 and 7.10.

Step 4:- The controller was programmed by setting the values of minimum load, maximum load, and load frequency. After verifying the program, the cycle counter that counts the repetitions was set to zero and the "on" option was selected. The program was put in a run mode and the test was started.

Step 5:- Number of cycles at beam failure was recorded and the testing machine as well the pump were shut off.

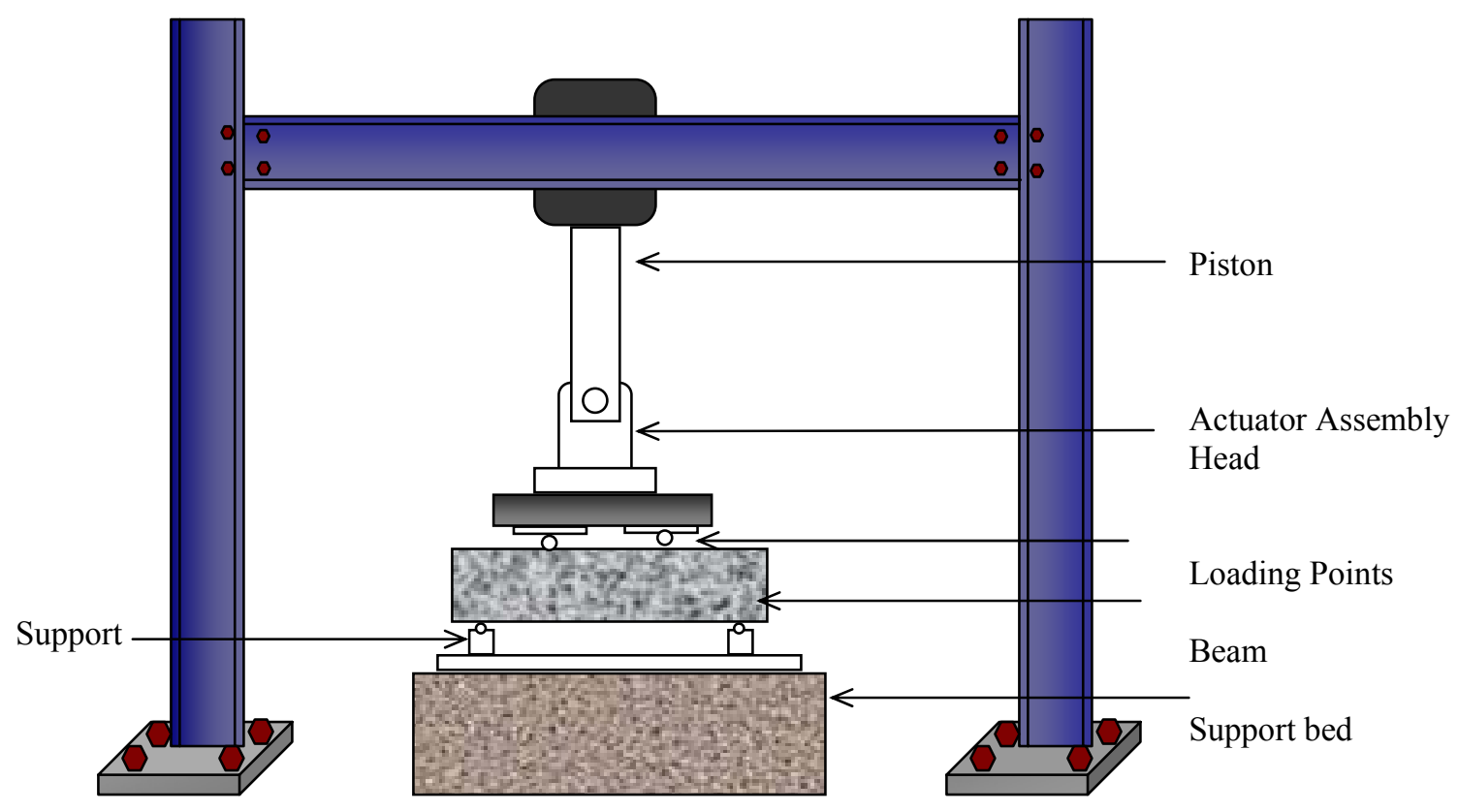

Fig. 7.9 Test setup for fatigue test 


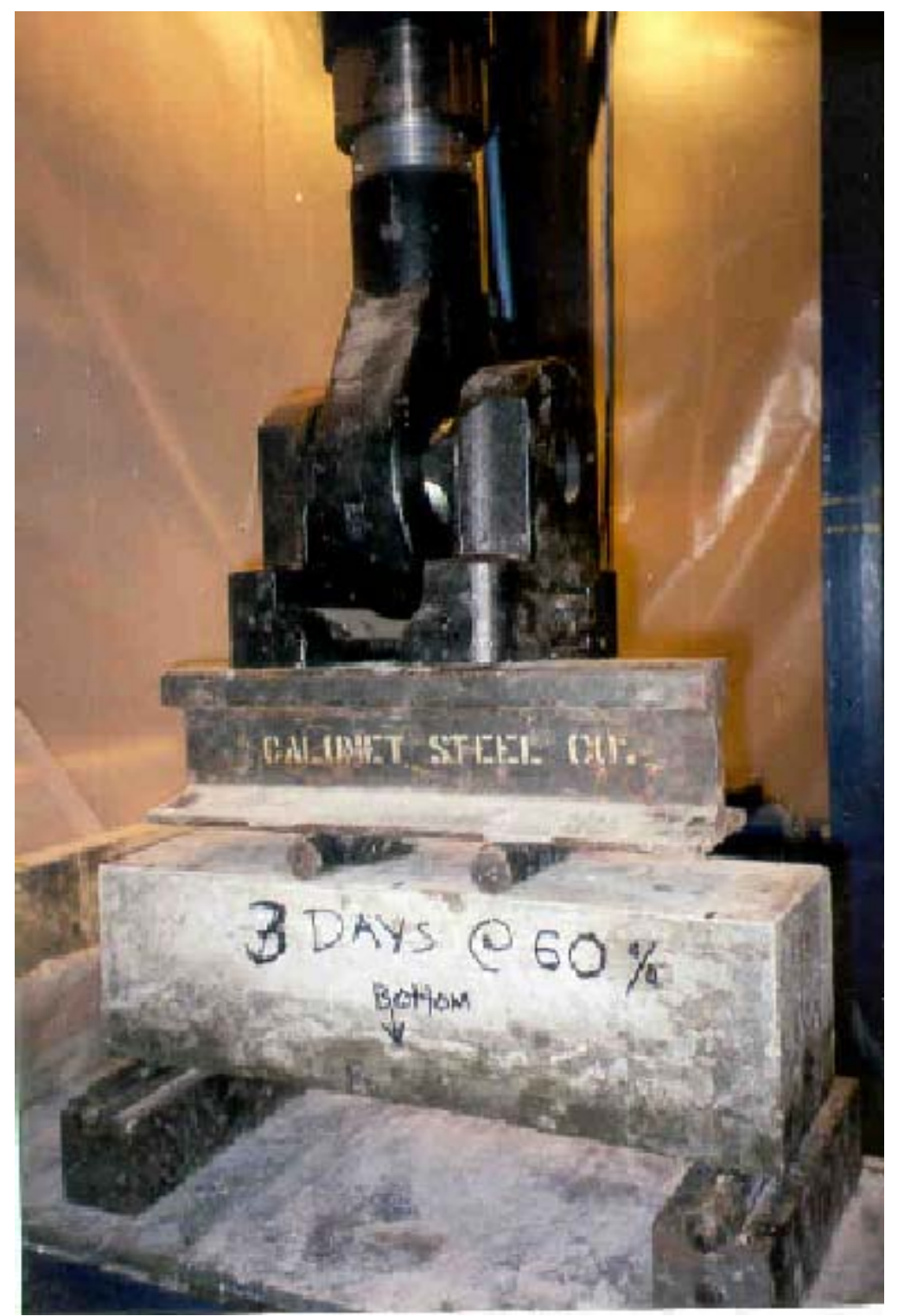

Fig. 7.10 Actuator head touching the loading assembly at the start of test 


\subsubsection{Fatigue Loading}

Full sets of specimens were cast based on the plan that was developed in the initial phase of research. For each set of specimens, two batches of mix were produced and both of these mixes were produced on same day to ensure identical environmental and curing. Time-temperature history was obtained from one of the two beams and same beam was tested for flexure. The load that produced this flexure strength was used as datum for determination of a required stress level. A stress level (SL) was defined as the ratio of stress induced by the load applied on the beam to the MOR of an identical beam tested at the same age.

Example: A beam that needed to be tested for fatigue at $60 \%$ stress level after 3 days of curing would undergo the following procedure:

Step 1: Determine maturity of the concrete beam in which thermocouples were inserted. Step 2: Detach the thermocouples and test the beam for flexure (third point mode) at a rate of 1800 psi per minute.

Step 3: Say the beam failed at 5.8 MPa (840 psi). From the above test, we have

$$
\begin{aligned}
& \sigma=840 \mathrm{psi} \\
& \text { Ultimateload }(P) \text { at failure }=\sigma \times 12 \\
& \therefore P=840 \times 12=10080 \mathrm{lbs}
\end{aligned}
$$

Fatigueload required at $60 \% S L=0.60 \times 10080$

$$
=6048 \mathrm{lbs}
$$


For 50 kip capacity load cell,

$$
\begin{aligned}
& \text { Minimum load }=\frac{500}{50000}=1 \% \\
& \text { Maximum load }=\frac{6548}{50000}=13.096 \%
\end{aligned}
$$

These minimum and maximum values shall be used in programming the MTS controller. A self-explanatory schematic diagram in Fig.7.11 shows the computation of load required to generate required stress level. The same steps were followed in determining fatigue life of beams at other ages and stress levels.

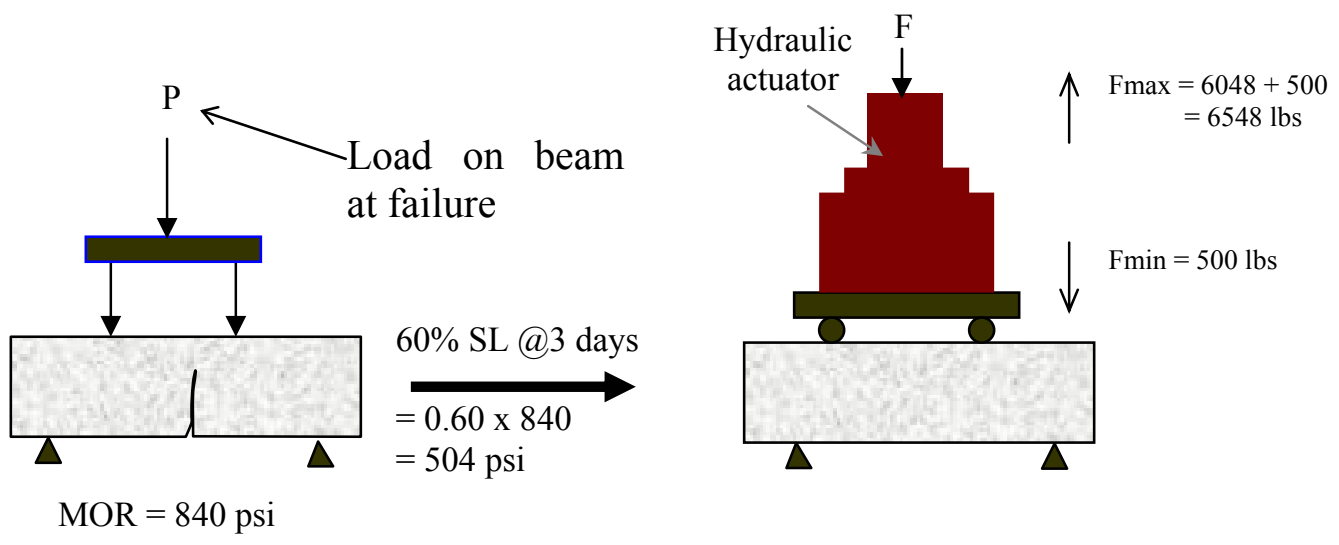

Fig. 7.11 Load computation for fatigue test using a 50-kip load cell

\subsection{Maturity Method ${ }^{(35)}$}

Maturity method can be used as a very effective tool in early opening of concrete pavements to traffic. The main advantage of maturity method is its ease of use and precision of time-temperature data that can be linked to the degree of hydration. A number of pavement construction projects have been using maturity method to predict the expected strength of concrete. Maturity method comprises of development of 
temperature curve as a function of time that is used for computation of TTF (timetemperature factor). TTF values plotted with respect to flexural strength at corresponding ages can be used to determine maturity required for achieving the desired strength level.

\subsubsection{Laboratory Setup for Maturity Determination}

The determination of maturity requires measurement of temperature as a function of time. The experimental system used for this experiment is shown in Fig. 7.12. The main components of this system include thermocouples embedded in the samples, a datalogger and a computer.

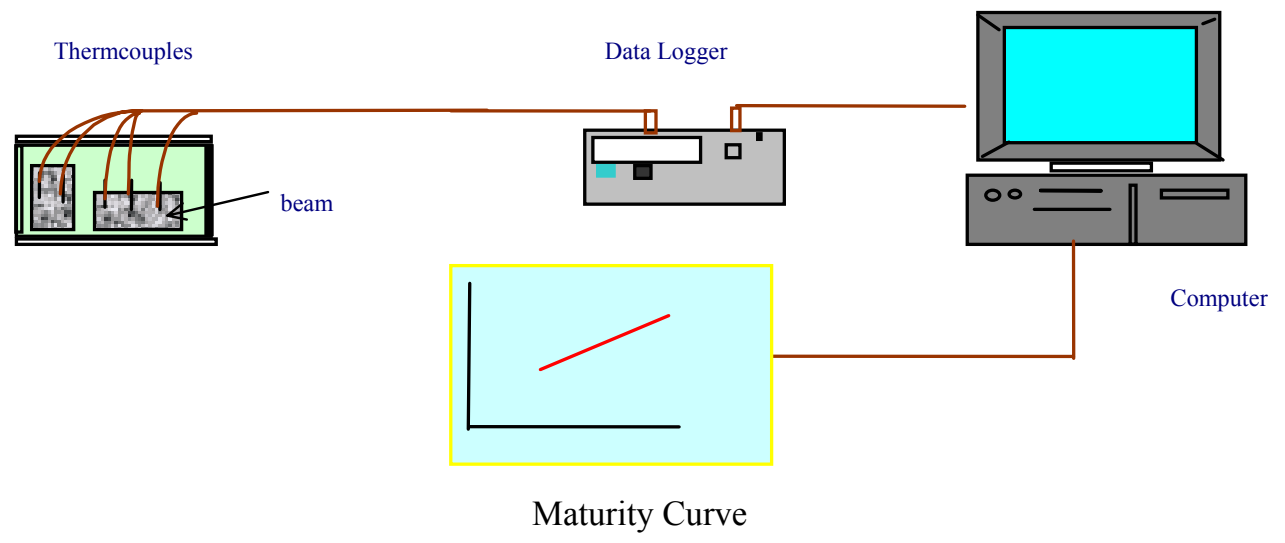

Fig. 7.12 Schematic diagram of time-temperature measurement setup in the laboratory

Thermocouples: Type $\mathrm{T}$ thermocouples were used in this research study. This thermocouple consisted of copper and constantan wires that were twisted and soldered together and used to measure voltage difference created due to temperature change. About 5 - 10 thermocouples were prepared for each mixture batch. 
Datalogger: For this project CR10X data-logger manufactured by Campbell Scientific was used. The datalogger was programmed to read temperature every minute over 10minute interval and an average of these 10 readings was recorded.

Computer: A personal computer was attached to the data-logger and was used to download the data from the data-logger. Using PC208w software (Campbell Scientific), the data was downloaded into the computer in the data file format. This data was exported to MS Excel for further calculations.

Curing Container: A plastic container $914 \mathrm{~mm}$ x $610 \mathrm{~mm}$ (36" x 24") was used to cure the test specimens. The specimens were partially $(\sim 15 \%$ of specimen's height $)$ submerged in the water and covered with wet burlap. The ends of the burlap were also immersed in water. The capillary action kept the burlap saturated at all times thus providing $100 \%$ humidity.

In addition, the burlap was also sprinkled with water every morning to ensure that $100 \%$ relative humidity conditions are maintained.

\subsubsection{Establishment of Flexural Strength-Maturity Relationship}

Strength-maturity relationship was developed with the help of procedure described in reference (9) previously developed by Iowa Department of Transportation (IDOT). In order to obtain the development of temperature as a function of time, the following steps were followed. 
Step 1:- A single $152 \mathrm{~mm}$ x $152 \mathrm{~mm}$ x $533 \mathrm{~mm}$ (6" x 6"x 21”) concrete beam along with two $102 \mathrm{~mm}$ dia. x $203 \mathrm{~mm}$ (4” x 8") cylinders were cast in the laboratory. Two thermocouple sensors were embedded at mid-depth and a single thermocouple sensor was installed at the center of each cylinder. The thermocouples were installed in the holes in concrete that were made to avoid damage to the thermocouple sensors. The hole was refilled with concrete after placing the thermocouple.

Step 2:- Samples were placed into the curing container and kept in the container through the entire curing period. The curing period varied from 3 to 7 days. All these specimens met the requirements of ASTM C 511 for curing.

Step 3:- The datalogger was initially programmed by exporting an "edlog" (Campbell Scientific) program from computer to the datalogger.

Step 4:- The specimens were detached from data-logger at the end of curing period and the beam was tested for flexural strength as described in section 7.2.2.

Step 5:- The data from data-logger was downloaded into the computer and converted into MS Excel format. A plot of temperature versus time was created and the cumulative maturity expressed as a time-temperature factor (TTF) at the end of curing period was computed.

Step 6:- Step 1 to 5 were repeated for different curing ages (3, 5 and 7 days in our case). Step 7:- Flexural strength versus maturity was plotted. This plot can be seen in Fig. 8.6 and 8.7 of this report. 


\subsubsection{Computation of Maturity}

Maturity was computed as the area under the time-temperature curve. Simpson's $3 / 8^{\text {th }}$ rule is commonly used for maturity calculation at the end of curing period.

$$
\text { Maturity }=\sum \mathrm{TTF}=\sum\left[\left(\text { temp }_{\mathrm{i}}+\text { temp }_{\mathrm{i}+1}\right) / 2+10\right] \times\left[\text { Age }_{\mathrm{i}}-\text { Age }_{\mathrm{i}-1}\right]
$$

where,

$\sum \mathrm{TTF}=$ cumulative maturity at a particular age $\left({ }^{\circ} \mathrm{C}-\mathrm{hrs}\right)$.

temp $_{\mathrm{i}}=$ Initial temperature during a particular time interval, ${ }^{\circ} \mathrm{C}$

temp $\mathrm{i}_{\mathrm{i}+1}=$ Final temperature during the time interval, ${ }^{\circ} \mathrm{C}$

$\mathrm{Age}_{\mathrm{i}}=$ Initial age of specimen at beginning, hrs

Age $_{\text {i- } 1}=$ Final age of specimen at the end of time interval, hrs

\section{Example:}

Project: xyz Pavement thickness: $254 \mathrm{~mm}(10$ ”)

\begin{tabular}{|l|l|l|l|l|l|}
\hline Date & Time & Age (hours) & Temp. $\left({ }^{\circ} \mathrm{C}\right)$ & TTF $\left({ }^{\circ} \mathrm{C}-\mathrm{h}\right)$ & Cum. TTF $\left({ }^{\circ} \mathrm{C}-\mathrm{h}\right)$ \\
\hline $2 / 12 / 99$ & $1.00 \mathrm{am}$ & 0 & 31 & 0 & 0 \\
\hline & $2.00 \mathrm{am}$ & 1 & 31 & 41 & 41 \\
\hline & $5.00 \mathrm{am}$ & 4 & 36 & 131 & 172 \\
\hline & $8.00 \mathrm{am}$ & 7 & 33 & 134 & 306 \\
\hline
\end{tabular}

Datum temperature was taken as $-10^{\circ} \mathrm{C}$.

$$
\begin{aligned}
& \sum \operatorname{TTF}_{(2.00 \mathrm{am})}=\left[\frac{(31+31)}{2}+10\right] x[1-0] \\
& =41^{\circ} \mathrm{C}-\mathrm{h} .
\end{aligned}
$$




\section{CHAPTER 8 - EXPERIMENTAL RESULTS \& DISCUSSION}

\subsection{Introduction}

In this chapter, results of various experiments that are related to early opening of concrete pavements to traffic are presented. These results include the time-temperature curves that were plotted for concrete specimens cured for 3, 5 and 7 days. MOR curve that was developed for the mix used in this research is also discussed. Several beams were tested for determination of fatigue life at 3,5 and 7 days. Fatigue curves for each of these ages at different stress levels are discussed in section 8.5. Finally, user-friendly plot that combines all fatigue curves at different ages is provided. This plot could be used by contractors to determine the time to opening-to-traffic for pavements that utilize similar mix design. This plot serves as a good reference in determining fatigue life of concrete pavement subjected to a specific magnitude of load. A brief re-introduction of the research aims and objectives is provided below. All raw data collected during this study are summarized in Appendix A.

The literature survey done in the first stage of this research work indicated that strength magnitude at which pavement is opened to traffic should be based on parameters that will impact long-term performance. Most of the Departments of Transportation (DOT) have been opening pavements to traffic based on the strength data accumulated from previous studies. But, to date there is a lack of information that would fully justify 
the significance of the flexural strength as the only parameter for purposes of early opening to traffic. INDOT requires that the pavement attain MOR of at least $3.8 \mathrm{MPa}$ (550 psi) before it is opened to traffic. Some DOTs use lower values of flexural strength (as low as 2.4 to $2.8 \mathrm{MPa}^{(4)}$ (350 to $400 \mathrm{psi}$ )) for opening pavements to the users. A question still arises whether pavements could be opened-to-traffic at an MOR lower than the presently used without having an adverse effect on long-term performance. This research focuses on several issues related to early opening time and fatigue life of a typical pavement constructed in Indiana.

\subsection{Time-Temperature History of Test Specimens}

Several specimens were tested at the ages of 1,3,5 and 7 days and during the entire curing period temperatures within these specimens were monitored using the setup shown in Fig. 8.1.

Figure 8.2 shows the change in temperature of the samples with time for specimens that were tested after 3 days of curing. Due to relatively high content of $\mathrm{C}_{3} \mathrm{~S}$ in the cement used in this study, the temperature development rate was high during the first 24 hours. This plot indicates a quick rise in temperature from an initial value of $24.5^{\circ} \mathrm{C}$ to $28^{\circ} \mathrm{C}$ within first 9 hours. The temperature dropped to $25^{\circ} \mathrm{C}$ after 15 hours of curing and stabilized at about $23^{\circ} \mathrm{C}$ after about 40 hours. Temperature remained at this level for the duration of measurements. 


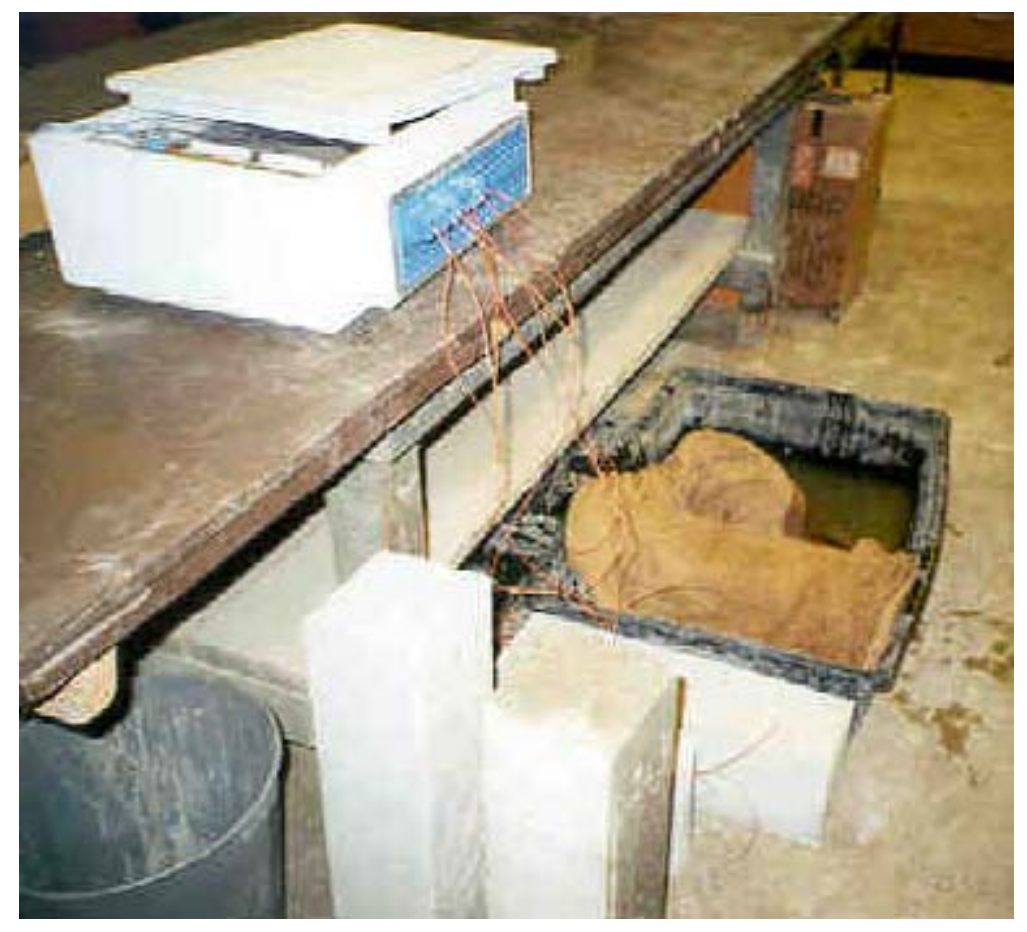

Fig. 8.1 Temperature in specimens being monitored by data-logger

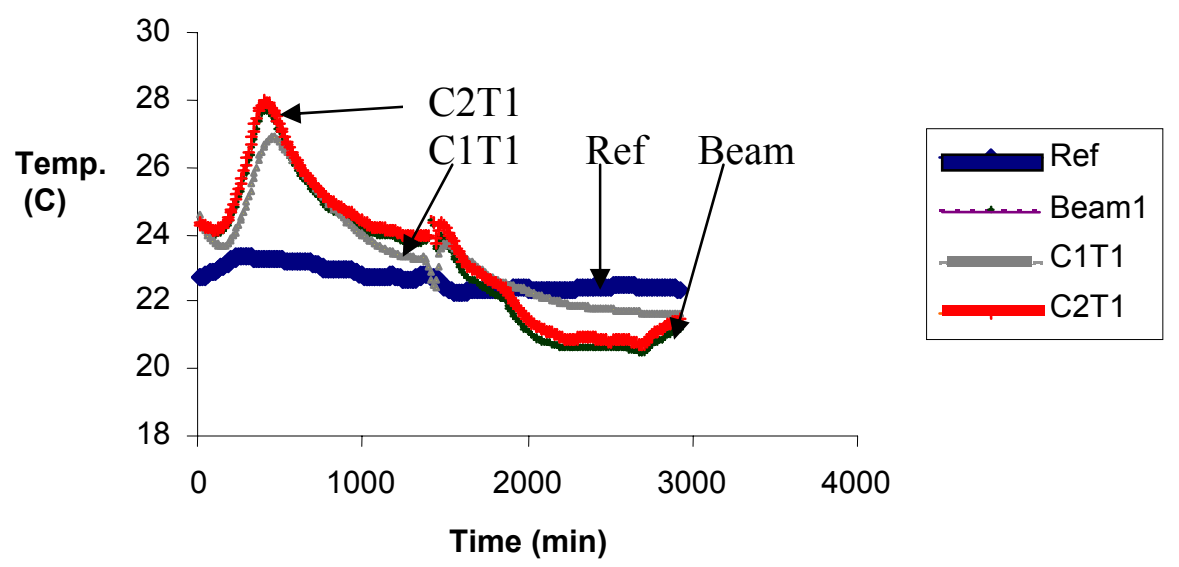

Fig. 8.2 Time-Temperature history of concrete specimens tested after 3 days of curing 
Fig. 8.3 shows the change in temperature of the concrete samples cured for 5 days. The temperature of the specimens increased from the initial value of $20.8^{\circ} \mathrm{C}$ to $23^{\circ} \mathrm{C}$ within the first 8 hours and later dropped to $19.5^{\circ} \mathrm{C}$ at 20 hours. The temperatures in the samples stabilized at $18.5^{\circ} \mathrm{C}$ between 1.5 and 3.5 days of curing.

$\Delta$

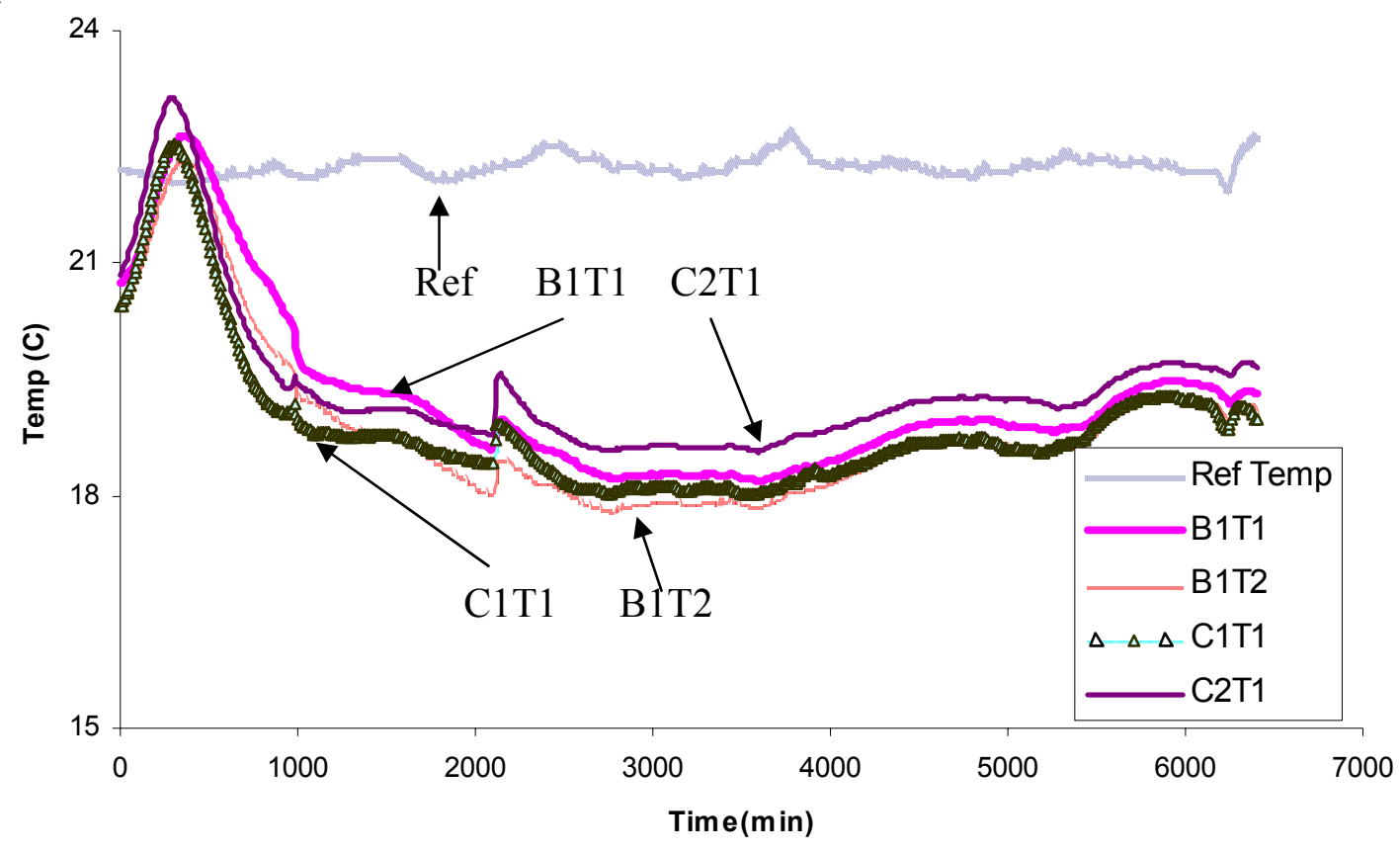

Fig. 8.3 Time-Temperature history of concrete specimens tested after 5 days of curing

Fig. 8.4 shows the time-temperature history of the samples that were cured for 7 days. Temperature in test specimens dropped slightly from $24^{\circ} \mathrm{C}$ to $22.5^{\circ} \mathrm{C}$ during the first hour, and then rose to $26.5^{\circ} \mathrm{C}$ after 10 hours. Later, temperatures dropped to $21.5^{\circ} \mathrm{C}$ at the end of 40 hours and remained steady until 100 hours of curing. Further mild drop in temperature from $21.5^{\circ}$ to $19^{\circ} \mathrm{C}$ was recorded after 150 hours of curing. 


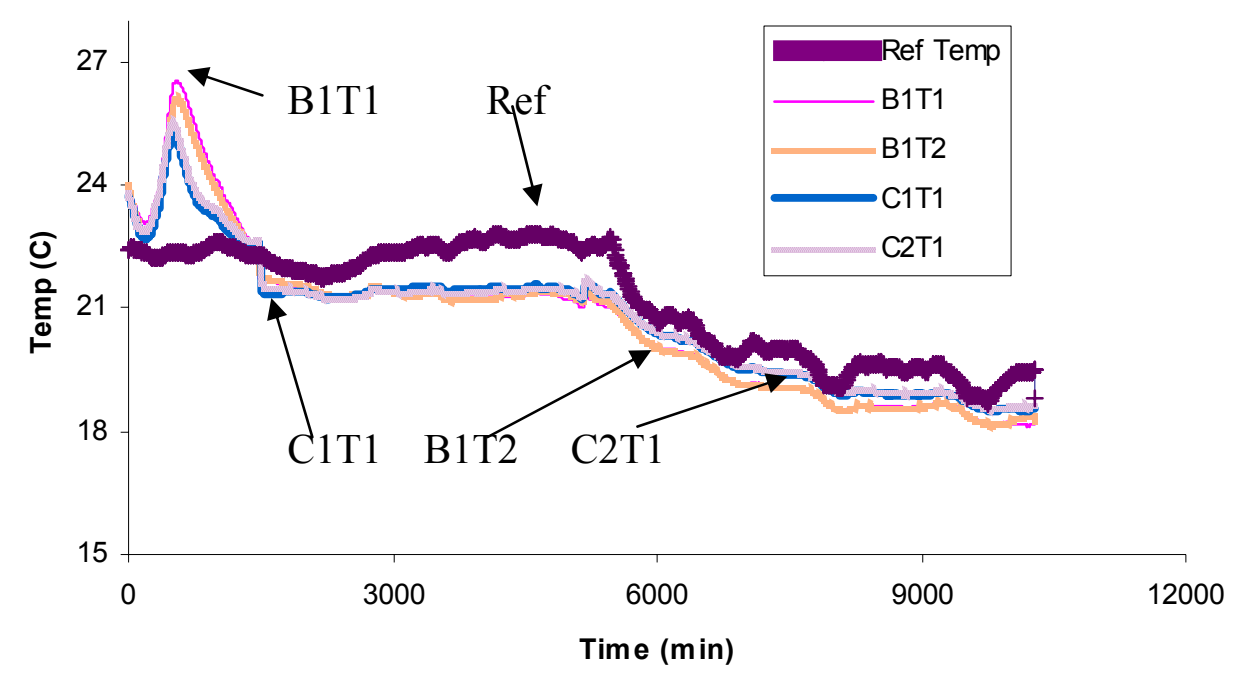

Fig. 8.4 Time-Temperature history of concrete specimens tested at 7 days

\subsection{Early Age Strength Analysis}

Early-age strength determination involved testing of $102 \mathrm{~mm}$ dia. x $203 \mathrm{~mm}$ (4” x 8 ") cylinders in compression and indirect tension and testing of 6 " $\times 6$ " 121 " beams in flexure. The results of the development of compressive strength with time are presented in Section 8.3.1. Sections 8.3.2 and 8.3.3 present development of indirect tensile and flexural strength, respectively, as a function of time.

\subsubsection{Compressive Strength Development}

The plot of compressive strength development as a function of time is shown in Fig. 8.5. Average compressive strength after 1 day was $5 \mathrm{MPa}(2174 \mathrm{psi})$. Also, the average compressive strengths at 3, 5 and 7 days were $29.1 \mathrm{MPa}(4217 \mathrm{psi}$ ), 41.0 $\mathrm{MPa}$ 
(5941 psi) and 53.3 $\mathrm{MPa}$ (7731 psi), respectively. Compressive strength data is summarized in Table 8.1.

Table 8.1 Compressive strengths at different curing periods

\begin{tabular}{|c|c|}
\hline Age (days) & $\begin{array}{c}\text { Avg. Compressive } \\
\text { Strength, } \mathbf{M P a}(\mathbf{p s i})\end{array}$ \\
\hline 1 & $15.0(2174)$ \\
3 & $29.1(4217)$ \\
5 & $41.0(5941)$ \\
7 & $53.3(7731)$ \\
\hline
\end{tabular}

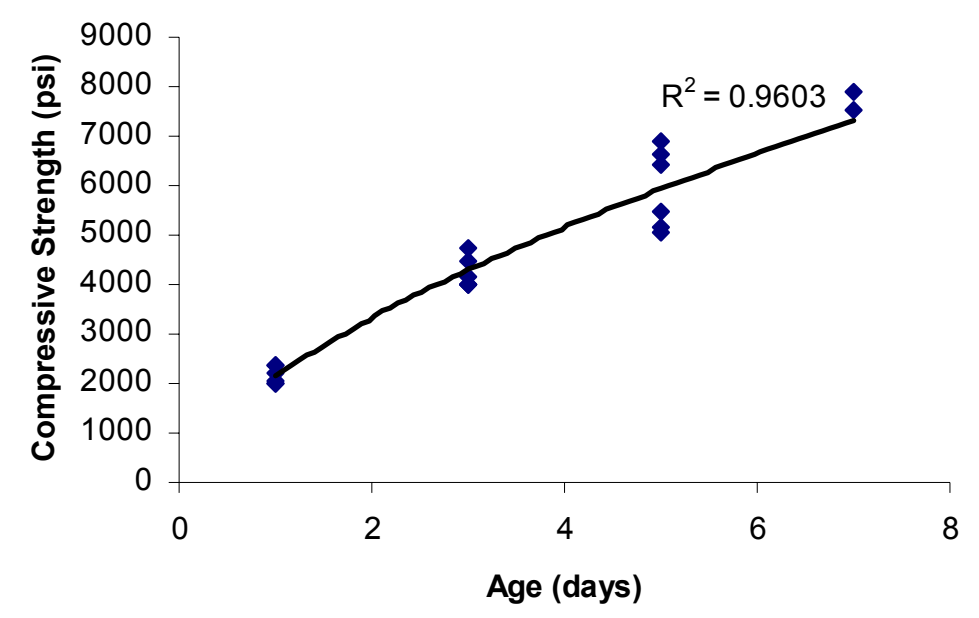

Fig. 8.5 Plot of compressive strength development with age

The compressive strength increased at a constant rate of approximately $13.1 \mathrm{MPa}$ (1900 psi) every two days between 1 and 7 days. 


\subsubsection{Split Tensile Strength Development with Time}

Development of split tensile strength with time is shown in Fig. 8.6. Average values of split tensile strengths at $1,3,5$, and 7 days were $1.8 \mathrm{MPa}(258 \mathrm{psi}), 3.2 \mathrm{MPa}$ (460 psi), 3.6 MPa (515 psi) and 4.0 MPa (588 psi), respectively. Table 8.2 provides the average values of indirect tensile strengths of cylinders. The $\mathrm{R}$-squared value for indirect tensile test data was 0.9576 , which indicates a good consistency of test results.

Table 8.2 Indirect tensile strengths at different curing periods

\begin{tabular}{|c|c|}
\hline Age (days) & $\begin{array}{c}\text { Avg. Split Tensile } \\
\text { Strength psi (MPa) }\end{array}$ \\
\hline 1 & $1.8(258)$ \\
\hline 3 & $3.2(460)$ \\
\hline 5 & $3.6(515)$ \\
\hline 7 & $4.0(588)$ \\
\hline
\end{tabular}

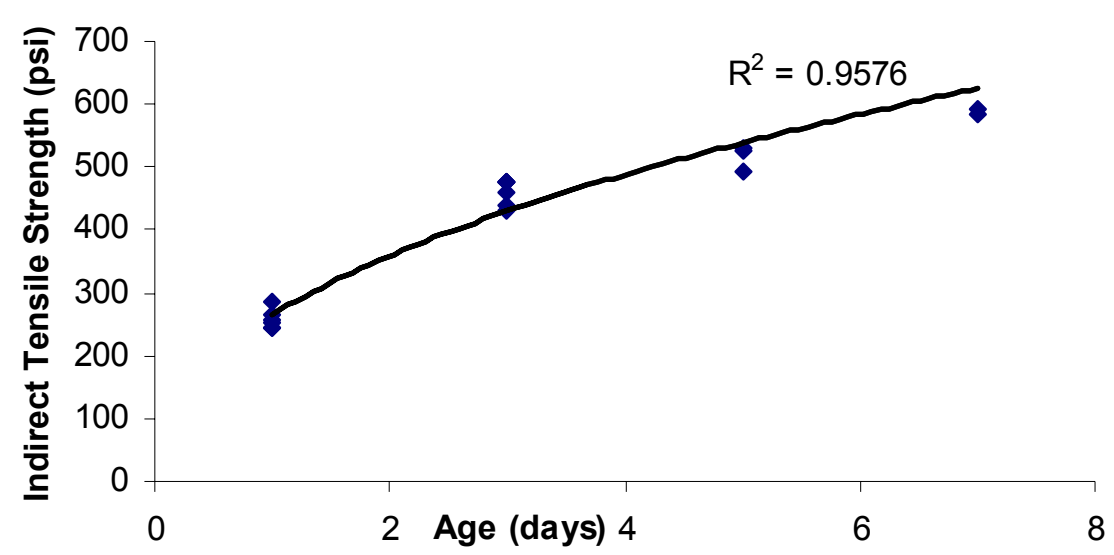

Fig. 8.6 Plot of indirect tensile strength gain v/s time.

Split tensile strength increased rapidly up to about 3 days of curing and became steady thereafter. 


\subsubsection{Flexural Strength Development and Opening-to-Traffic Time}

This section presents the development of modulus of rupture (MOR) with time and analyzes the opening-to-traffic period. Modulus of rupture is widely used as opening-to-traffic criterion based on the assumption that it represents the flexural stress of the kind that is produced by traffic moving on the pavement surface. In order to give this project a practical significance, and also to check the load carrying capacity of the pavement over its design life, the flexural strength data was correlated with fatigue test results that are discussed later in this chapter.

Table 8.3 Flexural strengths at different curing periods

\begin{tabular}{|c|c|}
\hline Age (days) & $\begin{array}{c}\text { Average MOR } \\
\text { MPa (psi) }\end{array}$ \\
\hline 1 & $3.2(471)$ \\
3 & $4.4(636)$ \\
5 & $5.8(840)$ \\
7 & $6.1(886)$ \\
14 & $6.4(928)$ \\
\hline
\end{tabular}

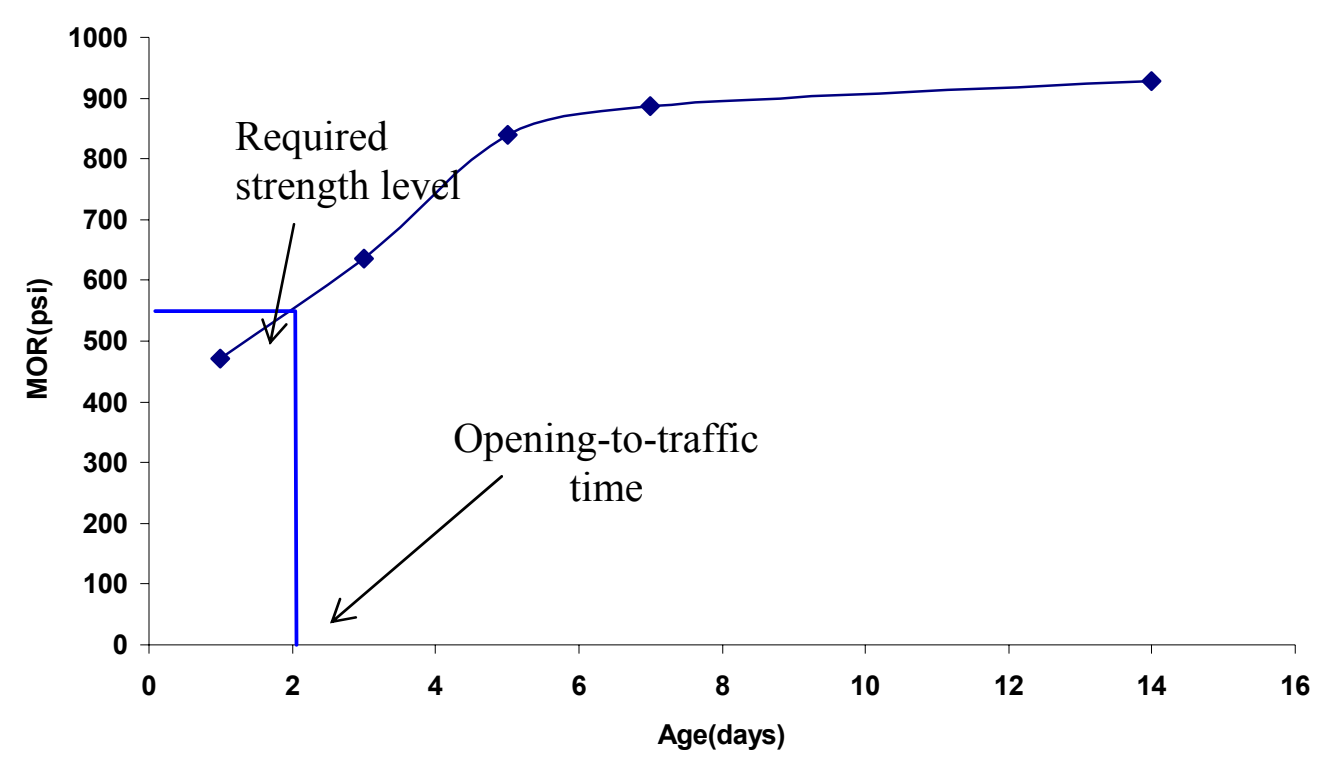

Fig. 8.7 Development of flexural strength with time for a typical mix used in this research 
Indiana Department of Transportation (INDOT) uses $3.8 \mathrm{MPa}$ (550 psi) flexural strength as an opening to traffic criterion. This value of flexural strength was selected based on the data obtained from previous projects ${ }^{(45)}$. Based on the conversation with several people from the industry, ${ }^{(46)}$ it appears that pavements that were opened to traffic at the time when they reached the value of MOR equal to $3.8 \mathrm{MPa}(550 \mathrm{psi})$ did not show any signs of significant damage when they were exposed to traffic for at least 3 years.

From Fig. 8.7, it can be seen that concrete used in this study developed strength of 3.2 $\mathrm{MPa}$ (471 psi) after 24 hours of curing. This strength increased to $6.1 \mathrm{MPa}$ (886 psi) after 7 days of curing. From the plot of MOR versus time shown in Fig. 8.7, it can be seen that concrete pavement develops a MOR of 3.8 MPa (550 psi) that is required for the opening to traffic during a time period slightly longer than 2 days. It is further noted that the rate of strength development slows down after about 5 days. The concrete strength increased only by about $0.3 \mathrm{MPa}$ (40 psi) in the time period from 7 - 14 days.

\subsection{Development of MOR -- Maturity Relationship}

To develop MOR-maturity relationship, 16 concrete beams were tested. Out of these 16 beams, 3 were prepared and cured in the laboratory and 13 were prepared and cured in the field (in a sand pit). The beams tested in the laboratory were also accompanied by 2 cylinders. Maturity and corresponding MOR and compressive strength values for the laboratory specimens are shown in Table 8.4. Two beams and six cylinders were cast from each set of mix and the time-temperature histories of specimens cured at 3, 5 and 7 days were obtained. 
Flexural strength - maturity relationship for the laboratory specimens is shown in Fig. 8.8(a). Compressive strength - maturity plot for the laboratory specimens is shown in Fig. 8.8(b). Both plots indicate strong linear relation between strength and maturity with r-squared values close to 1.0 .

Table 8.4 Maturity, MOR and compressive strength at 3, 5 and 7 days

\begin{tabular}{|l|c|c|c|c|c|c|}
\hline & $\begin{array}{c}\text { Time } \\
(\mathbf{m i n})\end{array}$ & $\begin{array}{c}\text { Time } \\
(\mathbf{h r s})\end{array}$ & $\begin{array}{c}\text { TTF } \\
\left({ }^{\circ} \mathbf{C}-\mathbf{m i n}\right)\end{array}$ & $\begin{array}{c}\text { TTF } \\
\left({ }^{\circ} \mathbf{C}-\mathbf{h r s}\right)\end{array}$ & $\begin{array}{c}\text { Log TTF } \\
\left({ }^{\circ} \mathbf{C}-h \mathbf{h r}\right)\end{array}$ & $\begin{array}{c}\text { MOR } \\
\text { MPa (psi) }\end{array}$ \\
\hline 3 Days & 2920 & 48.66 & 96963 & 1616.0 & 3.20 & $4.8(701)$ \\
5 Days & 6400 & 106.66 & 186332 & 3105.5 & 3.49 & $5.5(794)$ \\
7 Days & 10300 & 171.66 & 316308 & 5271.8 & 3.72 & $6.2(899)$ \\
\hline & Time & Time & TTF & TTF & Log TTF & Comp Strength \\
& (min) & (hrs) & $\left({ }^{\circ} \mathbf{C}-\mathbf{m i n}\right)$ & $\left({ }^{\circ} \mathbf{C}-\mathbf{h r s}\right)$ & $\left({ }^{\circ} \mathbf{C}-h \mathbf{h r}\right)$ & MPa (psi) \\
\hline 3 Days & 2920 & 48.66 & 97214 & 1620.2 & 3.21 & $33.0(4794)$ \\
5 Days & 6400 & 106.66 & 185023 & 3083.7 & 3.49 & $44.3(6430)$ \\
7 Days & 10300 & 171.66 & 316739 & 5278.9 & 3.72 & $52.0(7542)$ \\
\hline
\end{tabular}

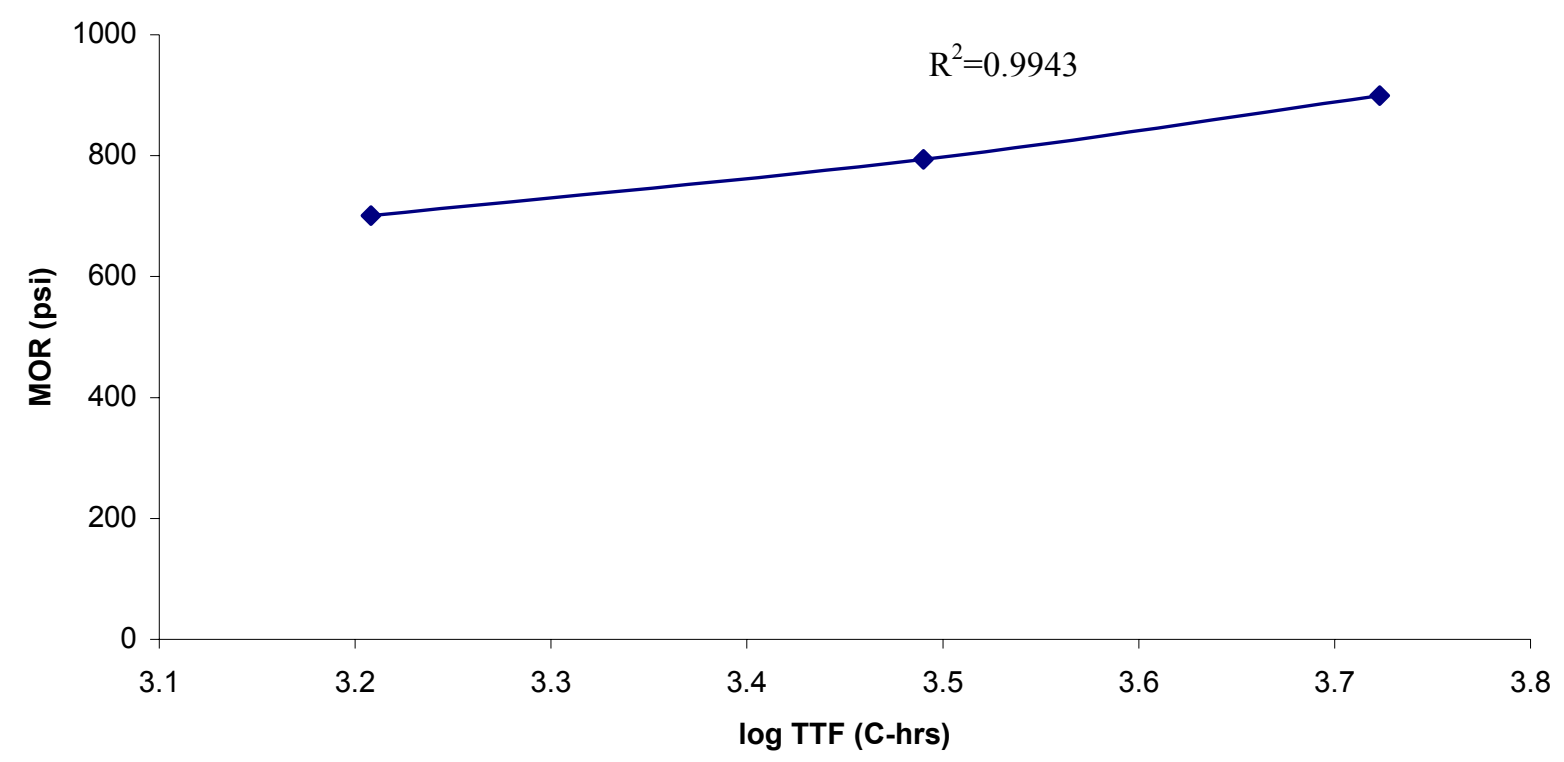

Fig. 8.8(a) Flexural strength-maturity relationship for laboratory specimens 


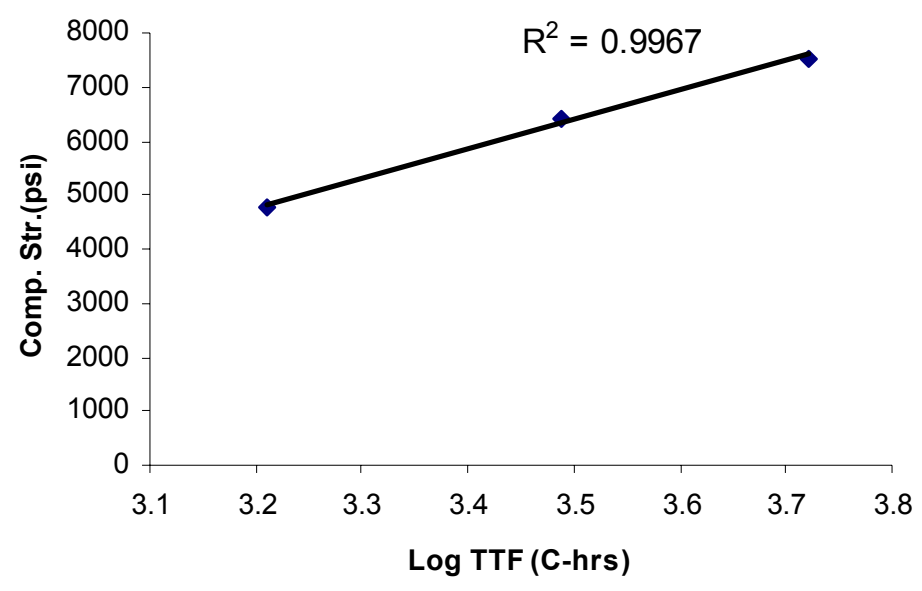

Fig. 8.8(b) Compressive strength-maturity relationship for laboratory samples

Combined beam and cylinder maturity values obtained from Table 8.4 were used to develop the strength - maturity curves for the laboratory specimens as shown in Fig. 8.8(a) and 8.8(b), respectively. Figure 8.8(a) indicates a linear relation between modulus of rupture and time-temperature factor plotted on a log scale.

Table 8.5 and Figure 8.9 show the maturity and MOR data for the field specimens. Unlike the laboratory specimens for which the w/c ratio was kept constant at 0.45 , the w/c ratio for field specimens ranged from 0.42 to 0.45 . As a result, the MOR values for the field specimens at a given maturity were generally lower than the corresponding MOR value for the laboratory specimens as illustrated in Figure 8.10. The opening-to-traffic maturity for laboratory concrete is $500^{\circ} \mathrm{C}-\mathrm{hr}$, whereas it was about $1995^{\circ} \mathrm{C}-\mathrm{hr}$ for field concrete. 


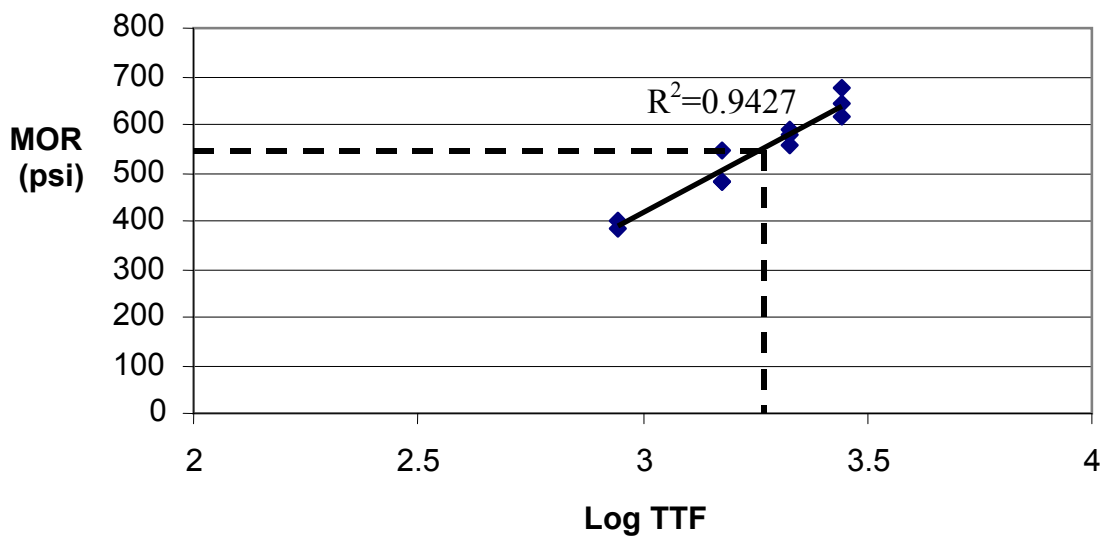

Fig. 8.9 Flexural strength - maturity relationship developed for field specimens

Table 8.5 Maturity and MOR for field specimens

\begin{tabular}{|c|c|}
\hline $\begin{array}{c}\text { TTF } \\
\left({ }^{\circ} \mathbf{C}-\mathbf{h r}\right)\end{array}$ & $\begin{array}{c}\text { Mean test values of MOR } \\
\text { MPa (psi) }\end{array}$ \\
\hline 883 & $2.7(388)$ \\
1508 & $3.5(503)$ \\
1887 & $3.8(559)$ \\
1910 & $6.9(568)$ \\
1979 & $4.5(650)$ \\
2120 & $4.0(574)$ \\
2203 & $4.3(620)$ \\
2230 & $4.6(663)$ \\
2307 & $4.0(586)$ \\
2771 & $4.4(645)$ \\
3794 & $5.0(731)$ \\
\hline
\end{tabular}




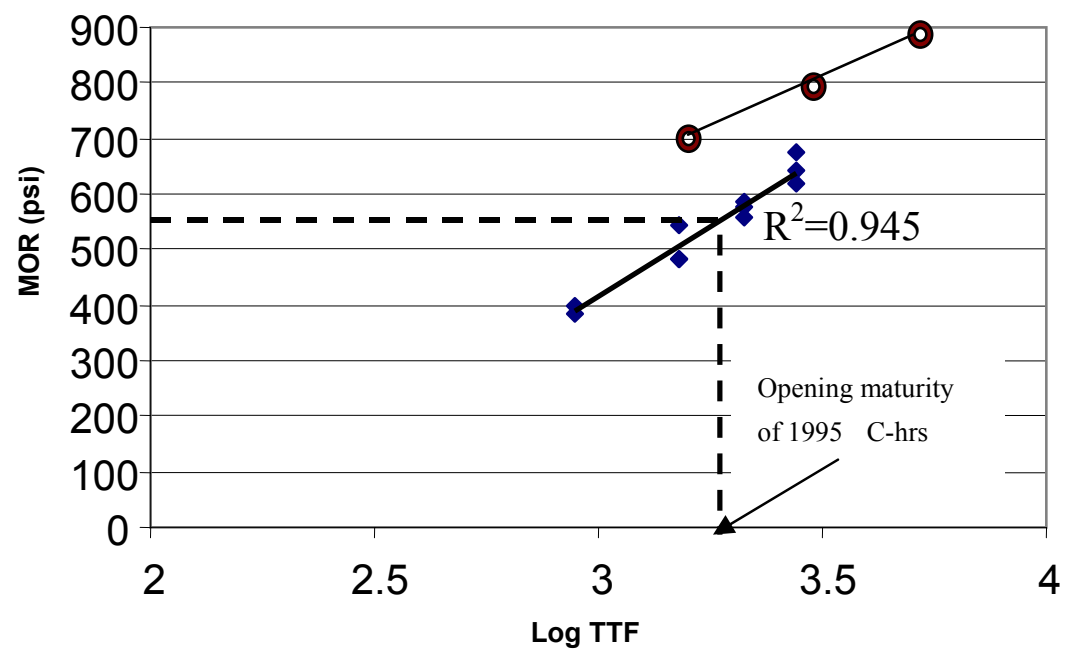

Fig. 8.10 Flexural strength - maturity relation from lab and field concretes

\subsection{Analysis of Fatigue Test Data}

Load controlled fatigue tests were performed on twenty 6" 6 " 621 " beams cured for 3, 5 and 7 days. At each age, 6 to 9 beams were tested at stress levels of 60, 80 and $90 \%$ capacity. The summary of the fatigue test results is presented in section 8.5.1. The description of some of the features of the cross sections of samples broken during fatigue testing is provided in section 8.5.2. Section 8.5.3 summarizes the use of S-N fatigue curves to determine the opening to traffic time.

\subsubsection{Development of Fatigue Curves}

Based on the results of the fatigue tests the relationship between the stress level and the number of cycles to failure was established. These results of the fatigue tests are summarized in Fig. 8.11, 8.12 and 8.13. 
Curve representing the relationship between the stress level and the number of cycles to failure (S-N curve) for specimens cured for 3 days is shown in Fig. 8.11.

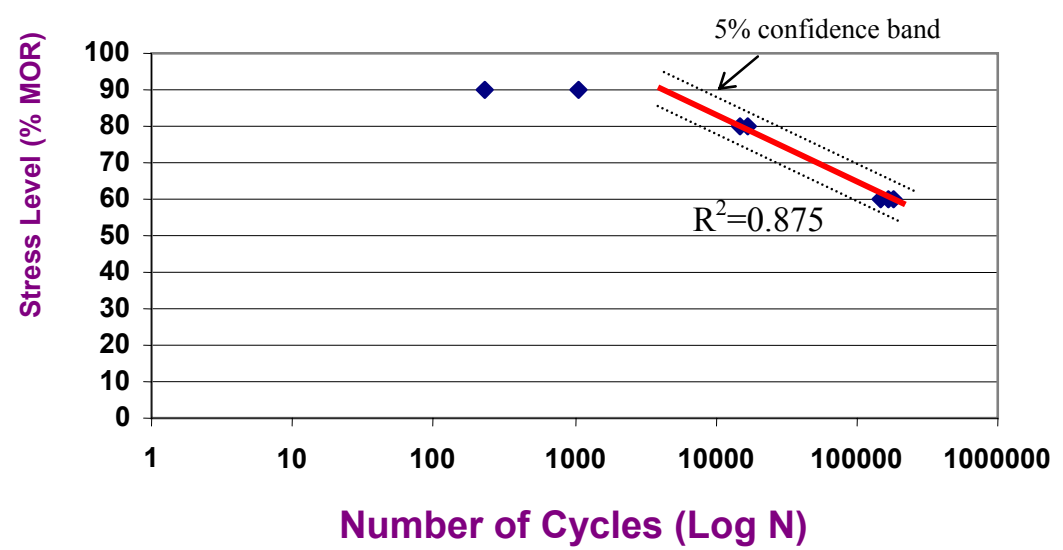

Fig. 8.11 Fatigue curve for beams tested at 3 days $\left(\mathrm{R}^{2}=0.875\right)$

Above plot exhibits a linear relation between number of cycles and stress level for stress levels of 60 and $80 \%$. Also while drawing the best-fit curve, only 60 and $80 \%$ stress levels were considered of importance. As the stress level increases, even a micro crack may result in instant failure of the specimen thereby resulting in some misleading data, as indicated by the very low number of cycles to failure exhibited by specimens tested at stress levels of $90 \%$ of ultimate stress.

Fig. 8.12 shows the relation between the number of cycles and stress level for beams tested after 5 days of curing. Most points are very close to best-fit curve, which indicates the consistency of fatigue data at 5 days. One of the beams that was tested at 80 $\%$ stress level seems to be an outlier as it failed after large number of cycles (i.e., 42480 cycles). 


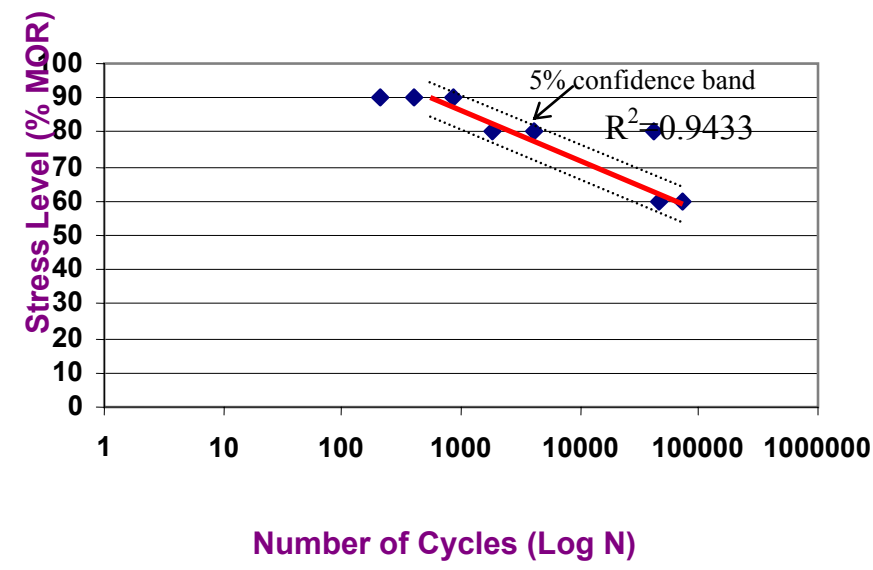

Fig. 8.12 Fatigue curve for beams tested at 5 days $\left(\mathrm{R}^{2}=0.9433\right)$

The relationship between number of cycles and stress level for beams tested for fatigue after 7 days of curing is shown in Fig. 8.13. The best-fit line passes through the average of number of cycles at each stress level.

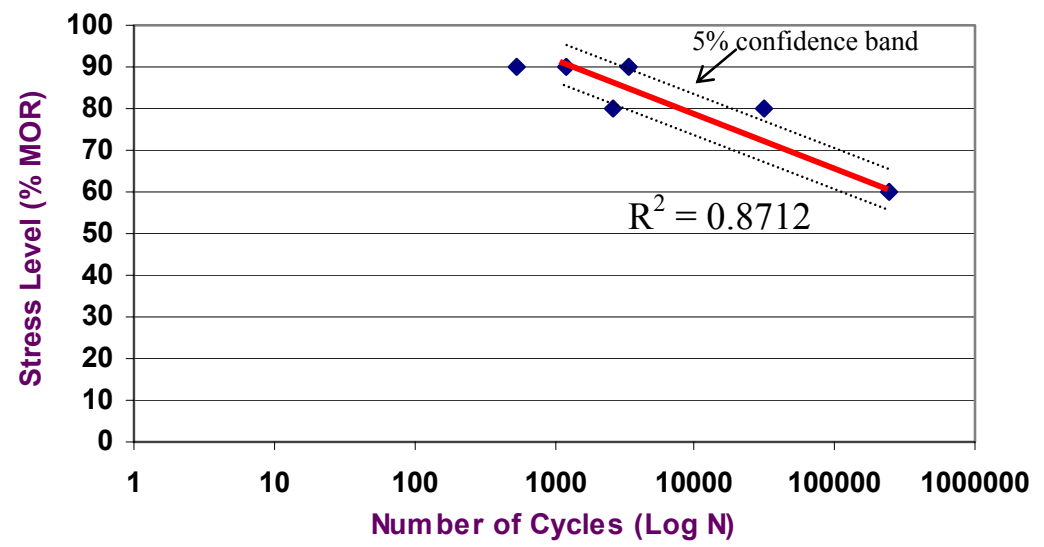

Fig. 8.13 Fatigue curve for beams tested at 7 days

The data presented in all three fatigue curves can be summarized as follows. The number of cycles a beam can withstand before failure depends on the stress level. All fatigue tests were performed under third point loading so that direct relation of stress 
level with modulus of rupture can be obtained. At $60 \%$ stress level, all beams were able to withstand more than 100,000 load cycles. On average, a fatigue test at $60 \%$ stress level took about 15 - 30 hours. The fatigue life of a beam is governed by the properties at any cross-section. The beam would fail sooner if the crack propagated through the matrix and through the transition zone between matrix and aggregates. In most of the cases where the cross-section was homogenous with enough of coarse aggregates, the crack propagation was much slower and resulted in higher fatigue life. Beams loaded to $80 \%$ stress level failed between 15,000 and 20,000 cycles. When the beam is loaded to $90 \%$ of its ultimate strength, it will break after only a small number of loading cycles are applied. At $90 \%$ stress level, beams cured for 3 and 5 days failed much earlier than expected based on the number of cycles predicted by best-fit line. However, when subjected to $90 \%$ stress level, beams cured for 7 days failed at almost expected number of cycles. From this it can be concluded that the beams are not capable of resisting high loads at early ages (for example, $90 \%$ at 3 days), but their capacity to resist higher loads increases with age. As the stress level approaches $100 \%$, it is almost certain that the beam will fail instantly. The number of cycles approaches infinity as the stress level drops below $50 \%$ of ultimate flexural strength.

There were initially two options discussed in order to generate enough useful data from the fatigue tests. One approach was to test one beam of each at many stress levels, say $50,55,60, \ldots$. up to 100 . Second option was to have at least two or three data points at fewer levels. In order to get a good correlation between stress level and number of cycles, 60, 80 and $90 \%$ stress levels were adopted as test protocols. 


\subsubsection{Observations on Broken Beams Tested for Fatigue}

Some unique features were observed in the cross section of broken fatigue specimens. The beam shown in Fig. 8.14 failed after a large number of cycles compared to average value that is indicated by best-fit curve. It can be seen that the failure plane passes through the coarse aggregates. It can thus be concluded that the beams in which the failure plane propagates through coarse aggregates will withstand higher number of cycles before failure. Typically, most of the aggregates in these specimens will be crushed.

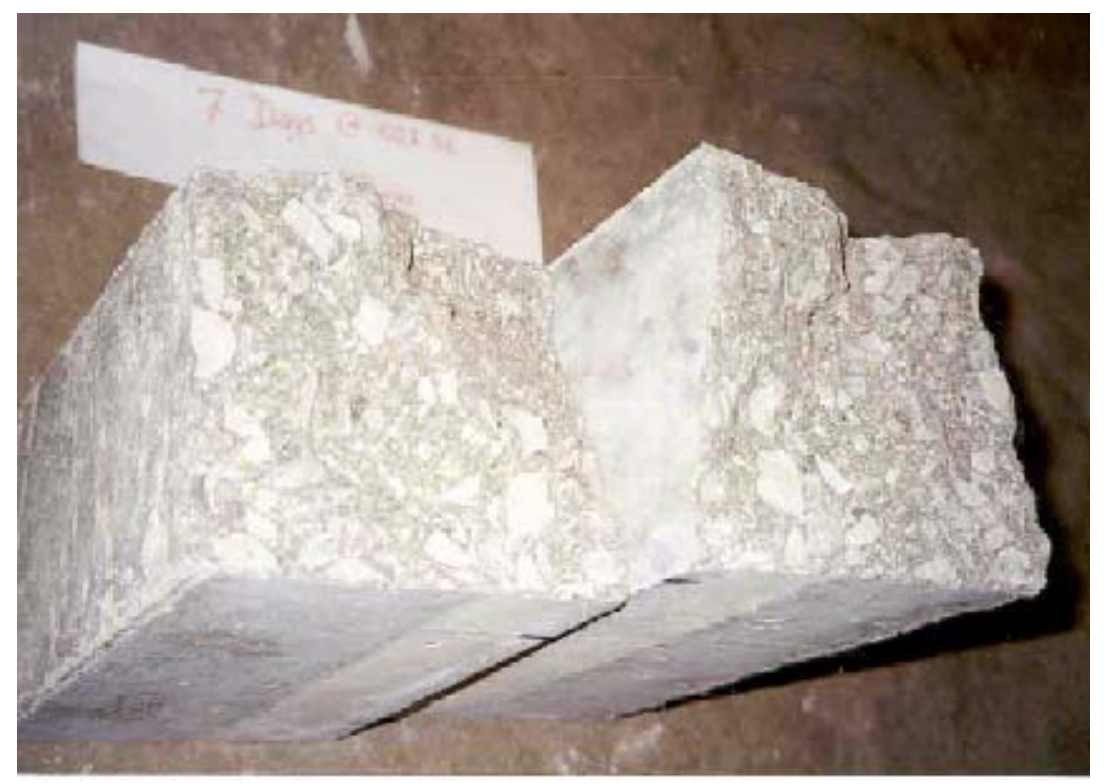

Fig. 8.14 Cross-section of a beam that failed at 3360 cycles at $90 \%$ stress level after 7 days of curing.

The beam shown in Fig. 8.15 failed at much lower number of cycles than expected based on fatigue curves. It can be seen from that picture that most of the 
aggregate particles were not broken, indicating that the failure crack propagated through the matrix (around the aggregate) thus resulting in premature failure.

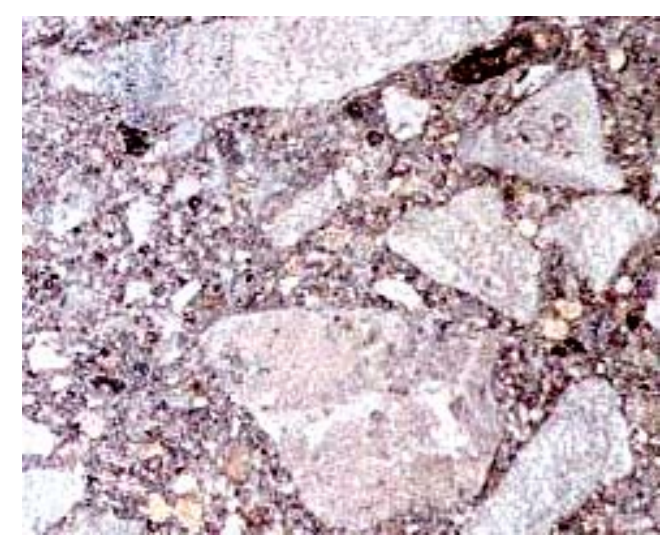

Fig. 8.15 Cross-section of a beam that failed at 1073 cycles at $90 \%$ stress level after 3 days of curing

The plane of failure for all specimens was located between the two loading points as shown in Fig. 8.16. Most of the beams failed at mid-point between two loads. 


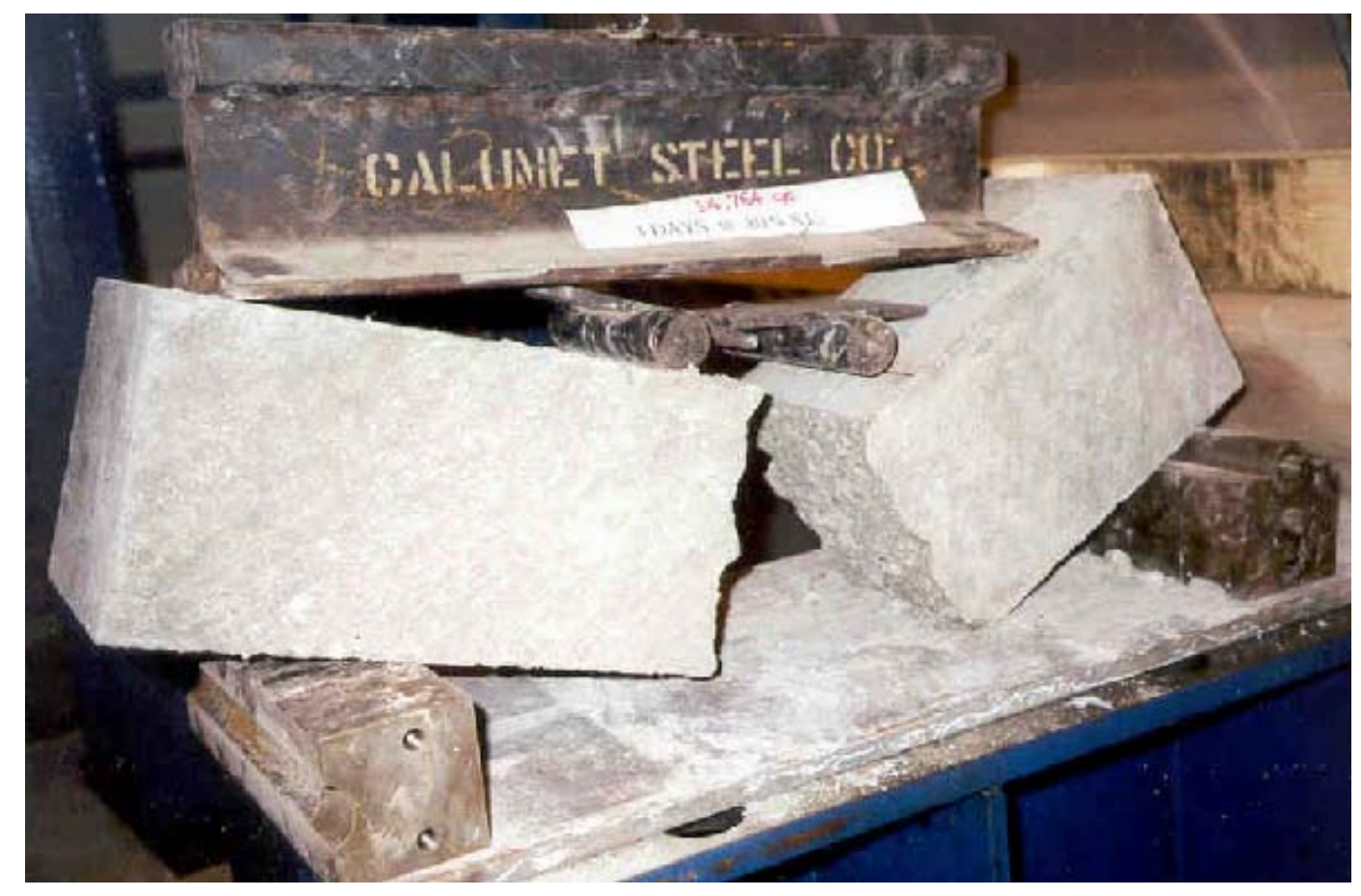

Fig.8.16 A beam that failed after 14764 cycles when tested at $80 \%$ stress level at 3 days

\subsubsection{Use of S-N Curves to Determine Opening-to-Traffic Time}

Based on information obtained from Indiana Department of Transportation, INDOT ${ }^{(47)}$, a typical concrete pavement can be opened to traffic if a beam of 6 " x 9" (cross section) can withstand more than 7000 cycles while loaded with 9000 lbs. load in third point loading mode. This load was selected based on 18 kips standard axle load.

In order to use this criterion for determining the time for opening to traffic time, one will need the following data:

Given: Traffic load $=9000 \mathrm{lb}$.

$\mathrm{N}=$ number of cycles that a pavement should withstand in order to open to traffic $=7000$ 
Cross-section $=6 \times 9$ in.

In the calculation shown below, the stress level in a $6 " \mathrm{x} 6 " \mathrm{x} 21$ " beam was determined that corresponds to stress level generated in 6" x 9" x 21 " beam when $40-\mathrm{kN}$ (9000-1b) load is applied at 3 days (earliest age for which fatigue curves were developed).

The following calculations are performed in order to check if the pavement can resist the number of load repetitions corresponding to 7000 cycles when a $40-\mathrm{kN}(9000-$ lb) load in applied on a 6" x 9" x 21 " beam cured for 3 days. The following notations used in these calculation:

MOR6 = MOR of a 6" x 6" x 21" beam

MOR9 = Equivalent MOR of 6" x 9" x 21" beam

$\mathrm{P} / 2=\operatorname{Load}$ applied at $1 / 3^{\text {rd }}$ distance from supports

$\sigma 6=$ Stress induced in a 6" x 6" x 21" beam by load P

$\sigma 9=$ Stress induced in a 6" x 9" x 21" beam by load P

Z6 = Section modulus of 6" 6 6" $\mathrm{x} 21$ " beam

Z9 = Section modulus of 6" 69 " 121 " beam

SL6 = Stress level induced in a 6" x 6" x 21" beam by load P

SL9 = Stress level induced in a 6" x 9"x 21" beam by load P

I6 = Moment of inertia of 6" x 6" x 21 " beam

I9 = Moment of inertia of 6" x 9" x 21 " beam 
At 3 days, Avg. MOR in a 6" x 6" x 21" beam = 636 psi (see Table 8.3)

$$
\begin{aligned}
& \therefore M O R_{6}=636 p s i \\
& M O R_{6} \times Z_{6}=M_{9} \times Z_{9} \\
& \text { (836) } x\left(\frac{1}{6} \times 6 \times 6^{2}\right)=\operatorname{MOR}_{9} \times\left(\frac{1}{6} \times 6 \times 9^{2}\right) \\
& \therefore M O R_{9}=282.67 \mathrm{psi} \\
& \sigma_{9} \text { when } P=9000 \mathrm{lbs} \text {. is applied }=\frac{\text { Max.Moment in beam }}{Z_{9}} \\
& =\frac{\left(\frac{P L}{6}\right)}{\left(\frac{1}{6} x b x d^{2}\right)}=\frac{\left(\frac{9000 \times 18}{6}\right)}{\left(\frac{1}{6} \times 6 \times 9^{2}\right)} \\
& \sigma_{9}=333.33 p s i \\
& S L_{9}=\frac{\sigma_{9}}{M O R_{9}}=\frac{333.33}{282.67} \\
& =1.18 \\
& \frac{S L_{6}}{S L_{9}}=\frac{I_{6}}{I_{9}} \\
& \therefore S L_{6}=1.18 \times\left(\frac{6}{9}\right)^{3} \\
& =0.349
\end{aligned}
$$

The fatigue test results presented in Fig. 8.10 indicate that when subjected to stress levels of about $35 \%$ of the ultimate stress, a $6 " \times 6 " \times 21$ " beam cured for 3 days 
can withstand more than 100,000 cycles of load before failure at 0.349 . Similar curves can be developed for different at various ages and at each age, and the number of repetitions for the given load to cause failure can be determined. If the number of repetitions to cause a failure is greater than the agency-specified minimum number of repetitions, the pavements can be opened at this age. In the case presented earlier in this section, it appears that it is safe to open the pavement to traffic after 3 days of curing.

\subsubsection{Overall Fatigue Curve}

The plot that summarizes all three fatigue S-N curves is shown in Fig. 8.17 for samples tested after 3,5 and 7 days of curing. This plot can be very useful in calculating the time of opening to traffic for different types of vehicles provided that the same mix design is used. To use this plot, the user should calculate the stresses induced in the pavement by the type of vehicles for which the pavement shall be opened. Since the curves shown in Fig. 8.17 were developed using 6" x 6" x 21 " beam, in order to use these curves for predicting the time of opening to traffic in pavement, the stresses generated in pavement under actual traffic have to be converted into an equivalent stress in $6 \times 6 \times 21$ in. beam. This stress level should be computed for each age (i.e., 3, 5 and 7 days) and compared with the corresponding MOR at that age. The minimum age at which the beam withstands the required number of cycles (specified by that particular Department of Transportation) should be considered as opening-to-traffic time. 


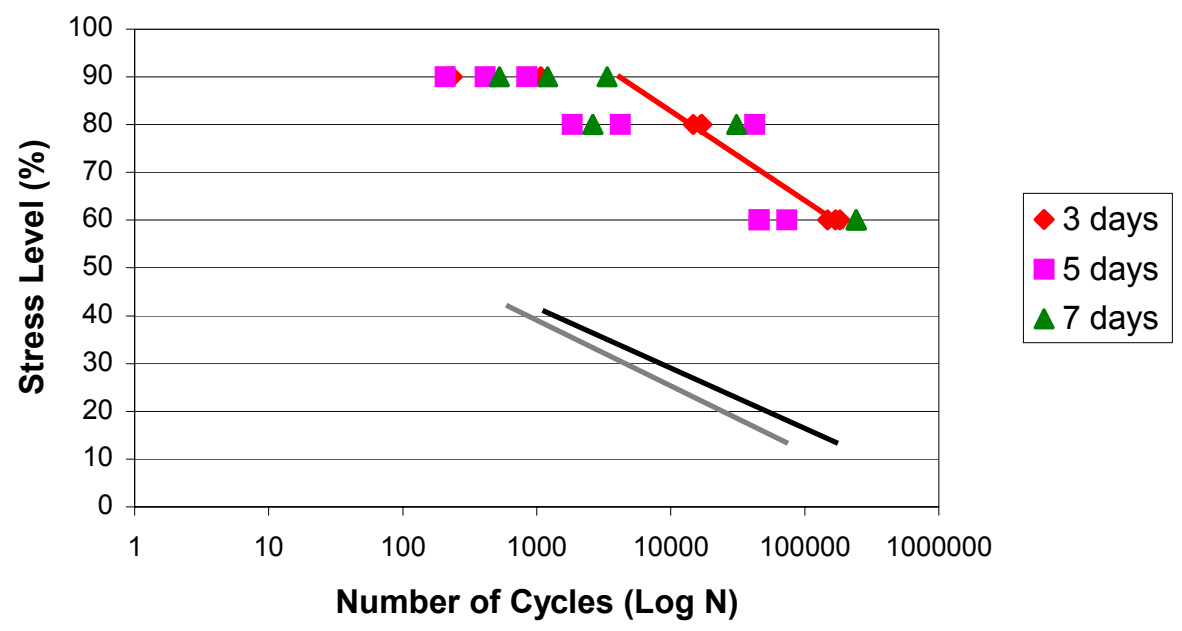

Fig. 8.17 Overall fatigue data at 3,5 and 7 days

Similarly, pavement can be opened for other types of vehicles by checking for fatigue life of beam with increasing load that would be a representative load of a vehicle category considered.

\subsubsection{Combining Maturity with MOR and Fatigue Data to Determine Opening to}

\section{Traffic Time}

Since the ultimate objective of this research project was to determine how to open the pavements to traffic earlier, this section provides a brief summary of the general methodology that can be implemented on a construction project to shorten the openingto-traffic time. The first step in this process will include establishing the relationship between maturity and MOR for a concrete mixtures selected for the project. This can be accomplished using trial batches and demonstration pours. Increasingly, more and more 
contractors already have this information as many are routinely testing flexural strength and maturity on part of their internal quality control.

The second step will involve determining the relationship between MOR and a fatigue life of a specimen under different stress level. This process is rather time consuming and probably not practical for every job. However, as shown by this study the actual level of stresses considered to be detrimental with respect to fatigue failure is rather low (about 35\%) for the mixture used in this study. This indicates that there is a considerable margin of safety with respect to fatigue failure even at early ages. Further discussion of this topic is included in the conclusion and recommendations section (Chapter 9) of this report. 


\section{CHAPTER 9 - CONCLUSIONS \& RECOMMENDATIONS}

The following conclusions can be drawn based on the results from this study:

- Mixtures used in this project when cured at a constant temperature of $23^{\circ} \mathrm{C}$ produced concrete with MOR as high as 636 psi after only 3 days of curing. When correlated with maturity and fatigue data, this strength value implies that concrete pavement made from mix of the same composition and cured under similar condition can be safely opened-to-traffic after 3 days of curing.

- Flexural strength has a strong relationship $\left(\mathrm{R}^{2}=0.945\right)$ with maturity. Based on the maturity data obtained from field, pavements can be opened at $1995 \mathrm{C}-\mathrm{hr}$ maturity that corresponds to a flexural strength of $3.8 \mathrm{MPa}(550 \mathrm{psi})$. These results indicate that maturity can be used as opening-to-traffic criterion, providing that $3.8 \mathrm{MPa}(550$ psi) represents realistic value of stress expected in the pavement.

- Fatigue tests at 3 days reveal that the pavement produced from the mixture used in this study can withstand more than 100,000 cycles of load, thus justifying a safe opening-to-traffic at 3 days.

- As long as the stress in pavement does not exceed $35 \%$ of ultimate MOR in equivalent $152.5 \mathrm{~mm} \times 152.5 \times 533.5 \mathrm{~mm}(6 " \times 6 " \times 21$ ") beam at age of 3 days, pavement will not experience fatigue damage during its service life. 
- To further refine opening-to-traffic criteria, the fatigue curves should be developed at various ages (ranging from 12 hours to 7 days) and for range of different mixtures exposed to different curing conditions.

- While the exact value for time to open pavement to traffic will vary depending in the composition of a particular mix, the methodology developed in this research program is of general applicability. Considering that the level of stress required to satisfy the minimum number of load repetitions to prevent fatigue failure was relatively low $(\sim$ $35 \%$ ), it is reasonable to assume that in general, for implementation purposes, it will probably be more critical to establish MOR-maturity relationship than fatigue-MOR relationships. This assumption is further reinforced by the fact that, in general, the strength-fatigue relationship will depend on several other variables, including type of the pavement (new construction versus rehabilitation), moisture and temperature gradients, volume and frequency of expected traffic, properties of the support system, thickness of the pavement, joint load-transfer efficiency, etc. Since the influence of all these variables cannot be reasonably accounted for during a parametric laboratory study, a complex modeling of stresses in the pavement should be undertaken. The stresses predicted from the model can then be combined with maturity and fatigue data for a series of several typical INDOT field mixtures to establish the range of opening-to-traffic times. 


\section{LIST OF REFERENCES}

1. Field Manual for Maturity and Pullout Testing of Highway Structures, SHRP-C376, Strategic Highway Research Program, National Research Council.

2. Accelerated Rigid Paving Techniques, State of the Art Report, Special Project 201, December 1994, FHWA-SA-94-080, Federal Highway Administration.

3. Optimization of Highway Concrete Technology, SHRP-C-373, Strategic Highway Research Program, National Research Council.

4. Grove, J. D.; Jones, K. B.; Bharil, K. S.; Abdulshafi, A.; and Calderwood, W., "Fast Track and Fast Track II, Cedar Rapids, Iowa," Transportation Research Record, v.1282, pp.1-7.

5. Ansari, F.; Luke, A.; Vitillo, N. P.; Blank, N.; and Turhan, I., "Developing Fast Track Concrete for Pavement Repair," Concrete International, May 1997, pp.2429.

6. Hossain, M. and Wojakowski, J., "Construction and Performance of a Fast Track Concrete Pavement in Kansas," Transportation Research Record, v.1465, pp.1-8.

7. Carino, N. J.; Lew, H. S.; and Volz, C. K., "Early Age Temperature Effects on Concrete Strength Prediction by the Maturity Method," ACI Journal, March-April 1993, pp.93-101.

8. Carino, N. J. and Lew, H. S., "Temperature Effects on Strength-Maturity Relation of Mortar," ACI Journal, May-June 1983, pp.177-182.

9. Grove, J. D. and Cable, J. K., "Early Opening of Portland Cement Pavement Using Maturity," Report from Iowa Department of Transportation.

10. Parsons, T. J. and Naik, T. R., "Early Age Concrete Strength Determination by Maturity,” Concrete International, February 1985, pp.37-42.

11. Chengju, G., "Maturity of Concrete: Method for Predicting Early Stage Strength," ACI Materials Journal, July-August 1989, pp.341-353. 
12. Oluokun, F. A.; Burdette, E. G.; and Deatherage, J. H., "Early Age Concrete Strength Prediction by Maturity- Another Look," ACI Materials Journal, November-December 1990, pp.565-572.

13. Pearson, R. I., "Fast-Track Concrete Paving," Concrete International, August 1988, pp.33-35.

14. Whiting, D.; Nagi, M.; and Okamoto, P. A., "Early Strength Gain of Rapid Highway Repair Concrete,” Concrete International, August 1994, pp.28-35.

15. Whiting, D. and Nagi, M., "Strength and Durability of Rapid Highway Repair Concretes," Concrete International, September 1994, pp.36-41.

16. Hsu, T. T. C., "Fatigue of Plain Concrete," ACI Journal, July-August 1981, pp.292-305.

17. Zhang, B., Phillips, D. V.; and Wu, K., "Effects of Loading Frequency and Stress Reversal on Fatigue Life of Plain Concrete," Magazine of Concrete Research, 1996, No.177, pp.361-375.

18. Hilsdrof, H. K. and Kesler, C. E., "Fatigue Strength of Concrete Under Varying Flexural Stresses," Journal of American Concrete Institute, October 1966, pp.1059-1075.

19. Zhang, B.; Phillips, D. V.; and Green, D. R., "Sustained Load Effect on the Fatigue Life of Plain Concrete," Magazine of Concrete Research, 1998, 50, No.3, pp.263-278.

20. Ramsamooj, D. V., "Prediction of Fatigue Life of Plain Concrete Beams from Fracture Tests," Journal of Testing and Evaluation, 1993, pp.183-194.

21. Tepfers, R. and Kutti, T., "Fatigue Strength of Plain, Ordinary and Lightweight Concrete," ACI Journal, May 1979, pp.636-652.

22. Okamoto, P. A. and Whiting, D., "Use of Maturity and Pulse Velocity Techniques to Predict Strength Gain of Rapid Concrete Pavement Repairs During Curing Period," Transportation Research Record, v.1458, pp.85-90.

23. Holland, T. C., "Using the Maturity Method to Predict Concrete Strength," Concrete Construction, October 1987, pp.867-869.

24. Kjellsen, K. O. and Detwiler, R. J., "Later-Age Strength Prediction by a Modified Maturity Model,” ACI Materials Journal, May-June 1993, pp.220-227. 
25. Dilly, R. L. and Olsen, P. J, "Software Uses Maturity Concept to Estimate Project Duration," Concrete International, August 1989, pp. 42-51.

26. Grove, J. D., "Blanket Curing to Promote Early Strength Concrete," Transportation Research Record, v.1284, pp.1-7.

27. Brown, B. and Lane, J., "Blanket Curing Promotes Early Strength," Better Roads, August 1989, pp.14-15.

28. Shi, X. P.; Fwa, T. F.; and Tan, S. A., "Flexural Fatigue Strength of Plain Concrete," ACI Materials Journal, September-October 1993, pp.435-440.

29. Cole, L. W. and Okamoto, P. A., "Flexural Strength Criteria for Opening Concrete Roadways to Traffic," Transportation Research Record, v. 1478, pp.5361.

30. Snell, L. M.; Roekel, J. V.; and Wallace, N. D., "Predicting Early Concrete Strength," Concrete International, December 1989, pp.43-47.

31. Cole, L. W. and Voigt, G. F., "More Than Just High Early Strength," Concrete International, May 1995, pp.32-35.

32. Brooks, J. J. and Al-Kaisi, A. F., "Early Strength Development of Portland and Slag Cement Cured at Elevated Temperatures," ACI Materials Journal, September-October 1990, pp.503-507.

33. Hall, M., "Early Strength Testing of Concrete Cores and Cylinders," Transportation Research Record, v.1478, pp.82-89.

34. Langlois, M.; Pigeon, M.; Bissonnette, B.; and Allard, D., "Durability of Pavement Repairs: A Field Experiment," Concrete International, August 1994, pp.39-42.

35. Standard Practice for Estimating Concrete Strength by the Maturity Method, ASTM C 1074 - 93, Annual Book of ASTM Standards, Vol. 04.02.

36. Standard Test Method for Pullout Strength of Hardened Concrete, ASTM C $900-$ 94, Annual Book of ASTM Standards, Vol. 04.02.

37. Standard Test Method for The Break-Off Number of Concrete, ASTM C 1150 96, Annual Book of ASTM Standards, Vol. 04.02.

38. Roller Compacted Concrete for Highway Applications, Thesis by GomezDominguez, J., Purdue University, December 1987. 
39. Standard Test Method for Determining Consistency and Density of RolerCompacted Concrete Using a Vibrating Table, ASTM C 1170 - 91, Annual Book of ASTM Standards, Vol. 04.02.

40. Standard Test Method for Slump of Hydraulic Cement Concrete, ASTM C 143 98, Annual Book of ASTM Standards, Vol. 04.02.

41. Standard Test Method for Air Content of Freshly Mixed Concrete by the Pressure Method, ASTM C 231 - 97, Annual Book of ASTM Standards, Vol. 04.02.

42. Standard Test Method for Compressive Strength of Cylindrical Concrete Specimens, ASTM C 39 - 96, Annual Book of ASTM Standards, Vol. 04.02.

43. Standard Test Method for Flexural Strength of Concrete (Using Simple Beam with Third Point Loading), ASTM C 78 - 94, Annual Book of ASTM Standards, Vol. 04.02.

44. Standard Test Method for Splitting Tensile Strength of Cylindrical Concrete Specimens, ASTM C496 - 96, Annual Book of ASTM Standards, Vol. 04.02.

45. Personal communication with Statistician at INDOT Research Division.

46. Communication with personnel from Missouri Department of Transportation and Virginia Department of Transportation.

47. Personal communication with Mr. S. Noureldin, INDOT Research Division. 
APPENDIX A

\section{EXPERIMENTAL RESULTS}




\section{$\underline{\text { ABBREVIATIONS }}$}

$\mathrm{Ca}=$ Coarse aggregates

$\mathrm{Fa}=$ Fine Aggregates

CompX $=$ Compressive strength of 4 " $\mathrm{x} 8$ " cylinder at " $\mathrm{X}$ " days

SpTnY= Split tensile strength of cylinder at "Y" days

MORZ = Modulus of rupture of 6" x 6" x 21" beam at "Z" days

$\mathrm{FAB}=$ Fatigue life of 6 " 6" 621 " beam at "A" days and at "B" stress level 


\begin{tabular}{|c|c|c|c|c|c|c|c|c|}
\hline Mix Code & 12 & 13 & 14 & 15 & 18 & 19 & 20 & 23 \\
\hline Date & 03-Jun-99 & 03-Jun-99 & 04-Jun-99 & 07-Jun-99 & 14-Jun-99 & 15-Jun-99 & 16-Jun-99 & 19-Jul-99 \\
\hline \multicolumn{9}{|c|}{ AGGREGATE MOISTURE } \\
\hline Moisture ca (\%) & 0.2 & 0.2 & -0.1 & 0.33 & 0.42 & 0.57 & 0.05 & 0.138 \\
\hline $\mathrm{Fa}(\%)$ & 0.88 & 0.88 & 0.354 & 0.64 & 0.96 & 0.21 & 2.24 & 0.8 \\
\hline \multicolumn{9}{|c|}{ FRESH CONCRETE PROPERTIES } \\
\hline VeBe (sec) & 14 & 17 & 13 & 14 & 12 & 14 & 12 & 12 \\
\hline Air Cont. (\%) & 6.5 & 6.7 & 6.5 & 6.6 & 6.5 & 5.9 & 6.2 & 6.4 \\
\hline Slump, in. & 0 & $1 / 4$ & $1 / 4$ & \begin{tabular}{|l|l|}
0 \\
\end{tabular} & $1 / 4$ & $1 / 4$ in & 0 & 0 \\
\hline \multicolumn{9}{|c|}{ COMPRESSIVE STRENGTH } \\
\hline \multirow[t]{3}{*}{ Comp1 psi (MPa) } & 1989(13.71) & & & & & $2387(16.46)$ & & \\
\hline & 1989(13.71) & & & & & $2228(15.36)$ & & \\
\hline & 2069(14.27) & & & & & $2387(16.46)$ & & \\
\hline \multirow[t]{3}{*}{ Comp3 psi (MPa) } & & & & $4178(28.81)$ & 4735(32.65) & & & \\
\hline & & & & $3979(27.44)$ & $3979(27.44)$ & & & \\
\hline & & & & \begin{tabular}{|l|}
$3979(27.44)$ \\
\end{tabular} & $4456(30.73)$ & & & \\
\hline \multirow{3}{*}{ Comp5 psi (MPa) } & & $5172(35.67)$ & & & & & 6884(47.47) & \\
\hline & & 5053(34.85) & & & & & 6645(45.83) & \\
\hline & & $5451(37.59)$ & & & & & $6445(45.83)$ & \\
\hline \multicolumn{9}{|l|}{ Comp7 psi (MPa) } \\
\hline \multicolumn{9}{|c|}{$\begin{array}{lc} & \text { SPLIT TENSILE STRENGTH } \\
\end{array}$} \\
\hline \multirow[t]{3}{*}{ SpTn1 psi (MPa) } & $243.5(1.68)$ & & $252.4(1.74)$ & & & $338.2(2.33)$ & & \\
\hline & $258.8(1.78)$ & & 263.4(1.82) & & & $311.4(2.15)$ & & \\
\hline & $285.5(1.97)$ & & $244(1.68)$ & & & $324.6(2.24)$ & & \\
\hline \multirow{3}{*}{ SpTn3 psi (MPa) } & & & $440.2(3.04)$ & $373.2(2.57)$ & 475.4(3.28) & & & \\
\hline & & & $476.8(3.29)$ & $396.6(2.73)$ & $431.2(2.97)$ & & & \\
\hline & & & $477.6(3.29)$ & $403.2(2.78)$ & 461.4(3.18) & & & \\
\hline \multirow[t]{3}{*}{ SpTn5 psi (MPa) } & & $629.6(4.34)$ & $531.6(3.56)$ & & & & $642.4(4.43)$ & \\
\hline & & 626.2(4.32) & 491.2(3.39) & & & & $680.6(4.69)$ & \\
\hline & & $607.2(4.06)$ & $525(3.62)$ & & & & & \\
\hline \multirow{2}{*}{\multicolumn{9}{|c|}{ SpTn7 psi (MPa) }} \\
\hline & & & & & & & & \\
\hline MOR1 psi (MPa) & $347(2.39)$ & & & & & $\begin{array}{l}482(3.32) \\
460(3.17)\end{array}$ & & \\
\hline MOR3 psi (MPa) & & & & $\begin{array}{l}571(3.94) \\
491(3.39)\end{array}$ & $\begin{array}{l}560(3.86) \\
713(4.92)\end{array}$ & & & \\
\hline MOR5 psi (MPa) & & $\begin{array}{l}703(4.84) \\
726(5.00) \\
\end{array}$ & & & & & $840(5.79)$ & \\
\hline MOR7 psi (MPa) & & & & & & & & $887(6.12)$ \\
\hline \multicolumn{9}{|l|}{ MOR14 psi (MPa) } \\
\hline \multicolumn{9}{|c|}{ FATIGUE RESULTS } \\
\hline \multicolumn{9}{|l|}{ F0360 } \\
\hline \multicolumn{9}{|l|}{ F0380 } \\
\hline F0390 & & & & & & & & \\
\hline F0560 & & & & & & & & \\
\hline F0580 & & & & & & & & \\
\hline F0590 & & & & & & & & \\
\hline F0760 & & & & & & & & \\
\hline F0780 & & & & & & & & \\
\hline F0790 & & & & & & & & \\
\hline
\end{tabular}

APPENDIX A-1: Data for Preliminary Tests 


\begin{tabular}{|c|c|c|}
\hline Mix Code & 24 & 25 \\
\hline Date & 19-Jul-99 & 28-Jul-99 \\
\hline \multicolumn{3}{|c|}{ AGGREGATE MOISTURE } \\
\hline Moisture ca(\%) & 0.226 & 0.14 \\
\hline $\begin{aligned} \mathrm{Fa}(\%) \\
\end{aligned}$ & 1.42 & -1.08 \\
\hline \multicolumn{3}{|c|}{ FRESH CONCRETE PROPERTIES } \\
\hline VeBe (sec) & 13 & 14 \\
\hline Air Cont. (\%) & 6.4 & 6.1 \\
\hline Slump (in.) & $1 / 4$ & 0 \\
\hline \multicolumn{3}{|c|}{ COMPRESSIVE STRENGTH } \\
\hline \multicolumn{3}{|l|}{ Comp1 psi (MPa) } \\
\hline & & \\
\hline \multicolumn{3}{|l|}{ Comp3 psi (MPa) } \\
\hline & & \\
\hline \multirow[t]{2}{*}{ Comp5 psi (MPa) } & & $6366(43.90)$ \\
\hline & & $6446(44.45)$ \\
\hline \multicolumn{3}{|l|}{ Comp7 psi (MPa) } \\
\hline & & \\
\hline \multicolumn{3}{|c|}{ SPLIT TENSION } \\
\hline \multicolumn{3}{|l|}{ SpTn1 psi (MPa) } \\
\hline & 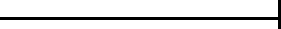 & \\
\hline \multicolumn{3}{|l|}{ SpTn3 psi (MPa) } \\
\hline & & \\
\hline \multirow[t]{2}{*}{ SpTn5 psi (MPa) } & & $539(3.72)$ \\
\hline & & $567.2(3.91)$ \\
\hline \multicolumn{3}{|l|}{ SpTn7 psi (MPa) } \\
\hline & & \\
\hline \multicolumn{3}{|c|}{ MODULUS OF RUPTURE } \\
\hline \multicolumn{3}{|l|}{ MOR1 psi (MPa) } \\
\hline \multicolumn{3}{|l|}{ MOR3 psi (MPa) } \\
\hline MOR5 psi (MPa) & & $876(6.04)$ \\
\hline \multicolumn{3}{|l|}{ MOR7 psi (MPa) } \\
\hline \multirow[t]{2}{*}{ MOR14 psi (MPa) } & 918(6.33) & \\
\hline & $940(6.48)$ & \\
\hline \multicolumn{3}{|c|}{ FATIGUE RESULTS } \\
\hline \multicolumn{3}{|l|}{ F0360 } \\
\hline \multicolumn{3}{|l|}{ F0380 } \\
\hline \multicolumn{3}{|l|}{ F0390 } \\
\hline \multicolumn{3}{|l|}{ F0560 } \\
\hline \multicolumn{3}{|l|}{ F0580 } \\
\hline \multicolumn{3}{|l|}{ F0590 } \\
\hline \multicolumn{3}{|l|}{ F0760 } \\
\hline \multicolumn{3}{|l|}{ F0780 } \\
\hline F0790 & & \\
\hline
\end{tabular}

APPENDIX A-1: Data for Preliminary Tests 


\begin{tabular}{|c|c|c|c|c|c|c|c|c|}
\hline Mix Code & 26 & 29 & 30 & 31 & 32 & 33 & 34 & 35 \\
\hline Date & 28-Jul-99 & 04-Aug-99 & 04-Aug-99 & 05-Aug-99 & 05-Aug-99 & 09-Aug-99 & 09-Aug-99 & $\begin{array}{r}\text { 09-Aug- } \\
99\end{array}$ \\
\hline \multicolumn{9}{|c|}{ AGGREGATE MOISTURE } \\
\hline Moisture ca (\%) & 0.13 & -0.32 & 0.26 & 0.167 & 0.36 & -0.62 & -0.58 & 0.27 \\
\hline $\mathrm{Fa} \mathrm{( \% )}$ & 2.35 & 1.81 & 1.81 & 1.67 & 3.14 & 2.08 & 1.77 & 1.85 \\
\hline \multicolumn{9}{|c|}{ FRESH CONCRETE PROPERTIES } \\
\hline VeBe (sec) & 12 & 12 & 13 & & 12 & 18 & 14 & 15 \\
\hline Air Cont.(\%) & 5.9 & $6.1 / 6.3$ & 6.2 & 6.5 & 6.4 & 5.0 & 6.8 & 6.5 \\
\hline \multicolumn{9}{|l|}{ Slump (in.) } \\
\hline Comm. & & 3.0 cu.ft. & & & & & & \\
\hline \multicolumn{9}{|c|}{ COMPRESSIVE STRENGTH } \\
\hline \multicolumn{9}{|l|}{ Comp1 psi (MPa) } \\
\hline & & & & & & & & \\
\hline & & & & & & & & \\
\hline \multicolumn{9}{|l|}{ Comp3 psi (MPa) } \\
\hline & & & & & & & & \\
\hline & & & & & & & & \\
\hline Comp5 psi (MPa) & & & & & & & 6430(44.34) & \\
\hline & & & & & & & & \\
\hline & & & & & & & & \\
\hline Comp7 psi (MPa) & & 7542(52.01) & $7921(54.62)$ & & & & & \\
\hline & & & & & & & & \\
\hline \multicolumn{9}{|c|}{ SPLIT TENSILE STRENGTH } \\
\hline \multicolumn{9}{|l|}{ SpTn1 psi (MPa) } \\
\hline & & & & & & & & \\
\hline & & & & & & & & \\
\hline \multicolumn{9}{|l|}{ SpTn3 psi (MPa) } \\
\hline & & & & & & & & \\
\hline & & & & & & & & \\
\hline SpTn5 psi (MPa) & & & & & & & $546(3.76)$ & \\
\hline & & & & & & & & \\
\hline & & & & & & & & \\
\hline SpTn7 psi (MPa) & & $585.2(4.03)$ & $591.3(4.06)$ & & & & & \\
\hline & & & & & & & & \\
\hline \multicolumn{9}{|c|}{ MODULUS OF RUPTURE } \\
\hline \multicolumn{9}{|l|}{ MOR1 ps (MPa) } \\
\hline MOR3 psi (MPa) & & & & & & $854(5.88)$ & & \\
\hline MOR5 psi (MPa) & $874(6.02)$ & & & $840(5.79)$ & $840(5.79)$ & & 794(5.47) & $836(5.7)$ \\
\hline MOR7 psi (MPa) & & $899(7.1)$ & $889(7.03)$ & & & & & \\
\hline \multicolumn{9}{|l|}{ MOR14 psi (MPa) } \\
\hline \multicolumn{9}{|c|}{ FATIGUE RESULTS } \\
\hline F0360 & & & & & & 147553 & & \\
\hline \multicolumn{9}{|l|}{ F0380 } \\
\hline F0390 & & & & & & 1073 & & \\
\hline F0560 & 73468 & & & & & & & 45612 \\
\hline F0580 & 42480 & & & 1843 & 4200 & & & \\
\hline F0590 & & & & & 843 & & $412 / 208$ & \\
\hline F0760 & & 241847 & & & & & & \\
\hline F0780 & & $30840 / 2612$ & & & & & & \\
\hline F0790 & & & $1201 / 3360$ & & & & & \\
\hline
\end{tabular}




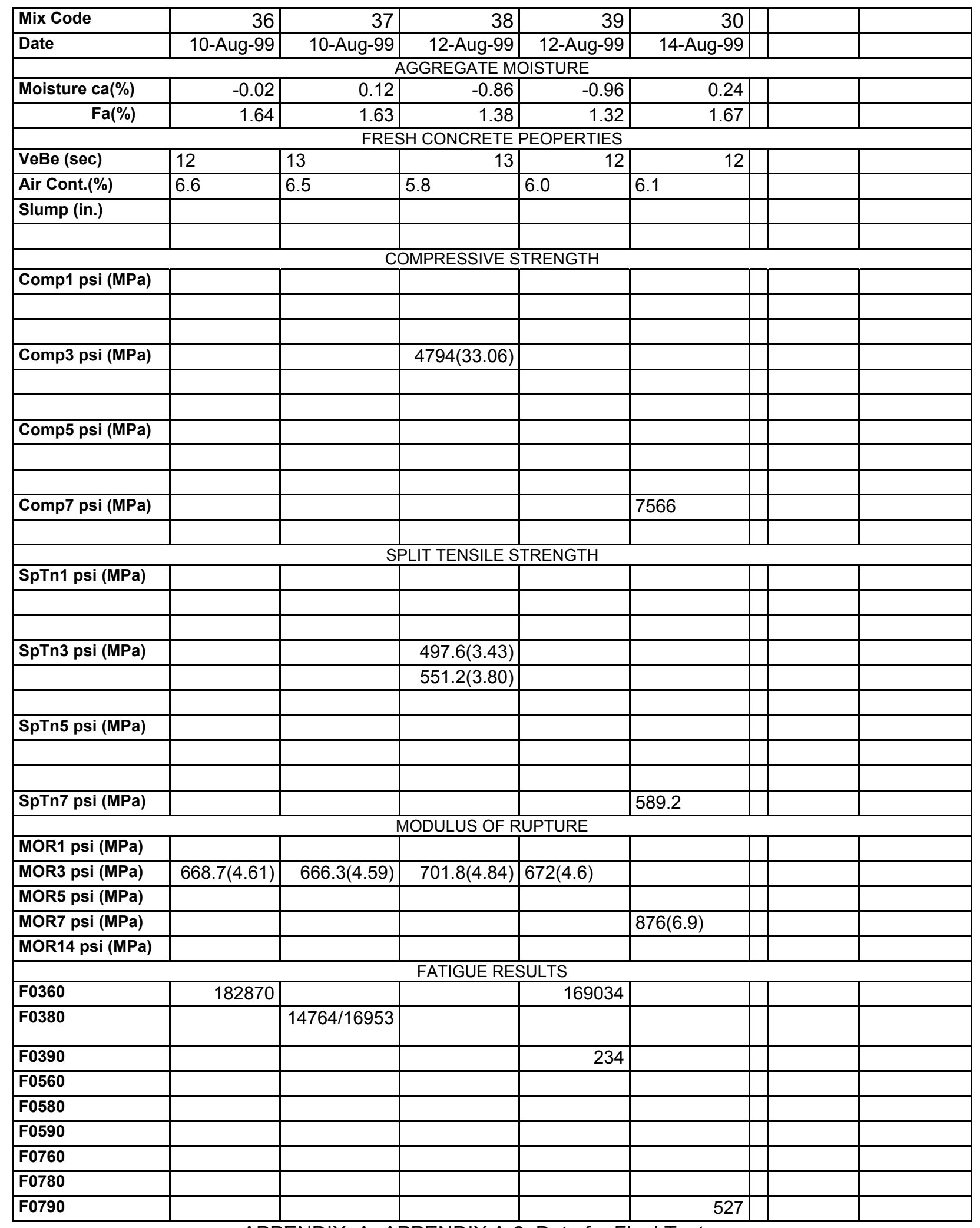


APPENDIX B

MIX DESIGN WORKSHEET 


\begin{tabular}{|lc|lc|}
\hline \multicolumn{2}{|c|}{ Design Factors } & \multicolumn{2}{c|}{ Design Factors } \\
\hline Test Batch Size & $3 \mathrm{cu} . \mathrm{ft}$. & Air content & $6.50 \%$ \\
Cement content & $442 \mathrm{lbs} . / \mathrm{cu} . y d$ & Fine Agg/ Total Agg. & $43.00 \%$ \\
Fly ash content & $70 \mathrm{lbs} . / \mathrm{cu}$. yd. & Air Entr. Content & $0.425 \mathrm{~g} / \mathrm{kg}$ of cement \\
Water-cement ratio & $0.42-0.45$ & Water reducer & $2.92 \mathrm{oz} / \mathrm{cwt}$ of cement \\
\hline
\end{tabular}

\begin{tabular}{|lllccc|}
\hline Material & Size/Type & Source & Bulk S.G. & Absorb. & Moist. \\
\hline Cement & Type I & Lonestar, Greencastle & 3.15 & ----- & ----- \\
Fly Ash & Class C & American Flyash, Rockport & 2.74 & ---- & ---- \\
Fine Agg. & \# 23 Sand & IMI, Greenwood & 2.608 & $1.41 \%$ & $4.10 \%$ \\
Coarse Agg. & \#8 Stone & Mart. Marietta, Indpls. & 2.685 & $1.33 \%$ & $2.30 \%$ \\
Air Entr. & Daravair 1400 & W.R. Grace & ----- & ----- & ----- \\
Water Red. & WRDA 82 & W.R. Grace & ---- & ---- & ---- \\
\hline
\end{tabular}

\begin{tabular}{|l|c|c|c|}
\hline \multicolumn{1}{|c|}{ Batch Weight for: } & 1 cu.yd. & 1 cu.ft. & 3 cu.ft. \\
\hline Cement & $442 \mathrm{lb} .(200.7 \mathrm{~kg})$ & $16.37 \mathrm{lb} .(7.43 \mathrm{~kg})$ & $49.11 \mathrm{lb} .(22.29 \mathrm{~kg})$ \\
Fly Ash & $70 \mathrm{lb} .(31.78 \mathrm{~kg})$ & $2.59 \mathrm{lb} .(1.17 \mathrm{~kg})$ & $7.78 \mathrm{lb} .(3.53 \mathrm{~kg})$ \\
Mix Water & $162 \mathrm{lb} .(73.54 \mathrm{~kg})$ & $6.00 \mathrm{lb} .(2.72 \mathrm{~kg})$ & $18.00 \mathrm{lb} .(8.17 \mathrm{~kg})$ \\
Fine Aggregate & $1,375 \mathrm{lb} .(624.25 \mathrm{~kg})$ & $50.92 \mathrm{lb} .(23.11 \mathrm{~kg})$ & $152.77 \mathrm{lb} .(69.36 \mathrm{~kg})$ \\
Coarse Aggregate & $1,845 \mathrm{lb} .(837.63 \mathrm{~kg})$ & $68.35 \mathrm{lb} .(31.03 \mathrm{~kg})$ & $205.05 \mathrm{lb} .(93.09 \mathrm{~kg})$ \\
Air Entrainment & $3 \mathrm{oz} .(85.05 \mathrm{~g})$ & $0.111 \mathrm{oz} .(3.14 \mathrm{~g})$ & $0.333 \mathrm{oz} .(9.44 \mathrm{~g})$ \\
Water Reducer & $14.9504 \mathrm{oz} .(423.83 \mathrm{~g})$ & $0.554 \mathrm{oz} .(15.7 \mathrm{~g})$ & $1.661 \mathrm{oz} .(47.09 \mathrm{~g})$ \\
\hline Total & 3,894 lb. $(1767.9 \mathrm{~kg})$ & $144.24 \mathrm{lb} .(65.48 \mathrm{~kg})$ & $432.71 \mathrm{lb} .(196.45 \mathrm{~kg})$ \\
\hline
\end{tabular}

Appendix B: Details of Mix Design Used in this Research 